NBER WORKING PAPER SERIES

\title{
EARNINGS INEQUALITY AND DYNAMICS IN THE PRESENCE OF INFORMALITY: THE CASE OF BRAZIL
}

\author{
Niklas Engbom \\ Gustavo Gonzaga \\ Christian Moser \\ Roberta Olivieri \\ Working Paper 29696 \\ http://www.nber.org/papers/w29696 \\ NATIONAL BUREAU OF ECONOMIC RESEARCH \\ 1050 Massachusetts Avenue \\ Cambridge, MA 02138 \\ January 2022
}

We thank the Editors and two anonymous referees for exceptionally constructive feedback. We thank Andrés Blanco, Jack Blundell, Bernardo Diaz de Astarloa, Andrés Drenik, Benjamin Friedrich, Eran Hoffman, Soren Leth-Petersen, Lance Lochner, Davide Malacrino, Daniela Puggioni, Kjetil Storesletten, Chris Taber, Abigail Wozniak, and seminar participants at Columbia University and the Global Income Dynamics Conferences at Stanford SITE in 2019 and held virtually in 2020 for helpful comments and suggestions. We also thank the Labor Statistics Dissemination Program within the Brazilian Ministry of the Economy and the Brazilian Institute of Geography and Statistics for providing us with data access and the Data Zoom initiative by the Department of Economics at PUC-Rio for sharing its data cleaning procedures. Special thanks go to Serdar Ozkan and Sergio Salgado for providing their code and support. The views expressed herein are those of the authors and not necessarily those of the Federal Reserve Bank of Minneapolis the Federal Reserve System, or the National Bureau of Economic Research. Any errors are our own.

NBER working papers are circulated for discussion and comment purposes. They have not been peer-reviewed or been subject to the review by the NBER Board of Directors that accompanies official NBER publications.

(C) 2022 by Niklas Engbom, Gustavo Gonzaga, Christian Moser, and Roberta Olivieri. All rights reserved. Short sections of text, not to exceed two paragraphs, may be quoted without explicit permission provided that full credit, including $(\mathcal{O}$ notice, is given to the source. 
Earnings Inequality and Dynamics in the Presence of Informality: The Case of Brazil

Niklas Engbom, Gustavo Gonzaga, Christian Moser, and Roberta Olivieri

NBER Working Paper No. 29696

January 2022

JEL No. D31,D33,E24,E26,J31,J46,J62

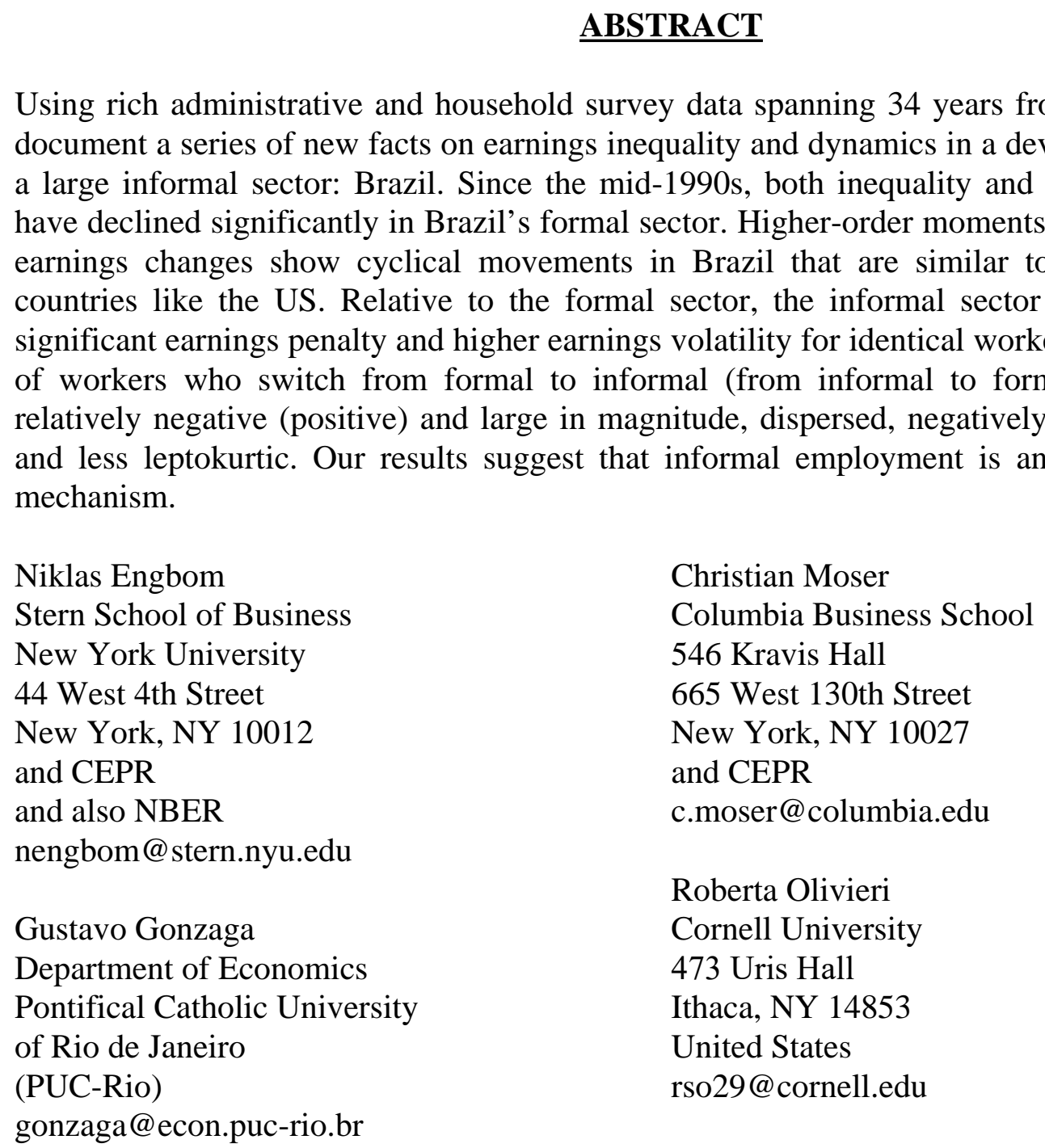




\section{Introduction}

A salient feature of many developing and even some developed countries is a large informal sector, in which jobs evade government oversight in the labor market. The informal sector can be thought of as serving a dual role in labor market dynamics. On one hand, it offers workers readily available employment in case a worker is laid off or decides to quit owing to unfavorable pay or business conditions in his or her previous job. Through this channel, the informal sector provides insurance against labor income risk. On the other hand, it allows workers and firms to avoid costly labor regulations and income taxes, thereby enhancing the efficiency of hiring, firing, and production. This increased efficiency also means that workers are not covered by labor regulations such as employment protection laws, the minimum wage, social security contributions, and other benefits offered by formal jobs. Through this channel, the informal sector increases labor income risk.

As part of the Global Income Dynamics Project, we study earnings inequality, volatility, and mobility in Brazil. As such, the statistics contained in this paper as well as many additional ones computed on the data will be publicly available through the Global Income Dynamics database together with harmonized statistics for the other countries in this special issue. Brazil is a an upper middle income country with a large informal sector. We find that among Brazilian metropolitan regions in 2004, 42 percent of all jobs were informal (i.e., without a formal work permit). At the same time, earnings inequality and informality rates significantly declined between the early 2000s and the late 2010s. This makes Brazil a particularly interesting setting to study for our purposes.

To dissect the distribution of earnings levels and earnings changes, we use a combination of rich administrative and household survey data from Brazil covering 34 years over the period from 1985 to 2018. The administrative records cover nearly the entire universe of formal sector workers in Brazil over those years. We complement these administrative records with detailed household survey data that follow individuals within households in Brazil's six largest metropolitan regions in a 16-month rotating panel structure from 2002 to 2015. The advantage of the household survey data is twofold. First, the data let us validate our findings on labor market outcomes in Brazil's formal sector, based on the administrative records. Second, they allow us to compare earnings levels and earnings changes between workers in Brazil's formal and informal sectors as well as for workers switching sectors between survey waves. In this way, we uncover a set of new facts for workers within and between the formal and informal sectors of Brazil.

In the first part of the paper, we compute a set of standardized statistics on earnings inequality, volatility, and mobility in Brazil's formal sector based on administrative data covering the period from 
1985 to 2018. We start by documenting a remarkable decrease in earnings inequality for both men and women, which starts around 1995 and lasts until the end of our sample. ${ }^{1}$ The decrease in overall earnings inequality is associated with relatively greater compression in the left tail of the distribution, which in turn is due to rapid real earnings growth among bottom earnings percentiles. The decrease in inequality is also widespread among the lower 95 percent of the distribution. In contrast, the top five earnings percentiles have fanned out because of growth rates in real earnings that were increasing in ranks between the 95th and the 99.99th percentiles of the distribution. Earnings inequality across cohorts entering the labor market also fell over this period, but more so in the upper than in the lower tail of the distribution.

We then turn to earnings dynamics among formal sector workers in Brazil. Overall dispersion in one-year earnings changes, conditional on gender-specific controls for worker age and educational attainment, rose rapidly during a volatile economic period in Brazil in the late 1980s and early 1990s, which included several inflation stabilization plans and a hyperinflationary period. This rise in dispersion of earnings changes is driven almost entirely by increasing lower-tail dispersion - that is, greater downside earnings risk. Following the macroeconomic stabilization after 1994, the dispersion of earnings changes decreased markedly, first driven by a decrease in the lower tail and later followed by a decrease in the upper tail of the distribution. We also find that the Kelley skewness of earnings changes is strongly procyclical (i.e., it is lower during recessions) but without much of a trend, while the excess Crow-Siddiqui kurtosis of earnings changes increased secularly from 1985 onward.

Although inequality in current earnings in Brazil has fallen dramatically over our period of study, this does not mean that inequality in more permanent earnings has followed the same trend. The relation between current and more permanent inequality is commonly summarized through measures of earnings mobility (Shorrocks, 1978). We find high levels of earnings mobility in Brazil, compared with those in concurrent studies for the US (McKinney and Abowd, 2021) and Canada (Bowlus et al., 2021), especially at the bottom of the distribution. Moreover, the extent of earnings mobility has not changed much over time, despite lower earnings volatility. That is, individuals now move across the earnings distribution to the same extent as in the past while the dispersion of earnings changes has declined. This suggests that the magnitude of the earnings change associated with a move between any two quantiles of the earnings distribution is, smaller now, consistent with the underlying earnings distribution being more compressed nowadays.

In the second part of the paper, we complement our analysis of Brazil's formal sector based on administrative records with longitudinal household survey data for 2002-2015 for the six largest metropolitan regions. We make the two data sets as comparable as possible and use them to validate our findings on

\footnotetext{
${ }^{1}$ See Barros et al. (2010) and Firpo and Portella (2019) for an overview of recent inequality trends in Brazil.
} 
earnings inequality and volatility across data sets. Although there remain important differences between the two data sets, the evolution of earnings inequality lines up quite closely between administrative and household survey data. Earnings volatility shows somewhat more diverging trends across the two data sources: the volatility of earnings changes is flat in the administrative records but decreasing in the household survey data over the 2002-2015 period. These differences are plausibly due to discrepancies in the coverages, income definitions, and the response rates across data sources. ${ }^{2}$

We proceed to exploit the longitudinal household survey data to study earnings inequality and dynamics within and between the formal and informal sectors. We draw four conclusions. First, mean one-year residual earnings changes are similar in formal and informal jobs, but informal changes are significantly more dispersed, with greater probability mass in both tails of the distribution. Second, workers who switch between sectors have highly asymmetric earnings changes: workers transitioning from the informal to the formal sector tend to make earnings gains, whereas workers making the opposite transition on average lose earnings. Third, there was a pronounced decrease in the dispersion of earnings changes in the overall economy (the formal sector pooled with the informal sector) during the early 2000s, which was followed by a period of stabilization from 2006 onwards. Fourth and finally, holding everything else fixed, the large employment shift toward the less volatile formal sector on its own results in a fall in the volatility of earnings; the fall corresponds to 50 percent of the total decline since 2002. In other words, the process of labor market formalization appears to have played an important role in the decline in earnings volatility over this period. Together, these facts paint a rich picture of earnings inequality and dynamics in Brazil-a developing country with a large informal sector.

Related literature. Our work combines two separate strands of the literature on informality and income dynamics. The first strand of the literature is concerned with labor market informality-see Ulyssea (2020) for an excellent review. Meghir et al. (2015) use a subperiod of the same household survey data that we use for the second part of our analysis. They show that both the distribution of wages and that of firm productivity substantially overlap between Brazil's formal and informal sectors. Ulyssea (2018) uses linked employer-employee survey of informal establishments to document facts about the distribution of (in-)formal employment across the firm size distribution. Among the drivers behind high levels of informality in developing countries are high labor regulation costs (Almeida and Carneiro, 2012), weak enforcement (Seminario-Amez, 2021), payroll taxes (Haanwinckel and Soares, forthcoming), and the incidence of social policies like the minimum wage and conditional cash transfer programs

\footnotetext{
${ }^{2}$ In this manner, we contribute to an emerging literature that compares administrative and household survey data in other lower-income countries, such as Argentina (Blanco et al., 2021) and Mexico (Calderón et al., 2021).
} 
such as Bolsa Família in Brazil (Fairris and Jonasson, 2020). We complement this body of research by studying earnings dynamics within and between the two sectors, highlighting the importance of the informal sector in particular.

Related work by Dix-Carneiro and Kovak (2019), Ponczek and Ulyssea (forthcoming), and DixCarneiro et al. (2021) also highlights the role of the informal sector as an insurance mechanism against negative shocks to Brazilian local labor markets in the context of international trade. Building on their insights, we characterize earnings inequality and dynamics within and between the formal and informal sectors.

We also contribute to a growing literature on the causes of the pronounced decrease in earnings inequality in Brazil since the mid-1990s. Firpo and Portella (2019) provide an excellent review of recent studies that quantify the importance of falling returns to education and experience (Ferreira et al., 2017), falling returns to firm productivity (Alvarez et al., 2018), trade liberalization (Gonzaga et al., 2006; Ferreira et al., 2007; Dix-Carneiro and Kovak, 2015), and the rapid rise of the minimum wage (Engbom and Moser, 2021) —among other factors—-toward this decrease in earnings inequality. ${ }^{3}$

The second strand of the literature is concerned with income dynamics. Earnings dynamics have been studied in administrative and household survey data in many developed countries (see, for example, Moffitt and Gottschalk, 1995 and Sabelhaus and Song, 2010). A seminal contribution in this area is that by Guvenen et al. (2014), who use 34 years of social security records to document new facts on the cyclical properties of higher-order moments of earnings changes in the US. Recent work has shed further light on the nature of earnings dynamics over the life cycle (Guvenen et al., 2019) and over time (Bloom et al., 2017) in the US context. Hoffmann and Malacrino (2019) show that unemployment insurance reduces some of the cyclicality in skewness of earnings changes in Italy. We contribute to this literature by presenting a set of new empirical facts on earnings dynamics in a developing country with a large informal sector.

A recent study by Gomes et al. (2020) also studies earnings dynamics in Brazil's formal and informal sectors. Their analysis is based on different survey data that are nationally representative over the period from 2012 to 2018. We find that our data confirm their finding of greater dispersion in earnings changes in Brazil's informal sector and complement their work in several ways. For instance, by using a longer panel from 2002 to 2015 in our household survey data and from 1985 to 2018 in our administrative data, we are able to document secular and cyclical movements over time of higher-order moments of the distribution of earnings changes. Our study provides a holistic picture of Brazil's formal and in-

\footnotetext{
${ }^{3}$ We here restrict attention to monetary earnings-see Morchio and Moser (2020) for a study of nonpecuniary job amenity values in the context of Brazil.
} 
formal sectors by jointly studying earnings inequality, volatility, and mobility by using a combination of administrative and household survey data.

Outline. The rest of the paper is structured as follows. Section 2 describes Brazil's institutional background from 1985 to 2018 and introduces the administrative and household survey data on which we base our analysis. Section 3 presents a set of standardized statistics pertaining to earnings inequality, volatility, and mobility. Section 4 validates findings between the administrative and household data and dissects the role of (in-)formality in Brazil's labor market. Finally, Section 5 concludes.

\section{Background and Data}

\subsection{Brazil's Macroeconomy from 1985 to 2018}

Between 1985 and 2018, Brazil underwent a transformative and volatile macroeconomic period. The period was characterized by rapid growth spurts interlaced with severe economic recessions, with negative GDP per capita growth recorded during the high-inflation period of the late 1980s and early 1990s, the financial crisis of the late 1990s, the global financial crisis around 2008, and the commodity price bust and political turmoil from 2014 to 2016-see panel A of Figure 1.

With rapid growth came other fundamental economic changes for Brazil. Over the period from 1985 to 2018, the services sector grew from 47 percent to 74 percent of total GDP, while the industrial sector shrank from 42 percent to 21 percent and the agricultural sector shrank from 11 percent to 5 percent, as illustrated by panel B. ${ }^{4}$

Although this statistic does not fully reflect labor market slack in the presence of a large informal sector, Brazil's unemployment rate fluctuated between 3 percent in the late 1980s and 13 percent in the early 2000s—see panel C.

A particularly scarring event in Brazil's recent macroeconomic history was a prolonged episode of high inflation in the first part of our sample period, from 1985 to 1994. Our preferred measure of inflation is based on the Extended National Consumer Price Index Índice Nacional de Preços ao Consumidor Amplo (IPCA) used by the country's central bank since 1999, when an inflation-target system was implemented. After fast-rising inflation during the early 1980s, Brazil eventually suffered from hyperinflation, with annual inflation rates above 6,500 percent and several different national currencies. After several

\footnotetext{
${ }^{4}$ The figures during Brazil's high-inflation period from 1985-1995 should be interpreted with caution due to the substantial volatility of nominal variables during these years.
} 
stabilization attempts, inflation was eventually brought under control with the implementation of the Plano Real in 1994 and was relatively stable thereafter (Ayres et al., 2019)—see panel description.

Over the same period, Brazil's currency fluctuated significantly in real terms, first depreciating heavily from the early 1990s until 2002, then appreciating quickly for a decade in the wake of a commodity supercycle, and eventually depreciating again with its reversal and the deterioration of fiscal accounts (Ayres et al., 2019) and (Benguria et al., 2021)—see panel E.

Finally, Brazil implemented several economic policy changes between 1985 and 2018. Among the most salient changes is the rapid rise of the minimum wage starting in the early 2000s; its increase coincided with the election of the left-leaning Workers' Party. Over the subsequent decade and a half, Brazil's minimum wage increased by over 100 percent in real terms-see panel F. ${ }^{5}$

\subsection{Data}

In this section, we describe the two data sets used in our empirical analysis and our sample selection criteria. Our administrative data source is the Relação Anual de Informações Sociais (RAIS), a linked employeremployee longitudinal data set that covers nearly all formal jobs in Brazil. We complement our empirical analysis with microdata from the Brazilian monthly labor force survey Pesquisa Mensal de Emprego (PME) to validate our findings based on administrative data and to investigate whether income dynamics differ between formal and informal workers.

\subsubsection{Administrative Data}

Data description. Our main data source is RAIS, which contains administrative records from Brazil's Labor Statistics Dissemination Program (Programa de Disseminação das Estatísticas do Trabalho) within the Brazilian Ministry of the Economy (Ministério da Economia), formerly the Ministry of Labor (Ministério do Trabalho). RAIS covers nearly the entire universe of workers in tax-registered firms. It excludes informal workers and firms, firm owners and shareholders unless they are (self-)employed, and certain less-populated regions in the years before 1994. The RAIS data are based on legally required annual reports made by firms that transmit information to the Brazilian government on all employees who were on the payroll in the previous year.

Compliance with filling in RAIS is high because of large penalties for late, incomplete, or inaccurate data. Since the main purpose of RAIS is to administer a federal wage bonus to formal employees, there

\footnotetext{
${ }^{5}$ Engbom and Moser (2021) and Haanwinckel (2020) show that the rise of the minimum wage had a pronounced effect on the earnings distribution over this period.
} 
FIGURE 1. MACROECONOMIC INDICATORS FOR BRAZIL, 1985-2018

(A) ANNUAL GDP PER CAPITA GROWTH RATE

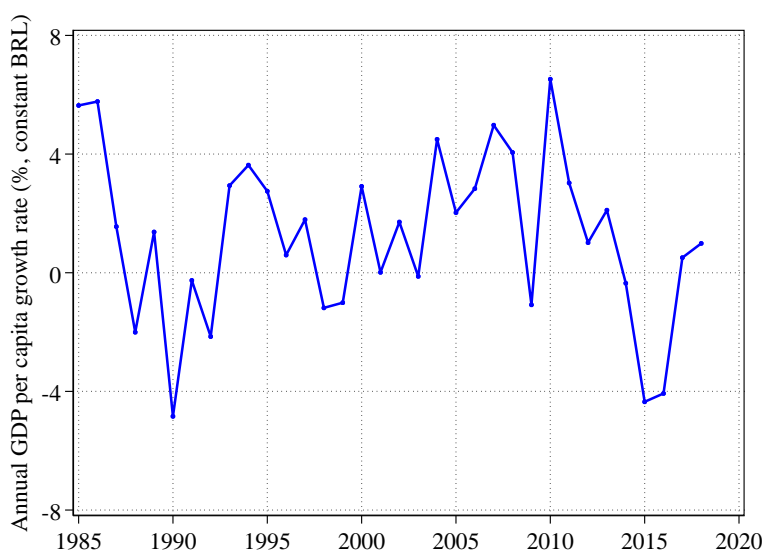

(C) UNEMPLOYMENT RATE

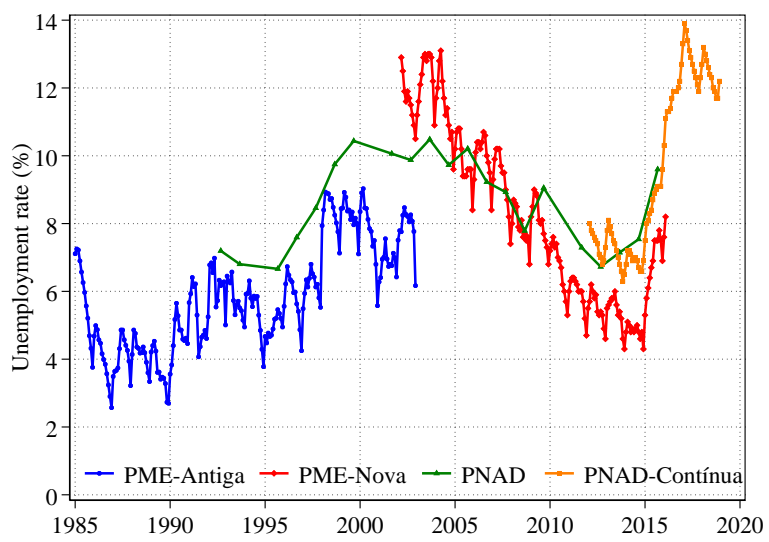

(E) NOMINAL EXCHANGE RATE

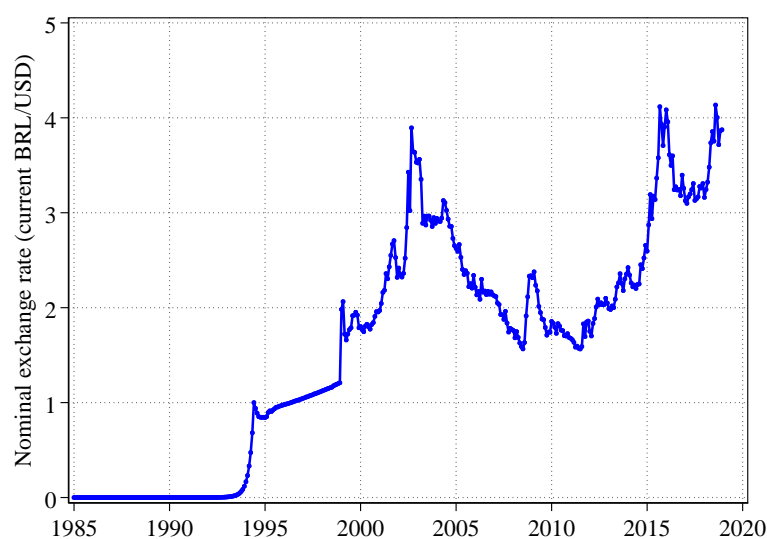

(B) SECTORAL COMPOSITION OF GDP

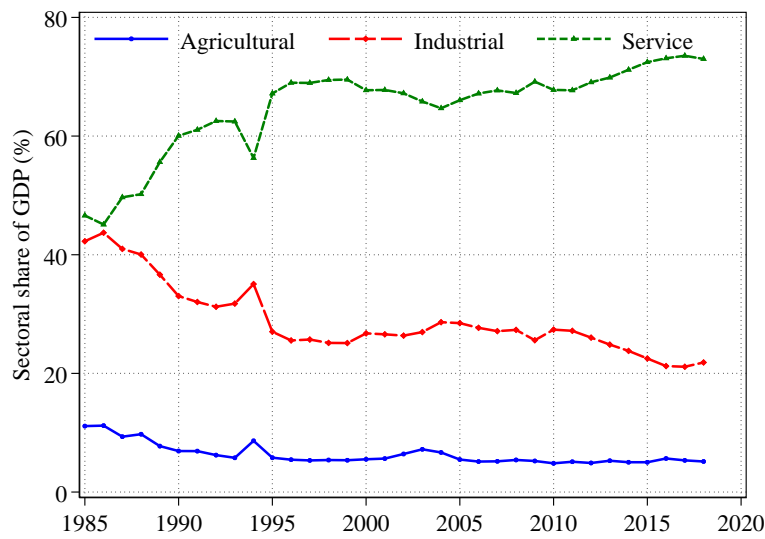

(D) YEAR-ON-YEAR INFLATION RATE

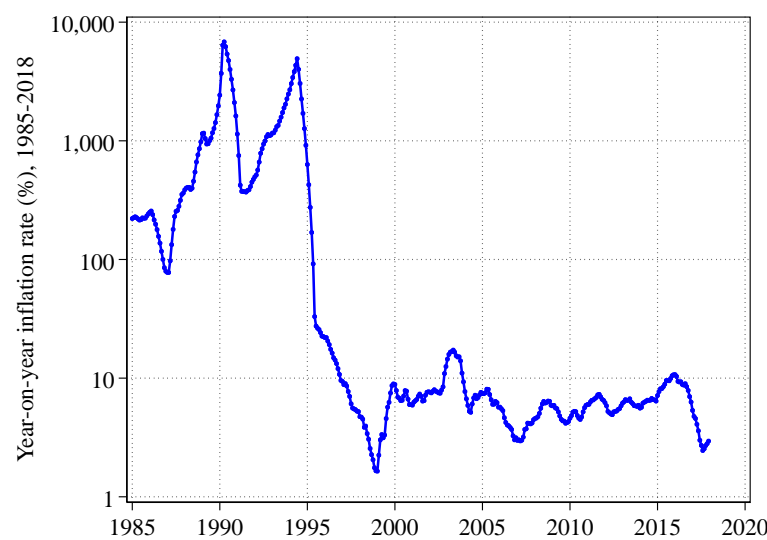

(F) REAL MiNimUM WAGE

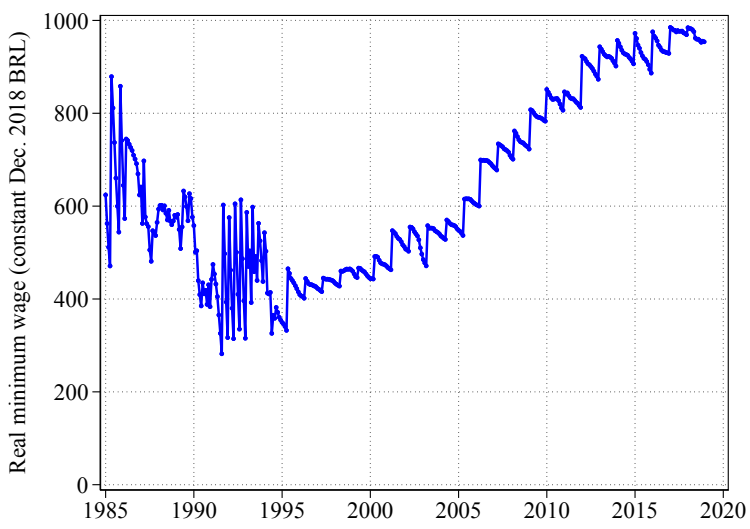

Note: Panel A shows annual GDP per capita growth in constant USD. Panel B shows shares of total GDP by three sectors: agriculture (blue circles), industrial (red diamonds), and services (green triangles). Panel C combines data from the PME-Antiga (blue circles, January 1985December 2002), the PME-Nova (red diamonds, March 2002-February 2016), PNAD (green triangles, September 1992-2014 except 1994, 2000, and 2010), and PNAD-Contínua. PME-Antiga and PME-Nova cover Brazil's six largest metropolitan areas: Recife, Salvador, Belo Horizonte, Rio de Janeiro, São Paulo, and Porto Alegre. PNAD and PNAD-Contínua are representative of Brazil as a whole. See footnote 10 for details. Panel D shows year-on-year inflation using the IPCA price index on a log scale. Panel E shows the nominal exchange rate between Brazilian Reais (BRL) and US Dollars (USD). Panel F shows the real minimum wage in constant December 2018 BRL. Source: Panel A plots data from World Bank. Panels B, D, and F plot data from IPEA. Panel C plots data from IPEA and IBGE. Panel E plots data from Federal Reserve Economic Data (FRED). 
are incentives for truthful reporting. RAIS is also used by ministries for administrating an array of social programs related to the monitoring of formal jobs.

Each observation in RAIS is a worker-establishment match, or job, in a given year. For each job, the data set includes worker-related variables (e.g., gender, age, education, and unique worker identifier), firm-related variables (e.g., sector of activity, establishment size, municipality, and unique establishment and firm identifiers), and job-related variables (e.g., mean monthly earnings during the current year, contractual weekly hours, tenure, occupation, months of hiring and separation, and reason for separation). Our income variable corresponds to mean monthly earnings during the current year and includes wage, salary, and (holiday and performance) bonus payments before taxes.

Each worker has a unique identification number in RAIS, which allows us to recover the full formal work history of all individuals in the database. We use data from 1985 to 2018. RAIS is very large, with an average of around 40 million observations per year, which sums to approximately 1.2 billion job records for the 1985-2018 period. For the year 1996, this corresponds to around 42.5 percent of the labor force, 46.0 percent of employment, and close to all formal employment (Engbom and Moser, 2021).

Sample selection. We apply some standard filters to the administrative data. First, we drop all workers without valid identification numbers or with zero earnings. We then restrict the data to workers in the 25-55 age range. Earnings data in RAIS are censored (i.e., reported as missing) above 120 times the national minimum wage. A Pareto tail imputation exercise suggests that censored observations correspond to a very small proportion, approximately 0.01 percent of the sample. To focus on workers with a meaningful attachment to the labor market, we drop those with total annual nominal earningsdefined in the next paragraph-below earnings associated with part-time employment at the minimum wage for three months. ${ }^{6}$

Variable construction. Our interest lies in features of the distribution of earnings or wages. ${ }^{7}$ Since the period from 1985 to 1994 was characterized by high inflation and multiple currency switches, we first focus on monthly earnings reported in multiples of the prevailing minimum wage. We multiply this multiple by the mean nominal minimum wage in current Brazilian Reais during the months of a given job spell. Since we know for each job spell the hiring and separation dates, we construct total annual nominal earnings for each individual by summing their mean monthly earnings over all months

\footnotetext{
${ }^{6}$ We drop any observation of an individual $i$ in year $t$ with total annual nominal earnings $y_{i t}$ if $y_{i t}<\frac{1}{2} \times 40 \frac{\text { hours }}{\text { week }} \times 4 \frac{\text { weeks }}{\text { month }} \times$ 3 months $\times \overline{\mathrm{MW}}_{t}$, where $\overline{\mathrm{MW}}_{t}$ is the mean prevailing minimum wage over the individual $i$ 's period of employment in year $t$.

${ }^{7}$ Throughout the paper, we use the terms "earnings" and "wages" to interchangably refer to total annual real earnings from all (formal) employment.
} 
of employment and all jobs recorded in RAIS in a given calendar year. Finally, we obtain total annual real earnings by deflating total annual nominal earnings by the mean IPCA, normalized in December 2018, during the months of employment. By measuring earnings in this way, we minimize measurement error related to volatility in nominal variables. For consistency, we apply the same method each year throughout the whole period 1985-2018.

Using the administrative data, we construct the following five variables for an individual $i$ of gender $G(i) \in\{$ male, female $\}$ and age group $A(i, t) \in\{25,26, \ldots, 55\}$ in year $t \in\{1985,1986, \ldots, 2018\}:$

1. Log total annual real earnings, or "log earnings," $\ln y_{i t}$, based on summing all of an individual's earnings across employment spells in a given year;

2. Residual log earnings conditional on gender-year-specific age dummies, or "residual earnings,"

$$
\varepsilon_{i t}=\ln y_{i t}-\sum_{G^{\prime}, t^{\prime}, A^{\prime}} \alpha_{G^{\prime} t^{\prime} A^{\prime}} \mathbb{1}\left[G(i)=G^{\prime}, t=t^{\prime}, A(i, t)=A^{\prime}\right],
$$

where $\alpha_{G^{\prime} t^{\prime} A^{\prime}}$ is a gender-year-age-specific coefficient on $\mathbb{1}\left[G(i)=G^{\prime}, t=t^{\prime}, A(i, t)=A^{\prime}\right]$, which denotes an indicator for the combination of gender $G^{\prime}$, year $t^{\prime}$, and age $A^{\prime} ;{ }^{8}$

3. One-year-forward change in residual earnings based on equation (1), or "one-year earnings changes,"

$$
g_{i t}^{1}=\varepsilon_{i, t+1}-\varepsilon_{i, t} ;
$$

4. Five-years-forward change in residual earnings based on equation (1), or "five-year earnings changes,"

$$
g_{i t}^{5}=\varepsilon_{i, t+5}-\varepsilon_{i, t} ;
$$

5. Residual log mean earnings over the previous three years, conditional on gender-year-specific age dummies, or "permanent earnings,"

$$
P_{i, t}=\ln \left(\frac{y_{i, t-2}+y_{i, t-1}+y_{i, t}}{3}\right)-\sum_{G^{\prime}, A^{\prime}} \gamma_{G^{\prime} t^{\prime} A^{\prime}} \mathbb{1}\left[G(i)=G^{\prime}, t=t^{\prime}, A(i, t)=A^{\prime}\right],
$$

\footnotetext{
${ }^{8}$ In Appendix A.2, we present results of an alternative definition of residual earnings that also conditions on the education group $E(i) \in\{$ primary, middle, high school, college ,

$$
\varepsilon_{i t}=\ln y_{i t}-\sum_{G^{\prime}, t^{\prime}, A^{\prime}} \alpha_{G^{\prime} t^{\prime} A^{\prime}} \mathbb{1}\left[G(i)=G^{\prime}, t=t^{\prime}, A(i, t)=A^{\prime}\right]-\sum_{G^{\prime}, t^{\prime}, E^{\prime}} \beta_{G^{\prime} t^{\prime} E^{\prime}} \mathbb{1}\left[G(i)=G^{\prime}, t=t^{\prime}, E(i)=E^{\prime}\right]
$$
}


where $\gamma_{G^{\prime} t^{\prime} A^{\prime}}$ is a gender-year-age-specific coefficient on $\mathbb{1}\left[G(i)=G^{\prime}, t=t^{\prime}, A(i, t)=A^{\prime}\right]$, which denotes an indicator for the combination of gender $G^{\prime}$, year $t^{\prime}$, and age $A^{\prime}$.

We will frequently refer to percentiles of the distribution of (residual) log earnings or (residual) $\log$ earnings changes. To this end, we use the notation $\mathrm{P} p$, for $p \in[0,100]$, to denote the $p$ th percentile in logs. For example, P50 denotes the median while $P 99.9$ denotes the top 0.1 percentile. Similarly, $\mathrm{P} p_{1}-\mathrm{P} p_{2}$, for $p_{1}, p_{2} \in[0,100]$, denotes the difference between $\mathrm{P} p_{1}$ and $\mathrm{P} p_{2}$, or the $\log$ ratio between the $p_{1}$ th percentile and the $p_{2}$ th percentile.

Summary statistics. Table 1 presents basic summary statistics for selected years between 1985 and 2018 on the gender and age composition, the earnings distribution, and sample sizes, based on our sample from RAIS data. 9 Among the noteworthy features of Brazil's formal sector over this period are the pronounced increases in female labor force participation, high school completion, and overall employment, with a concurrent decline in the standard deviation of log earnings.

Table 1. Summary Statistics on Formal Sector Workers in Administrative Data

\begin{tabular}{|c|c|c|c|c|c|c|c|c|}
\hline & \multicolumn{2}{|c|}{1985} & \multicolumn{2}{|c|}{1996} & \multicolumn{2}{|c|}{2007} & \multicolumn{2}{|c|}{2018} \\
\hline & Men & Women & Men & Women & Men & Women & Men & Women \\
\hline Share & 0.693 & 0.307 & 0.634 & 0.366 & 0.600 & 0.400 & 0.557 & 0.443 \\
\hline \multicolumn{9}{|l|}{ Age: } \\
\hline Mean & 34.288 & 33.917 & 35.548 & 35.731 & 35.890 & 36.067 & 36.999 & 37.118 \\
\hline Standard deviation & 7.658 & 7.407 & 8.079 & 7.956 & 8.413 & 8.444 & 8.370 & 8.348 \\
\hline \multicolumn{9}{|l|}{ Education shares: } \\
\hline Middle school & 0.180 & 0.161 & 0.212 & 0.172 & 0.219 & 0.153 & 0.190 & 0.119 \\
\hline High school & 0.177 & 0.303 & 0.232 & 0.352 & 0.386 & 0.476 & 0.536 & 0.590 \\
\hline College & 0.102 & 0.212 & 0.097 & 0.217 & 0.103 & 0.235 & 0.110 & 0.223 \\
\hline \multicolumn{9}{|l|}{ Earnings: } \\
\hline Mean & 30,687 & 21,820 & 29,297 & 23,342 & 28,263 & 24,620 & 33,674 & 29,709 \\
\hline Standard deviation & 41,580 & 25,672 & 42,168 & 31,850 & 44,689 & 36,625 & 46,626 & 38,139 \\
\hline \multicolumn{9}{|l|}{ Log earnings: } \\
\hline Mean & 9.770 & 9.532 & 9.655 & 9.480 & 9.698 & 9.584 & 9.969 & 9.871 \\
\hline Standard deviation & 1.069 & 0.966 & 1.133 & 1.080 & 1.000 & 0.979 & 0.917 & 0.889 \\
\hline Observations (mm) & 10.765 & 4.778 & 13.845 & 7.985 & 20.255 & 13.527 & 23.455 & 18.631 \\
\hline
\end{tabular}

\footnotetext{
${ }^{9}$ Table A1 in Appendix A1 presents detailed summary statistics on the distribution of earnings for each year between 1985 and 2018. Appendix Tables A2 and A3 show the same statistics separately for men and for women.
} 


\subsubsection{Household Survey Data}

Data description. To study earnings inequality dynamics for both formal and informal workers in Brazil, we use microdata from PME. The survey was conducted by the Brazilian Institute of Geography and Statistics (Instituto Brasileiro de Geografia e Estatística, or IBGE) in Brazil's six largest metropolitan areas: São Paulo, Rio de Janeiro, Belo Horizonte, Porto Alegre, Salvador, and Recife. It was administered from the early 1980s until 2016, when it was terminated and replaced with a different survey. While it was active, the survey was used to compute official unemployment statistics for Brazil.

The rotating panel design of PME is such that the surveys are representative at the metropolitanarea level in each month. We use data from the so-called New PME (PME-Nova), covering 2002-2015. We do not make use of the Old PME (PME-Antiga) survey data covering the period before 2002, since they do not contain the necessary information on employment and income to allow us to replicate all of our analysis for the earlier years it covers. ${ }^{10}$ By the end of the period, the sample covered around 34,000 households and 95,000 individuals in each month. The pooled data for the 2002-15 period feature approximately 7.3 million observations, or around 500,000 per year on average. The main variables we use are the worker ID, gender, age, schooling, monthly earnings, labor market status (employed, selfemployed, unemployed, or out of the labor force), and information on whether the individual holds a formal work permit (explained below). Monthly earnings are in 2018 BRL and include wage, salary, and (holiday and performance) bonus payments before taxes.

Formal employees in Brazil are hired under the Brazilian labor codes Consolidação das Leis do Trabalho, CLT. CLT states that each employer has to fill in and sign the employee's working card (Carteira de Trabalho) when formally hiring a worker in Brazil. ${ }^{11}$ After asking if he or she is employed, PME elicits whether the worker possesses a signed working card. Since RAIS covers only workers hired under CLT, workers with a working card correspond to those in the administrative data.

It is important to note that all household surveys run by IBGE are anonymous. IBGE has long had reputation of never granting outsiders access to any personally identifiable information of respondents.

PME surveys have a rotating panel structure similar to that of the Current Population Survey (CPS) in the US. Households are surveyed for two spells of four consecutive months; the spells are eight months apart from each other. This means that households complete four monthly interviews, followed by an

\footnotetext{
${ }^{10}$ The Old PME started in 1982 and ended in December 2002. The New PME, which started in March 2002, comprised major revisions that include a significantly larger questionnaire and more extensive checks on measures of labor market participation and other variables. The New PME, in turn, was discontinued after February 2016, since in the first quarter of 2012 IGBE had introduced the Continuous PNAD (PNAD-Contínua), a new household survey with five-quarter longitudinal information and nationally representative coverage.

${ }^{11}$ The working card is a booklet with information on an individual's complete formal labor market history, including all details of each job held by a worker-the hiring and separation dates, paid vacation periods, leaves of absence, etc.
} 
eight-month pause, and then by another four monthly interviews. This rotating panel structure means that the months the individual is interviewed are the same in any two consecutive years. Interviews are spread evenly within a month and households are always interviewed in the same week of the month.

Households are correctly identified throughout all eight interviews. However, PME does not assign the same identification number to each individual in the household across interviews. To reduce attrition, we use an algorithm developed by Ribas and Soares (2008), which identifies the same individual in each household across interviews using a fuzzy merge based on the combination of reported dates of birth and genders. ${ }^{12}$

Sample selection. We make several choices to make the information in the two data sets-RAIS and PME - as comparable as possible for formal workers. First, we use only data for workers in the 2555 age range. For the cross-sectional exercises, we construct comparable measures of annual earnings, $y_{i t}$. Since the panel structure of PME allows us to follow workers for only one year, we also compute one-year-forward residualized log annual earnings changes.

For comparability reasons, we drop all business owners who contribute to social security and domestic employees in PME, since they are not measured in the administrative data. We consider as formal (informal) workers only those individuals who show up as formal (informal) employees in all monthly observations within a calendar year. We drop individuals who work in both sectors within the same

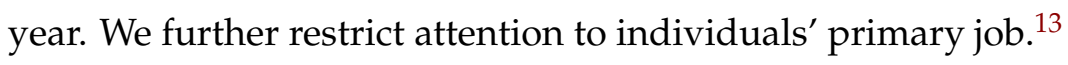

In addition, we apply the following selection criteria. We drop individuals with year-on-year survey attrition or without positive earnings from any (formal or informal) employment during any of the survey waves during a year. For the longitudinal statistics, we restrict ourselves to individuals to who have a full eight months of nonmissing responses in the two consecutive years. To mimic the top-coding in RAIS, we drop monthly earnings above 120 times the minimum wage. The reason for doing this is that the original RAIS data have dropped, and not winsorized, earnings above this threshold. Finally, we trim observations with annualized incomes below the equivalent of 1.5 months of full time work at the prevailing minimum wage, which is the equivalent of the bottom threshold we used in our baseline analysis of RAIS.

The final sample is thus composed of formal workers (i.e., employees with a valid working card) and informal workers (i.e., employees without a valid working card and self-employed individuals who do

\footnotetext{
${ }^{12}$ Standardized cleaning procedures and the panel linkage method are available from Data Zoom by PUC-Rio at http: //www.econ.puc-rio.br/datazoom/english/index.html.

${ }^{13}$ In Appendix A.4, we show that extending the analysis to workers with multiple concurrent jobs, who make up less than 3 percent of all workers, does not substantially alter our conclusions.
} 
not contribute to social security). Note that this sample includes workers employed in the public sector.

Variable construction. We construct variables in PME to be analogous to those in the administrative data whenever possible. Since the household survey follows a rotating panel format, we create seasonal dummy variables that identify each four-month period in the calendar year in which the individual is interviewed (which we refer to as a survey wave). ${ }^{14}$

Using the household survey data, we construct the following three variables for an individual $i$ of gender $G(i) \in\{$ male, female $\}$, age group $A(i, t) \in\{25,26, \ldots, 55\}$, and season group $S(i, t) \in$ $\{($ Jan-Apr $),($ Feb-May) $, \ldots,($ Jan-Mar; Dec $)\}$ in year $t \in\{2002,2003, \ldots, 2015\}$ :

1. Log total annual real earnings, or "log earnings," $\ln y_{i t}$, based on summing earnings during the (first or second set of) four consecutive interview months, multiplied by three;

2. Residual log earnings conditional on gender-year-specific age dummies and gender-year-specific season dummies, or "residual earnings,"

$\varepsilon_{i t}=\ln y_{i t}-\sum_{G^{\prime}, t^{\prime}, A^{\prime}} \delta_{G^{\prime} t^{\prime} A^{\prime}} \mathbb{1}\left[G(i)=G^{\prime}, t=t^{\prime}, A(i, t)=A^{\prime}\right]-\sum_{G^{\prime}, t^{\prime}, S^{\prime}} \eta_{G^{\prime} t^{\prime} S^{\prime}} \mathbb{1}\left[G(i)=G^{\prime}, t=t^{\prime}, S(i, t)=S^{\prime}\right]$,

where $\delta_{G^{\prime} t^{\prime} A^{\prime}}$ is a gender-year-age-specific coefficient on $\mathbb{1}\left[G(i)=G^{\prime}, t=t^{\prime}, A(i, t)=A^{\prime}\right]$, which denotes an indicator for the combination of gender $G^{\prime}$, year $t^{\prime}$, and age $A^{\prime}$, and $\eta_{G^{\prime} t^{\prime} S^{\prime}}$ is a genderyear-season-specific coefficient on $\mathbb{1}\left[G(i)=G^{\prime}, t=t^{\prime}, S(i, t)=S^{\prime}\right]$, which denotes an indicator for the combination of gender $G^{\prime}$, year $t^{\prime}$, and season $S^{\prime}$;

3. One-year-forward change in residual earnings based on equation (2), or "one-year earnings changes,"

$$
g_{i t}^{1}=\varepsilon_{i, t+1}-\varepsilon_{i, t} .
$$

Summary statistics. One may suspect that the workers employed in Brazil's formal sector are not identical to those in the informal sector. Indeed there are some important differences in worker composition across sectors, as shown in Table 2. Informal workers have earnings that are 83.7 log points lower on average and their distribution is more dispersed than that of formal workers, confirming the findings from

\footnotetext{
${ }^{14}$ There are twelve seasonal dummies for the cross-section statistics, based on PME's 4-8-4 rotating panel system: (Jan-Apr), (Feb-May), (Mar-Jun), (Apr-Jul), (May-Aug), (Jun-Sep), (Jul-Oct), (Aug-Nov), (Sep-Dec), (Oct-Dec; Jan), (Nov-Dec; Jan-Feb), (Dec; Jan-Mar). For the longitudinal exercises, only a subset consisting of nine seasons is relevant: (Jan-Apr), (Feb-May), (MarJun), (Apr-Jul), (May-Aug), (Jun-Sep), (Jul-Oct), (Aug-Nov), and (Sep-Dec).
} 
our visual analysis. Informal workers are slightly more likely to be female, less likely to be White and more likely to be Black, less likely to have a high school degree, older, have slightly more children in the household, are less likely to work in manufacturing or services (i.e., more likely to work in agriculture and residual sectors), less likely to work in white collar occupations, and less likely to work at firms with 6-10 or more than 10 persons. Informal workers also have significantly lower tenure in their current job, by around 4.5 years, and work significantly fewer hours, by around 8.5 hours per week.

TABle 2. Summary Statistics on Workers in Survey Data, Overall AND by SeCtor

\begin{tabular}{lccc}
\hline \hline & Overall & Formal & Informal \\
\hline Mean log earnings & 9.653 & 9.934 & 9.097 \\
Standard deviation of log earnings & 0.922 & 0.796 & 0.902 \\
Share female & 0.432 & 0.430 & 0.437 \\
Share Nonwhite & 0.418 & 0.398 & 0.459 \\
Share with at least high school education & 0.564 & 0.651 & 0.393 \\
Share age 35-44 & 0.344 & 0.343 & 0.345 \\
Share age 45-55 & 0.285 & 0.258 & 0.338 \\
Share with children in household & 0.356 & 0.352 & 0.365 \\
Share in manufacturing & 0.192 & 0.212 & 0.153 \\
Share in services & 0.529 & 0.580 & 0.428 \\
Share white collar & 0.383 & 0.457 & 0.237 \\
Share employed at firm with 6-10 employees & 0.037 & 0.039 & 0.034 \\
Share employed at firm with $>10$ employees & 0.637 & 0.915 & 0.175 \\
Mean tenure in years & 7.659 & 7.810 & 7.360 \\
Standard deviation of tenure in years & 7.286 & 7.223 & 7.401 \\
Mean weekly hours worked & 36.899 & 39.747 & 31.265 \\
Standard deviation of weekly hours worked & 12.690 & 9.778 & 15.579 \\
& & & \\
Observations (weighted) & $311,895,692$ & $207,175,606$ & $104,720,086$ \\
Observations (unweighted) & 743,975 & 489,555 & 254,420 \\
\hline
\end{tabular}

Note: All statistics are for workers aged 25-55. Earnings are in 2018 BRL. Residual categories for which no share is reported are men, White, less than high school education, age 25-34, no children in household, agriculture, blue collar, and firms with 1-5 persons. The weighted number of observations corresponds to the sum of survey sampling weights, while the unweighted number of observations corresponds to the number of data points in the sample. Source: PME, 2002-2015.

\section{Core Statistics on Earnings Inequality and Dynamics in Brazil's Formal Sector}

This section documents patterns of earnings inequality and earnings dynamics in the formal sector in Brazil using the administrative RAIS matched employer-employee data. In the next section, we turn to the informal sector and compare administrative and survey data. 


\subsection{Earnings Inequality}

Most percentiles of the earnings distribution in Brazil experienced significant cumulative real wage growth over the 34 years in our data, as illustrated by Figure 2. Wage growth was not, however, monotone. In particular, real wages fell consistently during the high inflationary years of the late 1980s and early 1990s. Since the extensive macroeconomic reforms undertaken in the early 1990s, most workers across the earnings distribution have seen real wage growth. The patterns are quite similar for men and women, as well as when pooling both genders (see Appendix A.2).

While all parts of the earnings distribution experienced significant real wage growth since the early 1990s, there is also important heterogeneity across the earnings distribution. In particular, since the early 1990s, earnings have grown disproportionately at the bottom of the earnings distribution. For instance, since 1995, earnings at the 75th percentile grew by about 10 log points, while at the 25th percentile, they rose by $60 \log$ points. This pattern is reversed at the very top of the earnings distribution, which experienced widening inequality similar to that of many developed countries. For instance, earnings at the 99th percentile rose by more than at the 90 th percentile.

Due to the faster real wage growth at the bottom of the distribution, earnings inequality fell dramatically in Brazil starting in the early 1990s, as shown in Figure 3. The 90-10 percentile ratio declined from 3 to 2.3. The patterns are again quite similar among men and women, as well as when pooling both genders (see Appendix A.2). Moreover, the fall in inequality was particularly pronounced at the bottom of the earnings distribution, as evidenced by the larger fall in the 50-10 ratio compared with that of the 90-50 percentile ratio. Nevertheless, the 90-50 percentile ratio also fell by a significant amount, driven by fast real median wage growth. This large decrease in inequality is particularly remarkable given that many countries experienced increases in inequality over the same period. That said, Brazil continues to have high levels of inequality.

The role of entry conditions. Figure 4 plots lower and upper tail inequality among 25 -year-olds by gender over time. As for the aggregate trends, from the early 1990s onwards, young workers experienced a large decline in inequality. In other words, the large overall decline in inequality was not solely the result of changes in earnings dynamics after labor market entry. Instead, inequality is lower also among labor market entrants. The compression in the earnings distribution among young workers was again particularly pronounced at the bottom of the earnings distribution, as evidenced by the larger fall in the 50-10 percentile ratio relative to that of the 90-50 ratio.

To further investigate the role of changes in initial conditions versus that of changes in post-entry 
Figure 2. Evolution of Earnings Percentiles, By Gender

(A) Overall, Men

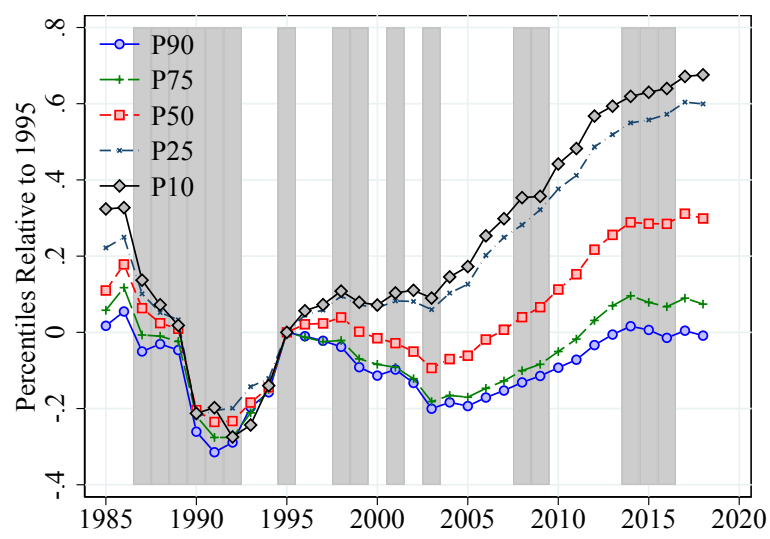

(C) Top Percentiles, Men

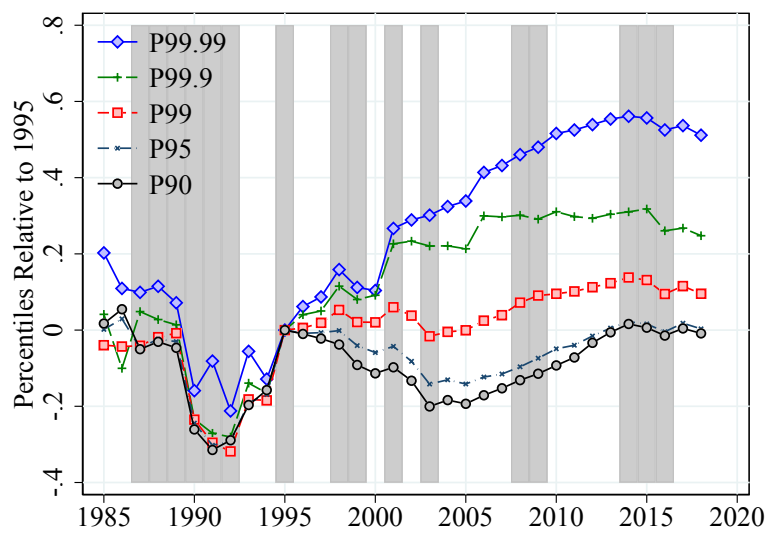

(B) OVERALl, WOMEN

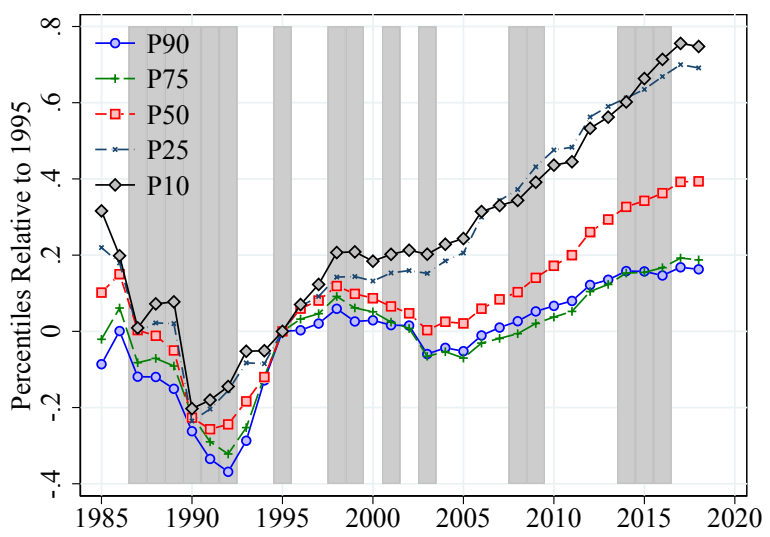

(D) Top Percentiles, Women

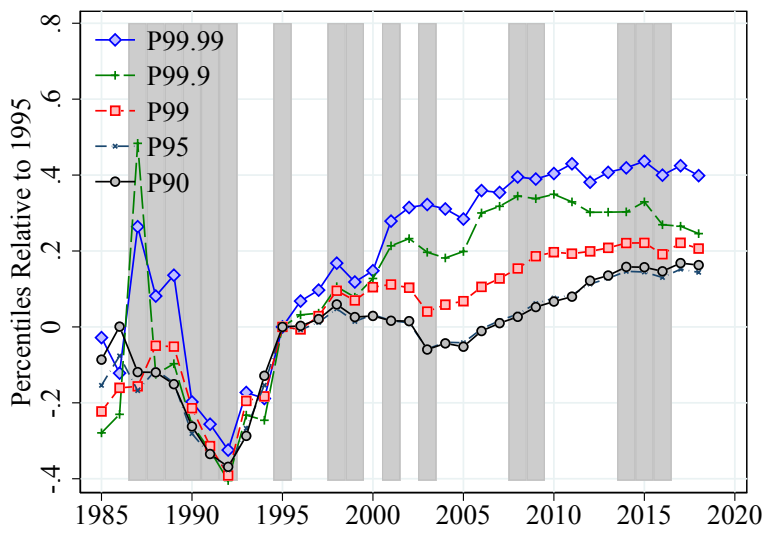

Note: Workers aged 25-55. Percentiles of the distribution of log real annual earnings, normalized to 1995. Source: RAIS, $1985-2018$. 
FIGURE 3. EARNINGS INEQUALITY, BY GENDER

(A) Overall, Men

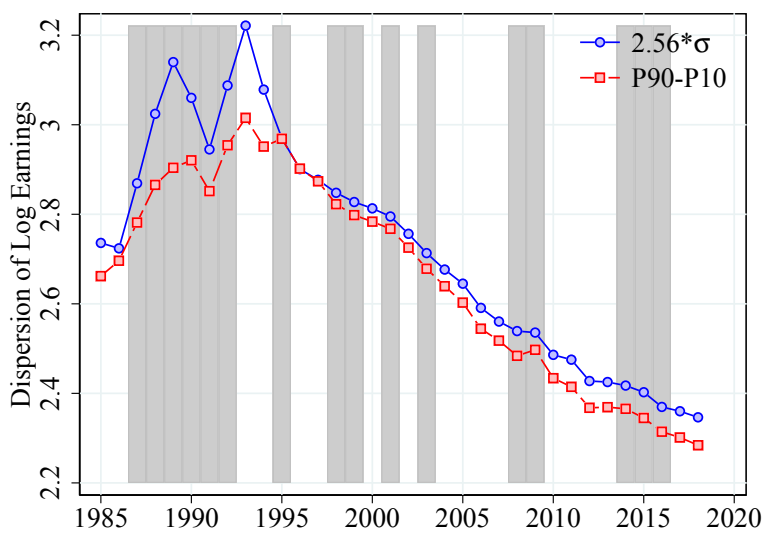

(C) Right And Left Tails, Men

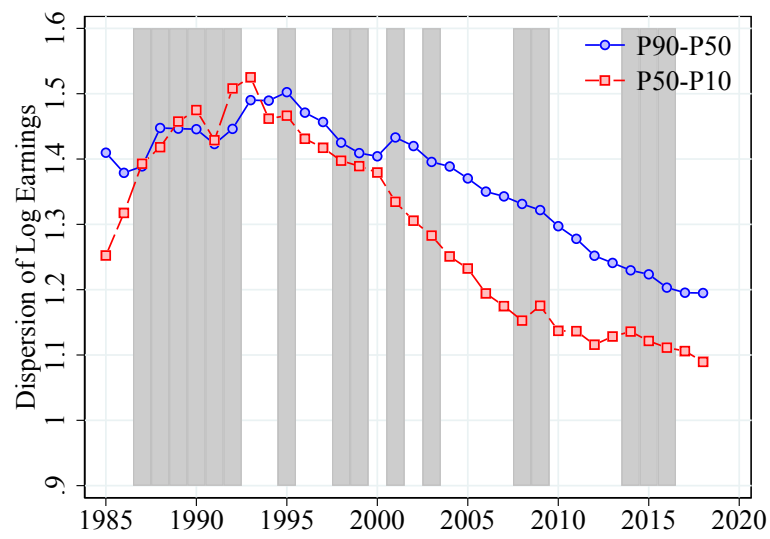

(B) Overall, Women

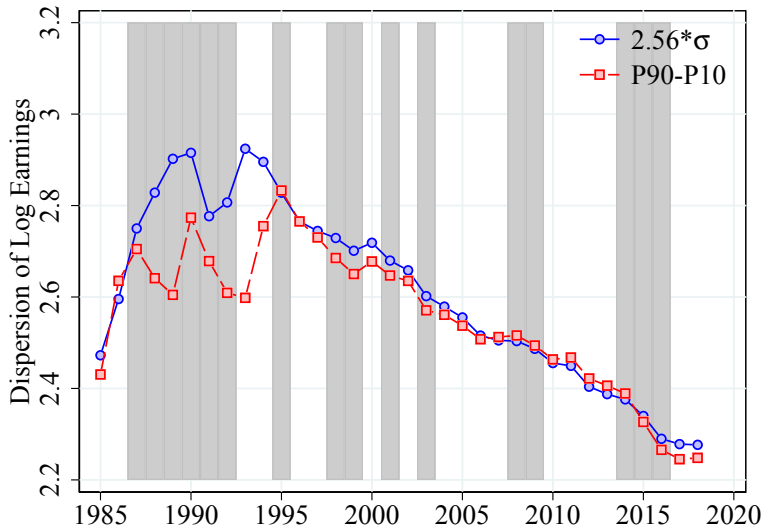

(D) Right And Left TAils, Women

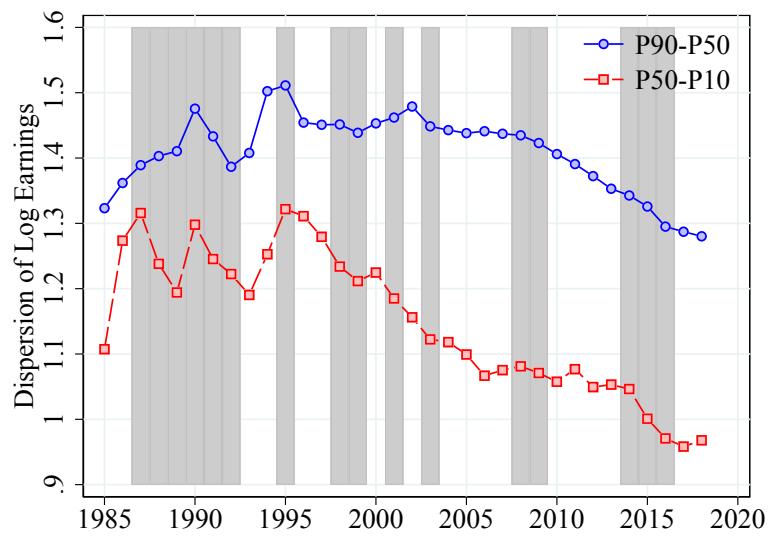

Note: Workers aged 25-55. $\sigma$ denotes the standard deviation of log real annual earnings. Source: RAIS, 1985-2018.

Figure 4. EARnings InequAlity Among 25-YeAR OldS, By Gender

(A) MEN

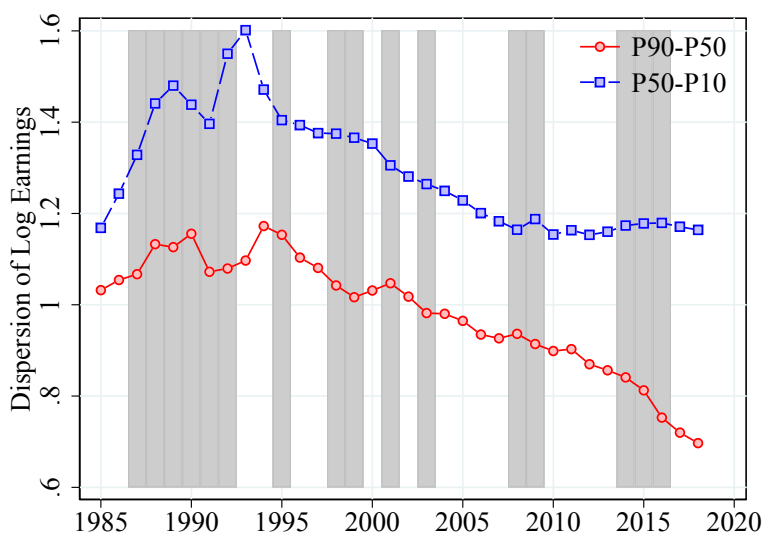

(B) WOMEN

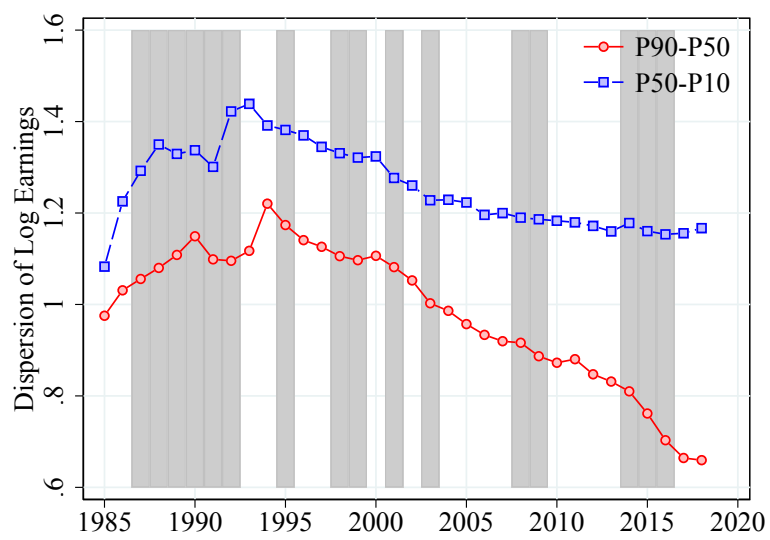

Note: Workers aged 25. Source: RAIS, 1985-2018. 
life-cycle dynamics, in Figure 5 we follow cohorts over time as they age. The earliest cohort to turn 25those who did so in 1985—saw an initial increase in inequality during the first 10 years, followed by a subsequent decline. This initial increase, however, may be the result of a time effect associated with the period of high inflation experienced by Brazil over this period. Subsequent cohorts of men and women have seen a gradual flattening and eventual reversal of the profile of within-cohort inequality with age. One possible factor behind this interesting pattern is the rapid increase in the minimum wage over this period. It is well known that a minimum wage tends to disproportionately affect young workers, and it may have contributed to a particular compression in inequality at labor market entry. As older workers are less affected by the minimum wage, inequality has fallen by less at older ages, which by itself has contributed toward a steepening of life-cycle inequality profiles.

\section{Figure 5. LIFE-CyCle INEQUALITy ACROSS COHORTS, By GENDER}

(A) MEN

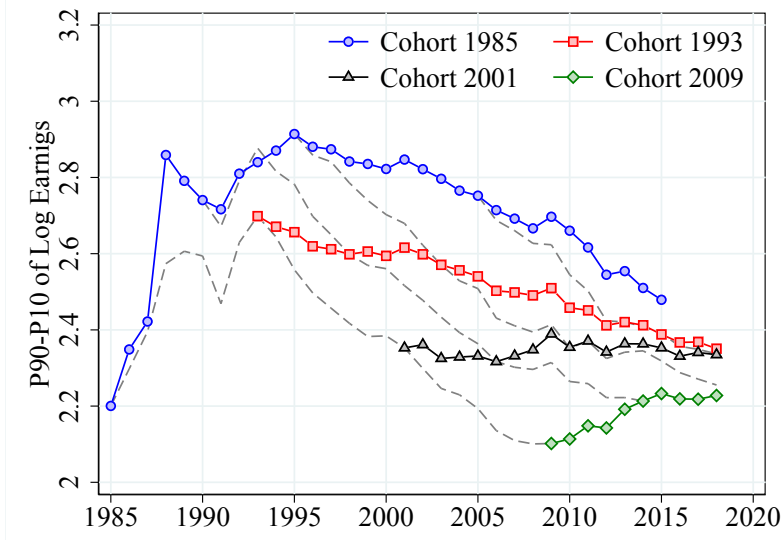

(B) WOMEN

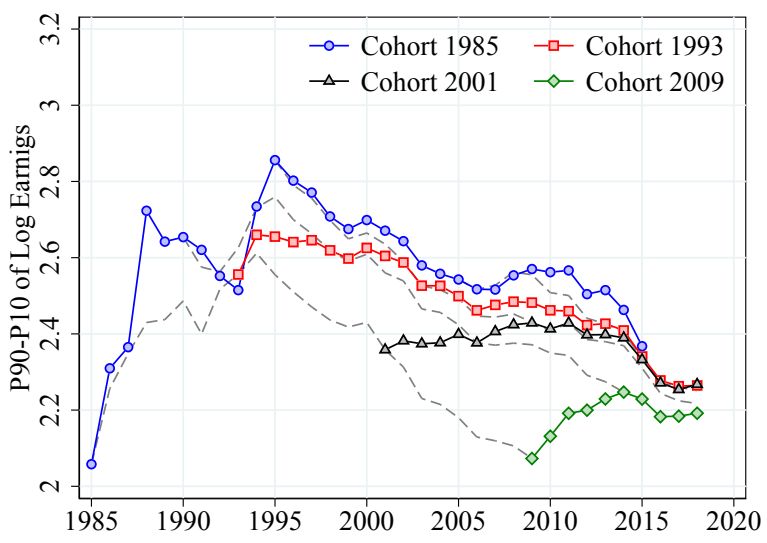

Note: Workers aged 25-55. Source: RAIS, 1985-2018.

\subsection{Earnings Dynamics}

We now turn to trends in earnings dynamics. Figure 6 plots upper-tail (i.e., 90-50) and lower-tail (i.e., 50-10) percentile ratios of one-year residual log earnings changes separately by gender. Overall, men have somewhat more dispersed earnings changes, especially in the lower tail of the distribution. Relatively low (high) earnings changes became more (less) dispersed during the years of high inflation in the late 1980s and early 1990s. Since then, earnings have gradually become less volatile. The lower-tail dispersion of earnings changes is countercyclical-meaning that the dispersion in relatively low earnings changes increases during recessions, while the upper tail of earnings changes is procyclical-meaning that the dispersion in relatively high earnings changes decreases during recessions. It is worth noting that these patterns are qualitatively different from the results documented by Busch et al. (2020) for 
Germany, Sweden, and the US.

Figure 6. Dispersion of ONE-YEAR LOG EARnings Changes, By GENDER

(A) MEN

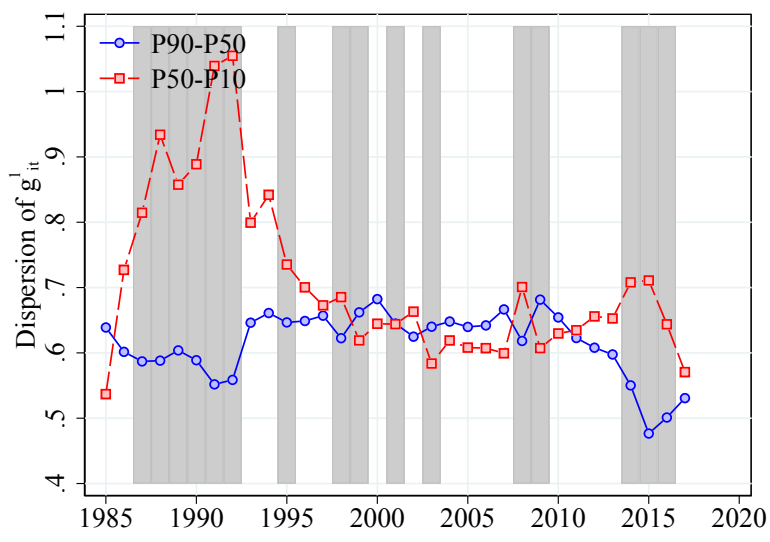

(B) WOMEN

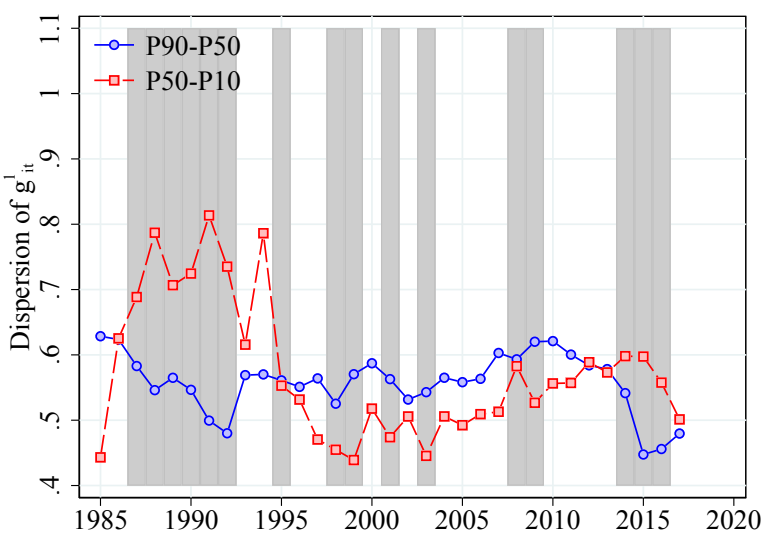

Note: Workers aged 25-55. Source: RAIS, 1985-2018.

Letting P $p$ denote the $p$ th percentile of the distribution of (log real) earnings changes, we adopt two quantile-based measures of higher-order moments. First, Kelley skewness is defined as [(P90-P50) (P50-P10)] / P90-P10), which is identically zero for a Gaussian distribution. Second, the Crow-Siddiqui kurtosis is defined as (P97.5-P2.5) / (P75-P25), which equals 2.91 for a Gaussian distribution. Based on this, we define the excess Crow-Siddiqui kurtosis as the Crow-Siddiqui kurtosis minus 2.91, which is then also identically zero for a Gaussian distribution.

Figure 7 plots the Kelley skewness and excess Crow-Siddiqui kurtosis of one-year residual earnings changes. As suggested by Figure 6, the Kelley skewness of earnings changes is procyclical: relatively low earnings changes become more dispersed during recessions. In contrast, it is difficult to reach a definitive conclusion about the cyclicality of the excess Crow-Siddiqui kurtosis. While the Kelley skewness displays little secular trend over the past 34 years, the excess Crow-Siddiqui kurtosis has gradually risen. In other words, the likelihood of relatively large negative and positive shocks has risen over time. One possible factor behind this pattern is the decline in informality in Brazil over this period. It may be that workers 20 years ago were more likely to leave the formal sector in response to large negative shocks, whereas today they tend to remain formally employed, though at lower earnings. If earnings were to later revert, this would account for an increase in the excess Crow-Siddiqui kurtosis. ${ }^{15}$ Another potential explanation behind the rise in the excess Crow-Siddiqui kurtosis over time pertains to the process of trade liberalization that Brazil underwent during the 1990s (Dix-Carneiro and Kovak, 2017; Martínez

\footnotetext{
${ }^{15}$ In Section 4.1, we further investigate the distribution of earnings changes within and between the formal versus informal sector as well as the rates of switching sectors.
} 
and Mello, 2021).

\section{Figure 7. Higher-Order Moments of the One-Year Log Earnings Change DISTRIBUTION}

(A) Kelley SKeWNesS

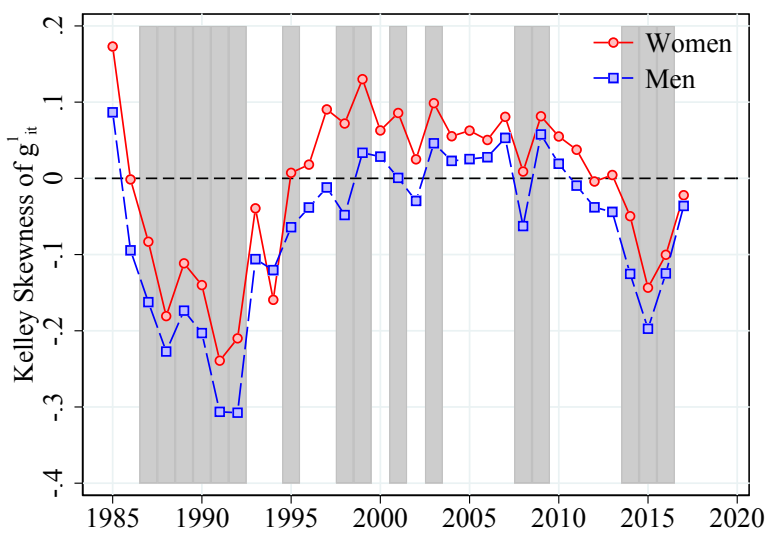

(в) ExCESS CROW-Siddiqui KuRTOSIS

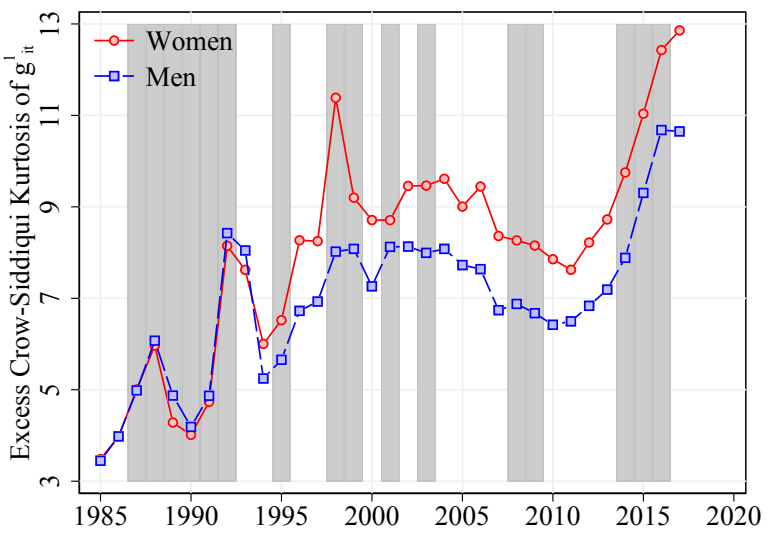

Note: Workers aged 25-55. Source: RAIS, 1985-2018.

Life-cycle dynamics. Complementing our time-series evidence, Figure 8 studies the distribution of one-year earnings changes over the life cycle. ${ }^{16}$ In particular, it plots the 90-10 percentile ratio, the Kelley skewness, and excess Crow-Siddiqui kurtosis of one-year log earnings changes by age group as a function of permanent earnings. To this end, for reasons of standardization across countries in the special issue, we use 20 years of the RAIS data covering the period from 1999 to 2018. Young workers have more volatile earnings as measured by the 90-10 percentile ratio of earnings changes, as do lowerpermanent-earnings workers within all age groups. There is no pronounced systematic pattern for the Kelley skewness across permanent-earnings quantiles, although younger workers have a lower Kelley skewness of earnings changes, especially among women. The ranking of Kelley skewness across age groups is reversed compared to the US (Guvenen et al., 2019). Interestingly, the pattern for the excess Crow-Siddiqui kurtosis of earnings changes is partly inverted relative to that for the 90-10 percentile ratio. While low-permanent-earnings workers also have the highest excess Crow-Siddiqui kurtosis within all age groups, older workers have higher excess Crow-Siddiqui kurtosis than their younger counterparts. Younger workers are subject to more dispersed but more negatively skewed and less leptokurtic shocks earnings changes compared to older workers. Women are less likely than men to experience negative earnings shocks as evidenced by the higher Kelley skewness of earnings changes, possibly because they are more likely to drop out of the formal sector in response to large negative shocks.

\footnotetext{
${ }^{16}$ Appendix Figures A11-A13 present the same statistics for the distribution of five-year earnings changes, as well as the corresponding second, third, and fourth standardized moments of the distributions of one-year and five-year earnings changes.
} 
Figure 8. Moments of the Distribution of One-Year EARnings Changes, by Gender

(A) P90-P10, MEN

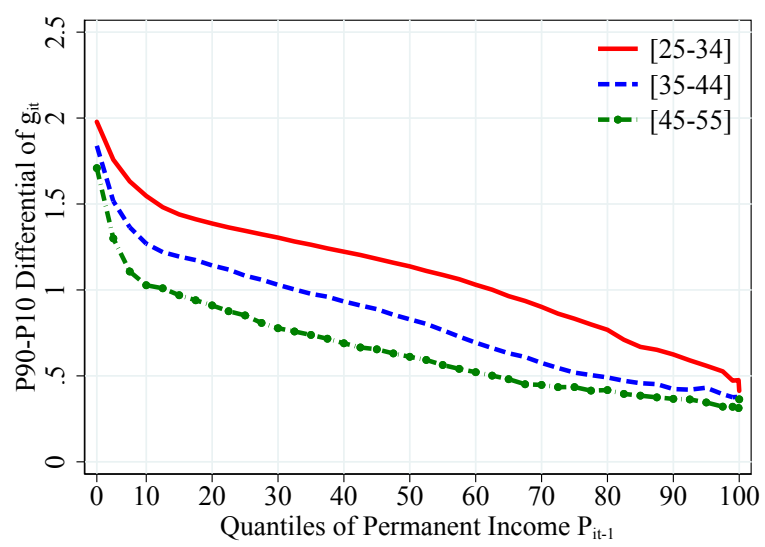

(C) Kelley SKeWness, MEN

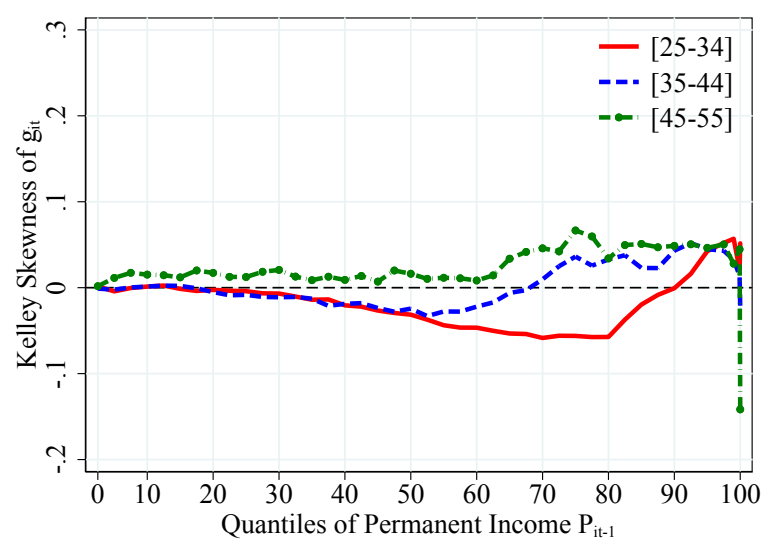

(E) Excess CROW-SidDiQui KuRTOSIS, MEN

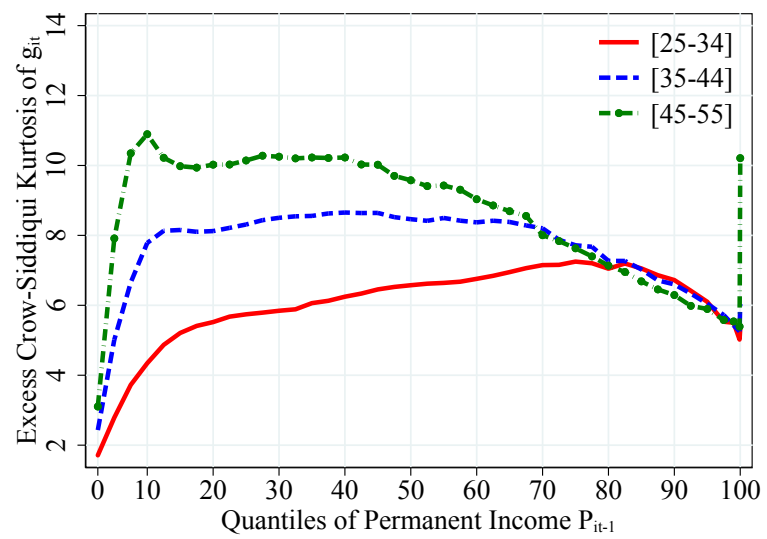

Note: Workers aged 25-55. Source: RAIS, 1999-2018.
(B) P90-P10, WOMEN

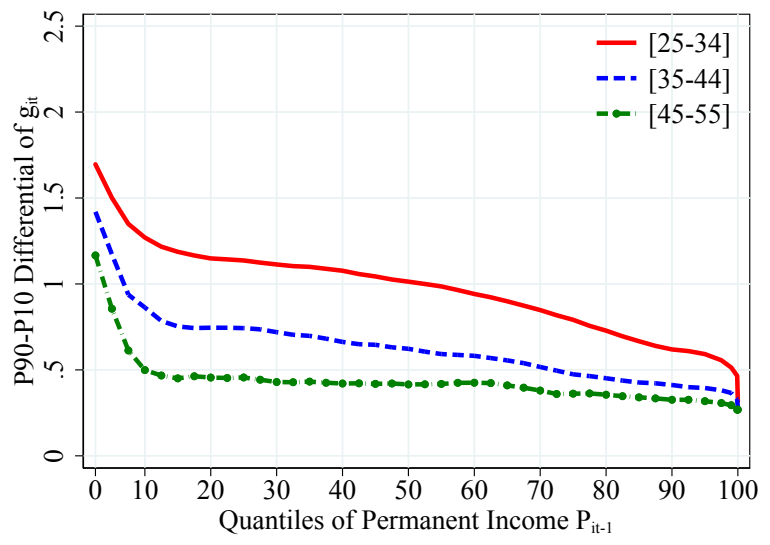

(D) KeLley SKeWNess, WOMEN

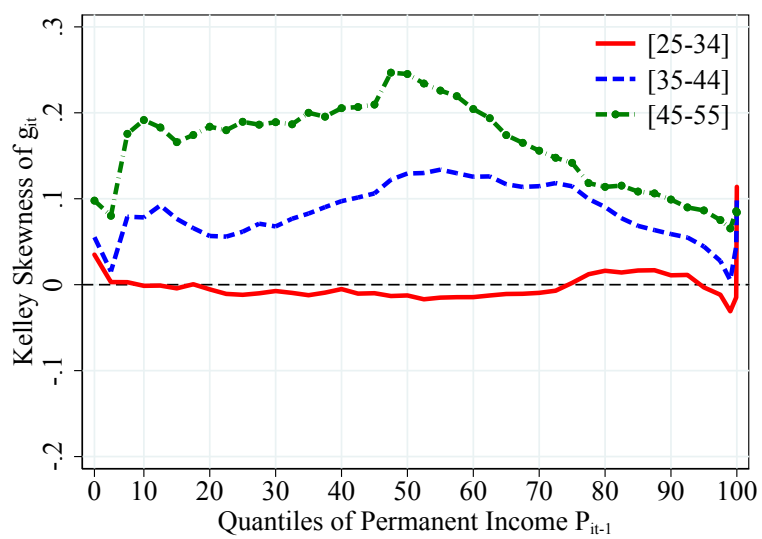

(F) ExCESS CROW-SidDiQui KuRTOSIS, WOMEN

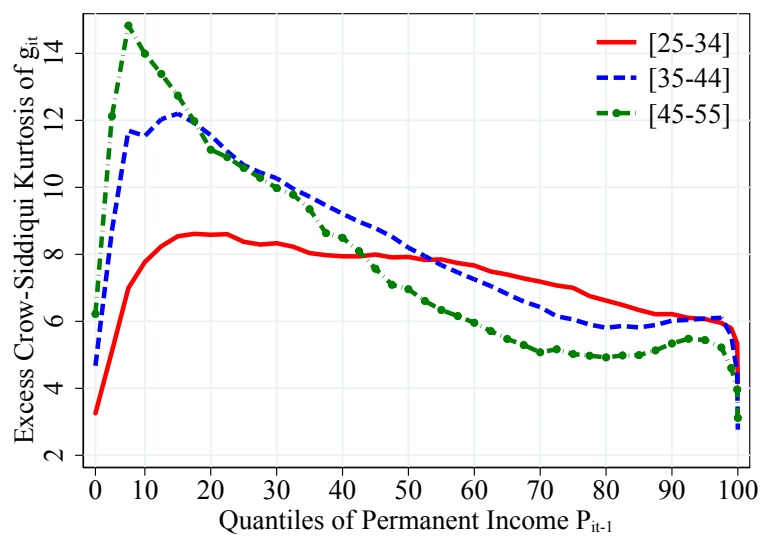


Earnings mobility. Figure 9 investigates earnings mobility. In particular, it plots a worker's average rank in the earnings distribution 10 years later as a function of his or her rank in the distribution in the current period, separately by age and gender (the Appendix contains similar plots for outcomes five years later, with a similar conclusion). The distribution is mean reverting, in the sense that individuals currently at the bottom of the distribution tend to move up the distribution over time and vice versa. Specifically, workers in the bottom 40 percent of the permanent-income distribution on average gain ranks over the subsequent ten years, while workers in the top 60 percent of the permanent-income distribution on average move down in ranks over the subsequent ten years. Younger workers are more mobile in the sense that their permanent-income rank is more mean reverting, as evidenced by the flatter solid red line in the figure.

Figure 9. Evolution of 10-Year Mobility Over the Life Cycle, By Gender

(A) MEN

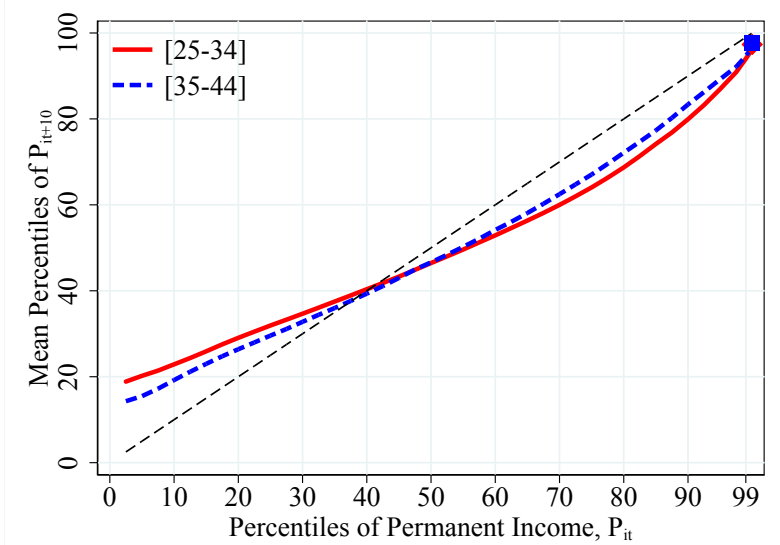

(B) WOMEN

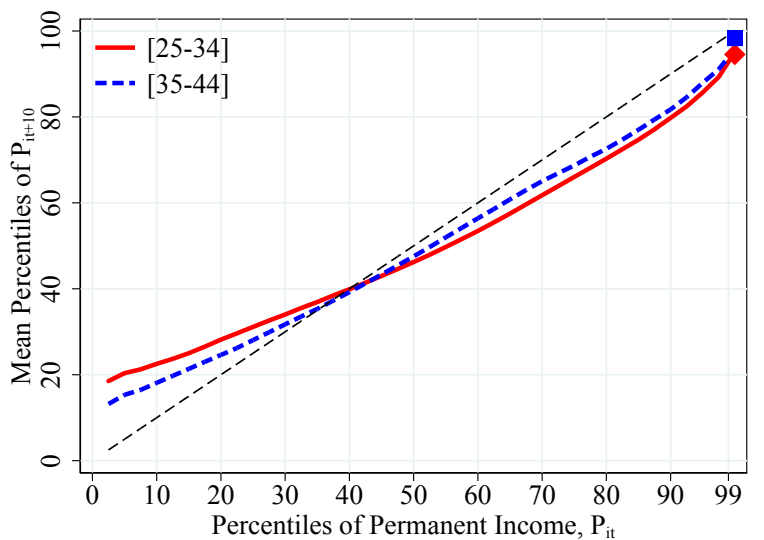

Note: Workers aged 25-55. Colored markers denote the top 0.1\% of permanent income $P_{i t}$. Source: RAIS, $1985-2018$.

Figure 10 conducts the same analysis instead over time: it plots the average rank of workers 10 years later as a function of their rank in the earnings distribution today, separately by year and gender. There is little systematic variation in mobility between 1995, shown as a solid red line, and 2015, shown as a dashed blue line. This observation is quite interesting in light of the pronounced decline in earnings volatility over this period shown in Figure 6. That is, in spite of lower earnings volatility, individuals move across the earnings distribution to a similar extent now as in the past. Since the underlying earnings distribution is more compressed now than in the past, however, the earnings change associated with a move between two particular rungs of the earnings distribution is smaller. 
Figure 10. Evolution of 10-Year Mobility Over Time, by Gender

(A) MEN

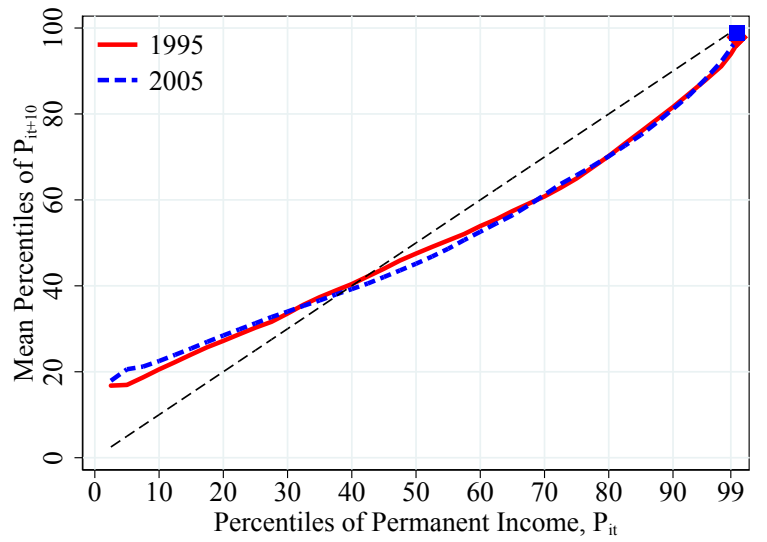

(B) WOMEN

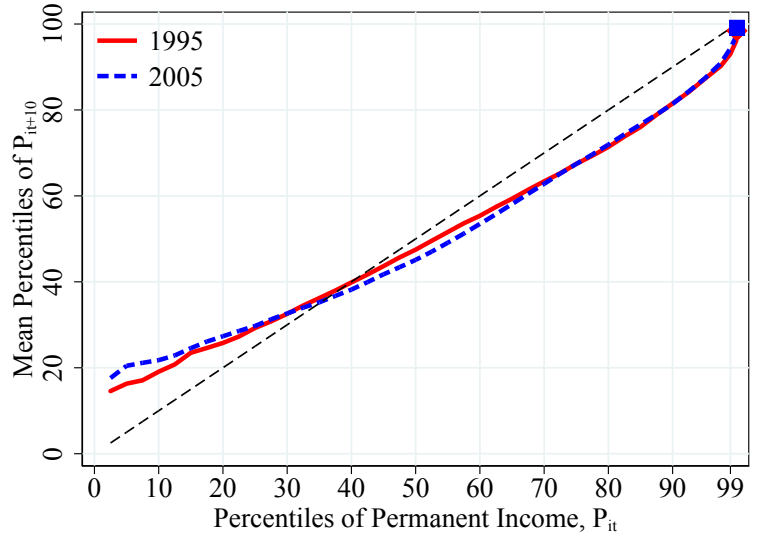

Note: Workers aged 25-55. Colored markers denote the top 0.1\% of permanent income $P_{i t}$. Source: RAIS, $1985-2018$.

\subsection{Comparing Administrative and Household Survey Data}

To what extent do the patterns in administrative data correspond with what households self-report in surveys? To address this question, we compare our results for the formal sector from the RAIS administrative data with the PME household survey. We replicate our exercises for the formal sector from the previous section for the formal sector in the PME. To that end, we restrict the RAIS sample to the subset of the six metropolitan areas covered by the PME and to 2002-2015 to align with the available data from the PME. Since trends for men and women are quite similar, in the interest of space, we pool both genders. We also abstract from an analysis of the very top of the earnings distribution and limit our discussion of higher-order moments of earnings changes, as we believe that the modest sample size of the PME prevents a reliable analysis of these outcomes.

Figure 11 plots percentiles of the log earnings distribution, normalized to 2002. Note that, in general, the results in Panel A differ from those in the previous section, since we here restrict the RAIS data to the subset of the six metropolitan areas covered by the PME. In practice, however, the time trends closely correspond to the trends for the full country in the previous section. Reassuringly, the percentile ratios evolve similarly in the administrative and in the household survey data.

Not surprisingly, given that the percentiles line up closely across the two data sets, Figure 12 finds that measures of inequality follow similar trends in the RAIS and in the PME. That said, the household survey data understate the level of inequality in the administrative data; for instance, the 90-10 percentile ratio is higher by almost 30 log points in the RAIS.

We next turn to a comparison of earnings dynamics in the administrative and survey data. Figure 13 
Figure 11. Comparison of Percentiles of the Log Real Earnings Distribution

(A) RAIS

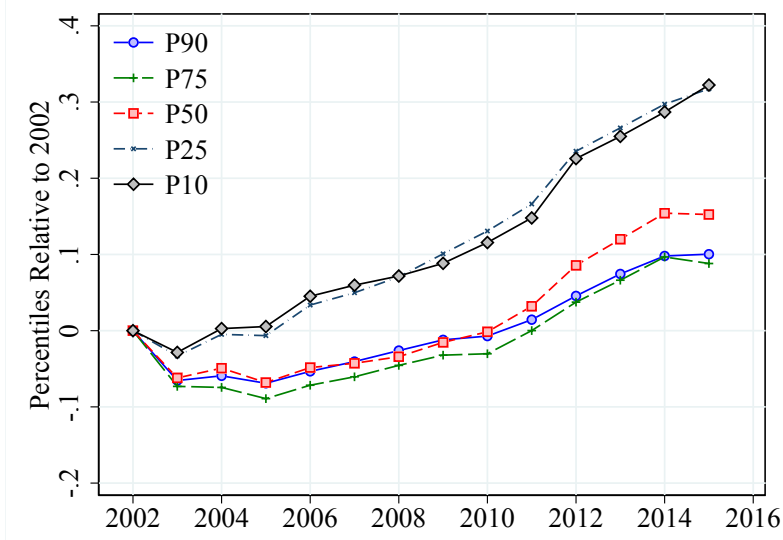

(B) PME

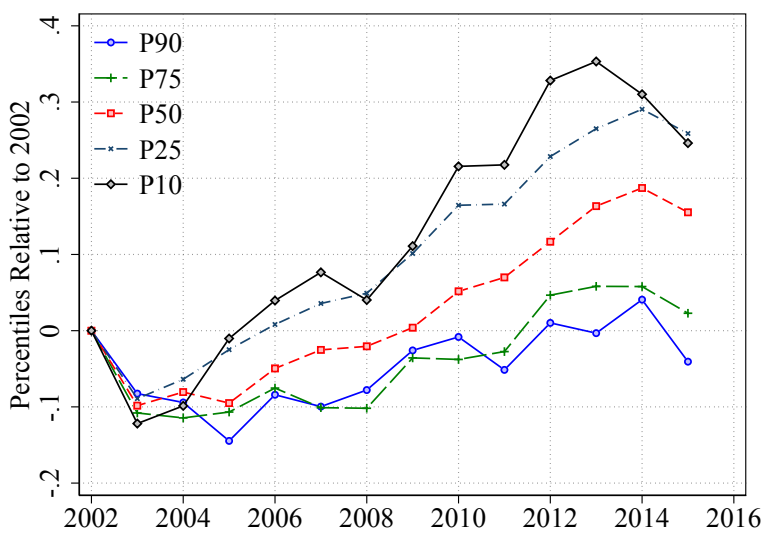

Note: Workers aged 25-55. Source: PME and RAIS, 2002-2015.

FIGURE 12. COMPARISON OF EARNINGS INEQUALITY

(A) RAIS

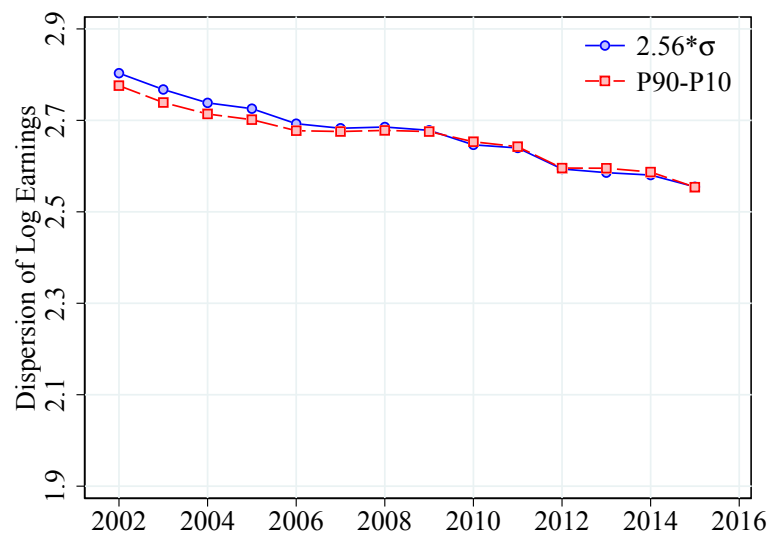

(B) PME

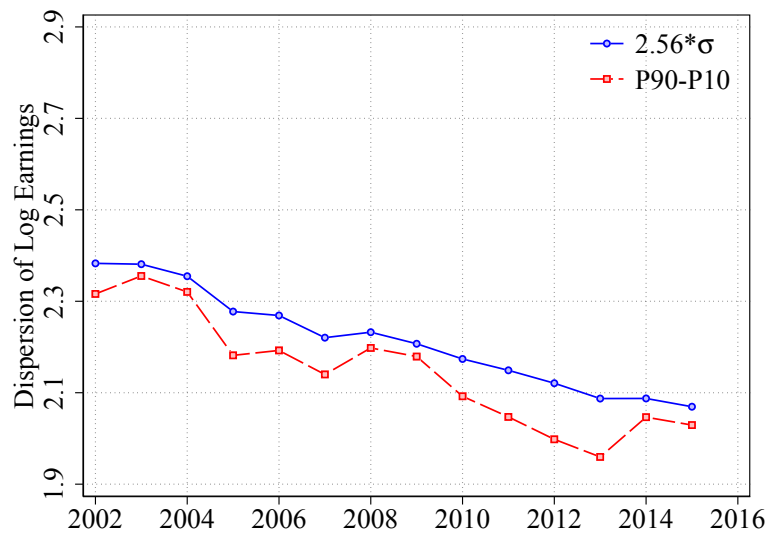

Note: Workers aged 25-55. Source: PME and RAIS, 2002-2015. 
plots dispersion in one-year earnings changes in the RAIS and the PME. The two data sets show broadly similar patterns, although with some important differences, especially during the 2002-2006 period. For instance, according to PME, dispersion in both the top and the bottom of the earnings change distribution fell sharply from 2002 to 2004, whereas it was fairly stable in RAIS. One possibility is that the modest sample size of the PME results in a noisy estimate of the underlying population variance of earnings changes. That said, the two surveys give broadly similar results for the period from 2006 onwards, showing a pattern of relative stability.

\section{Figure 13. COMPARISON OF DisPERSION OF ONE-YEAR LOG EARNINGS CHANGES}

\section{(A) RAIS}

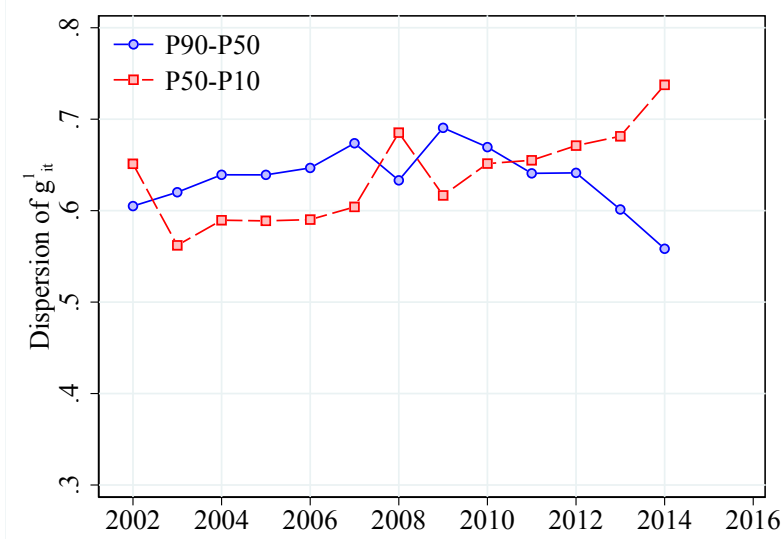

(B) PME

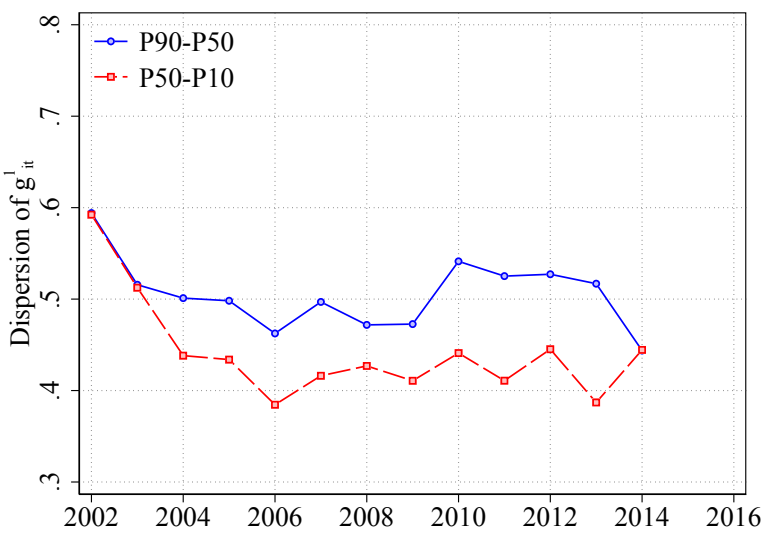

Note: Workers aged 25-55. Source: PME and RAIS, 2002-2015.

\section{Earnings Inequality and Dynamics in Brazil's Formal and Informal Sec- tors}

This section studies earnings inequality in Brazil's formal and informal sectors as well as earnings dynamics within and across Brazil's formal and informal sectors.

\subsection{Earnings Inequality and Dynamics within and across Sectors}

An analysis of informal labor markets is highly relevant in developing countries such as Brazil, which is characterized by a large share of employment in the shadow economy (Ulyssea, 2010; Bosch and EstebanPretel, 2012; Meghir et al., 2015; Ulyssea, 2020). How different is the cross-sectional distribution of earnings in Brazil's informal sector relative to that in the formal sector? How do the distributions of earnings changes compare across the two sectors? How have earnings inequality and volatility evolved within 
each sector? And what are the mechanics by which earnings inequality and volatility in the two sectors differ, both in the cross section and over time?

To answer these questions, we extend our empirical analysis to Brazil's informal sector, exploiting the power of rich household survey data to complement our analysis of administrative records in the previous sections. We proceed in four steps. First, we study earnings inequality in Brazil's formal and informal sectors. Second, we dissect earnings dynamics within and across the two sectors. Third, we analyze the process of labor market formalization in Brazil over the period from 2002 to 2015. Fourth and finally, we shed light on the large decline in earnings volatility in Brazil over this period.

\subsubsection{Earnings Inequality in Brazil's Formal and Informal Sectors}

We begin with an analysis of earnings inequality in Brazil's formal and informal sectors based on the PME household survey data.

A first look at the sectoral earnings distributions. Figure 14 compares the distribution of (residual) log earnings across the two sectors. ${ }^{17}$ We find that mean pay is significantly higher in the formal sector. This confirms the results in Ulyssea (2020), who first estimates and then performs Oaxaca-Blinder decompositions of the informality penalty in Brazil. At the same time, there is significant overlap between the distributions of earnings in each sector, as documented by Meghir et al. (2015). Qualitatively, this pattern is similar for log earnings (Panel A) and residual log earnings (Panel B). ${ }^{18}$

Mincerian estimates of the informal earnings penalty. Why do workers in Brazil's informal sector earn less on average than those in formal jobs? A second look at Table 2 suggests that there are stark differences in worker composition across sectors. To understand the importance of worker selection for observed differences in mean earnings across sectors, we estimate the informal earnings penalty in a sequence of Mincerian earnings regressions. To this end, we restrict the data to observations that have nonmissing information in all relevant control variables. Table 3 shows the result from four specifications with different sets of control variables.

First, we estimate the raw earnings penalty by simply projecting log earnings on an informality indicator. In doing so, we find a 75.4 log points earnings penalty from being informal, which we regard as the baseline value to be explored.

\footnotetext{
${ }^{17}$ Recall that our measure of residual earnings controls for gender-year-specific age dummies.

${ }^{18}$ Figures A22-A25 in Appendix A.3 show that there remains significant overlap across sectors in the distributions of (residual) log earnings by demographic subgroups defined by the intersection of gender, education groups, and age groups in 2002 and 2015 .
} 
Figure 14. Densities of (Residual) Log EARNings, by SECtOR

(A) LOG EARNINGS

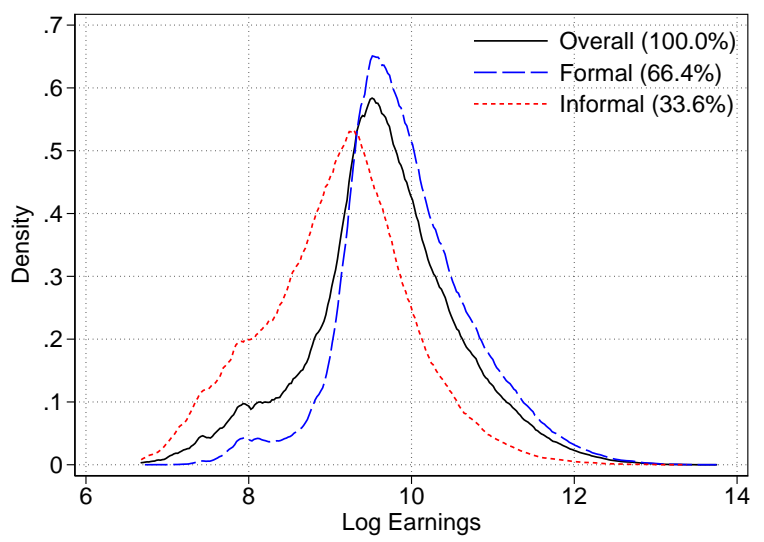

(B) Residual LOG EARNINGS

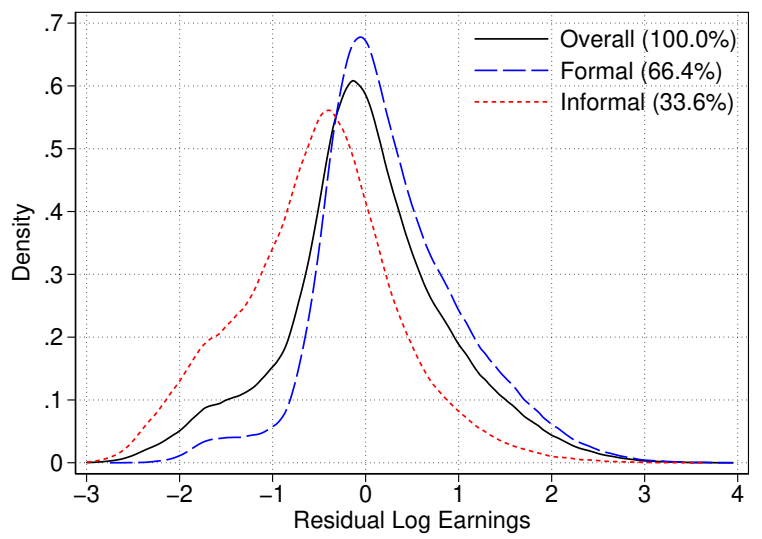

Note: Workers aged 25-55. Kernel densities of log earnings (Panel A) and residual log earnings (Panel B) in each sector. Residual log earnings are calculated controlling for age and survey wave fixed effects, separately by gender and year. Formal sector includes all employees with a work permit. Informal sector includes all employees without a work permit and the self-employed. Source: PME, $2002-2015$.

Second, when additionally controlling for year-season-region fixed effects, worker demograpics (i.e., gender, race, education, age, number of children), industry, occupation, tenure, and hours worked, the conditional informal earnings penalty is lower by around two thirds, standing at $26.7 \log$ points. This suggests that worker selection along these dimensions is important for understanding pay across sectors.

Third, adding additional controls for the size of the firm at which a worker is employed, the informal earnings penalty is further cut in half, reaching $12.7 \mathrm{log}$ points. This points toward the importance of firms in understanding informal versus formal labor markets (Ulyssea, 2020). ${ }^{19}$

In the fourth and final specification, we add person fixed effects in order to control for (unobserved) permanent individual heterogeneity by using the panel dimension of the data. This effectively identifies the informal earnings penalty of sector switchers, similar to the identification strategy in Alvarez (2020). This most stringent specification yields an informal earnings penalty of $12.0 \mathrm{log}$ points, close to the previous specification that already included a rich set of controls for observable characteristics.

Overall, we conclude that around 84 percent of the 75.4 log points raw informal earnings penalty is explained by worker selection, with the remainder explained by identical—observationally identical in specifications 1-3, and literally identical in specification 4-workers receiving lower pay in informal employment.

\footnotetext{
${ }^{19}$ In this way, our work contributes to recent work highlighting the importance of firm size for worker pay in other contexts (Babina et al., 2019; Engbom et al., 2021).
} 
TABle 3. Mincerian Estimates of the Informal EARnings Penalty

\begin{tabular}{lcccc}
\hline \hline & $(1)$ & $(2)$ & $(3)$ & $(4)$ \\
\hline Informal & -0.744 & -0.263 & -0.122 & -0.116 \\
& $(0.003)$ & $(0.002)$ & $(0.003)$ & $(0.007)$ \\
Year-season-region FE & & & & \\
Gender FE & & $\checkmark$ & $\checkmark$ & $\checkmark$ \\
Race FE & & $\checkmark$ & $\checkmark$ & \\
Education FE & & $\checkmark$ & $\checkmark$ & \\
Age FE & & $\checkmark$ & $\checkmark$ & \\
Number-of-kids FE & & $\checkmark$ & $\checkmark$ & $\checkmark$ \\
Industry FE & & $\checkmark$ & $\checkmark$ & $\checkmark$ \\
Occupation FE & & $\checkmark$ & $\checkmark$ & $\checkmark$ \\
Tenure controls & & $\checkmark$ & $\checkmark$ & $\checkmark$ \\
Hours controls & & & $\checkmark$ & $\checkmark$ \\
Firm size FE & & & & $\checkmark$ \\
Person FE & & & & $\checkmark$ \\
& & & & \\
$R^{2}$ & & & & \\
Observations (weighted) & $264,997,721$ & $264,997,721$ & $264,997,721$ & $264,997,721$ \\
Observations (unweighted) & 630,021 & 630,021 & 630,021 & 630,021 \\
\hline
\end{tabular}

Note: Regressions are estimated on the same subset of observations with nonmissing information for all variables. The dependent variable is log earnings. The independent variable of interest is an indicator for being informally employed. Other control variables include indicators for year-season-region combinations (978 categories), gender (2 categories), race (6 categories), education (4 categories), age (31 categories), number of children living in the household (12 categories), industry ( 7 categories), occupation ( 9 categories), log tenure, log hours worked, indicators for firm size (11 categories), and indicators for persons' identity (495,577 categories). The weighted number of observations corresponds to the sum of survey sampling weights, while the unweighted number of observations corresponds to the number of data points in the sample. Source: PME, 2002-2015. 
Evolution of earnings inequality in both sectors. A striking fact documented in Alvarez et al. (2018) is the marked decline in earnings inequality in Brazil's formal sector since the early 2000s. More broadly, there was an equally striking decline in overall earnings inequality across Brazil's formal and informal sectors over this period. Figure 15 shows the evolution of the overall dispersion of (residual) log earnings in Brazil when pooling both sectors. Between 2004 and 2013, overall earnings dispersion declined gradually, both in terms of the scaled standard deviation and the P90-P10 percentile ratio. We find qualitatively similar patterns for log earnings (Panel A) and residual log earnings (Panel B).

\section{Figure 15. Overall Dispersion of (Residual) Log EARnings Over Time}

(A) LOG EARNINGS

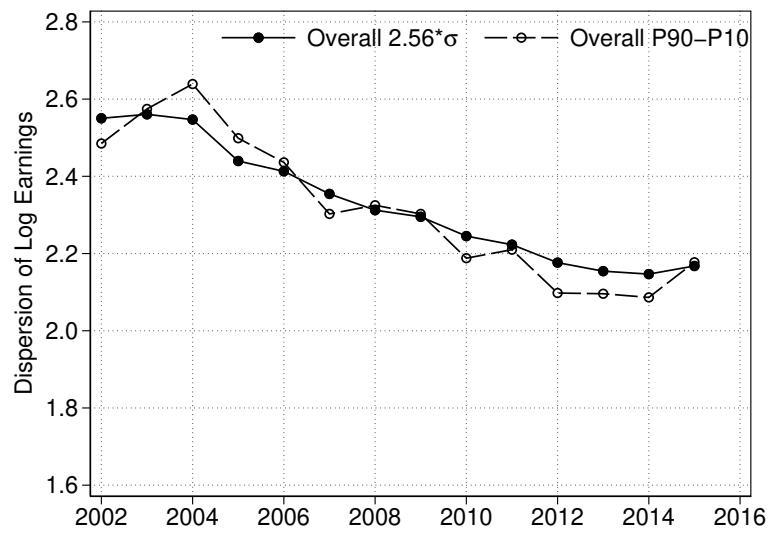

(B) RESIDUAl LOG EARNINGS

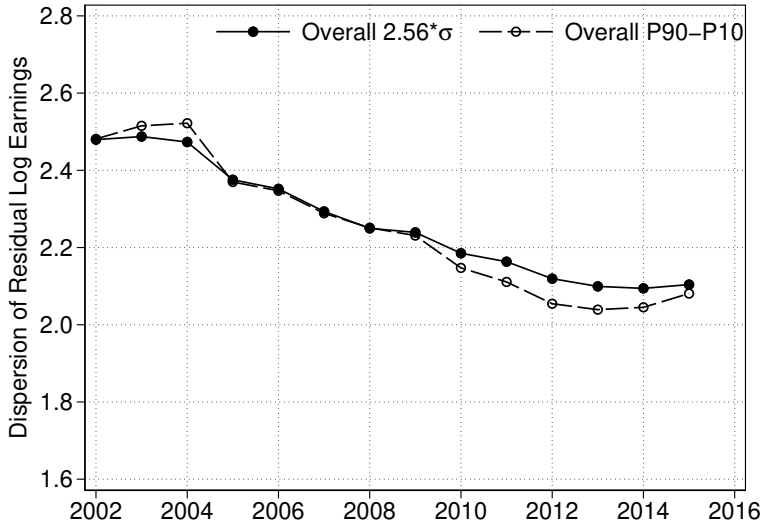

Note: Workers aged 25-55. Measures of dispersion of log earnings (Panel A) and residual log earnings (Panel B). Residual log earnings are calculated controlling for age and survey wave fixed effects, separately by gender and year. Formal sector includes all employees with a work permit. Informal sector includes all employees without a work permit and the self-employed. Source: PME, 2002-2015.

One possible reason behind falling earnings inequality in Brazil is that mean earnings in the two sectors-formal and informal-approached one another over time. Indeed, Figure 16 shows that this is the case, both in terms of sectoral means of log earnings (Panel A) and residual log earnings (Panel B). All else equal, this trend means that a falling between-sector component of the overall variance of earnings has contributed towards the overall decline in earnings inequality.

Another possible reason why overall earnings inequality in Brazil fell is that within-sector earnings dispersion has declined. To investigate this, Figure 17 plots trends in inequality in (residual) log earnings, separately within Brazil's formal and informal sectors over time. ${ }^{20}$ As apparent from the analysis above, inequality is higher in Brazil's informal sector relative to its formal sector. Furthermore, inequality has significantly declined in both the formal and informal sector between 2002 and 2015. The fall in inequality is significant in both sectors, although somewhat more pronounced for the formal sector when

\footnotetext{
${ }^{20}$ Because we apply here the PME sample selection criteria, the pattern for the formal sector differs slightly from that in Figure 12, which applies the RAIS sample selection criteria to the PME household survey data, even though both figures are based on the same data source.
} 
Figure 16. MeAn (Residual) Log Earnings Over Time, by SEctor

(A) LOG EARNINGS

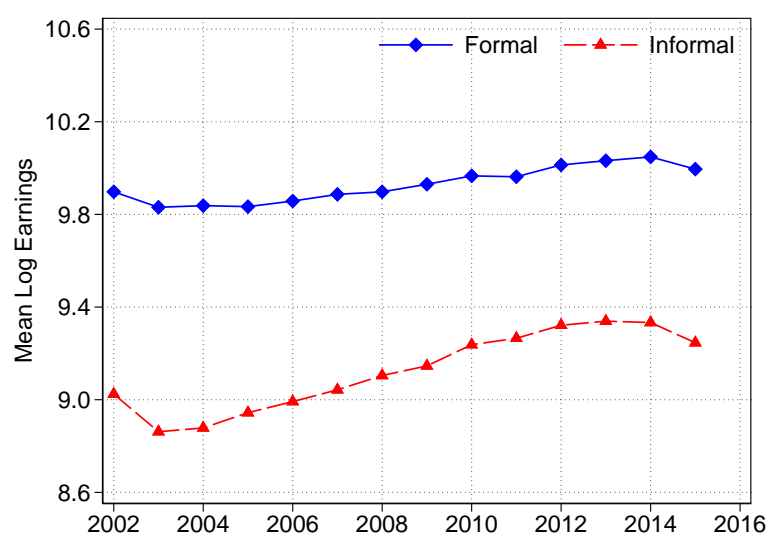

(B) Residual Log EARNings

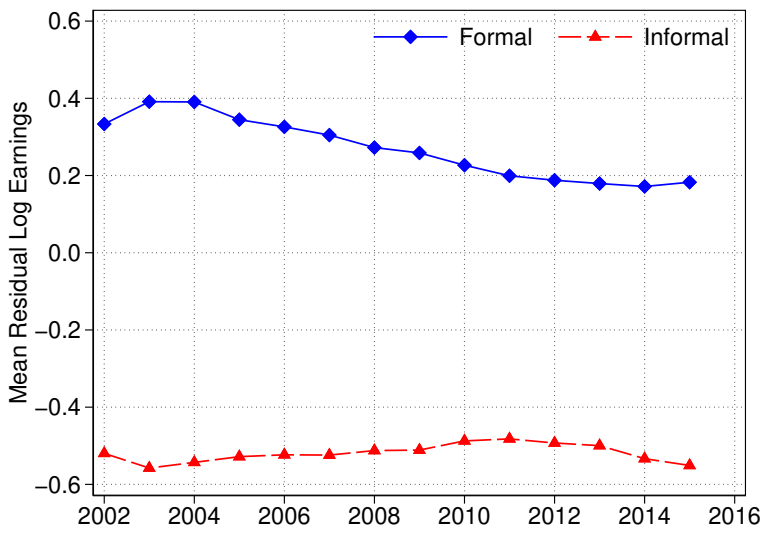

Note: Workers aged 25-55. Mean log earnings (Panel A) and mean residual log earnings (Panel B). Residual log earnings are calculated controlling for age and survey wave fixed effects, separately by gender and year. Formal sector includes all employees with a work permit. Informal sector includes all employees without a work permit and the self-employed. Source: PME, 2002-2015.

looking at the P90-10 log percentile ratio. A possible explanation for this is that the rapid increase in Brazil's minimum wage over this period has contributed to a disproportionate reduction in inequality in the formal sector, where it is enforced (Engbom and Moser, 2021). Again, these patterns are qualitatively similar across log earnings (Panel A) and residual log earnings (Panel B).

\section{Figure 17. Dispersion of (Residual) Log EARnings Over Time, by SEctor}

\section{(A) LOG EARNINGS}

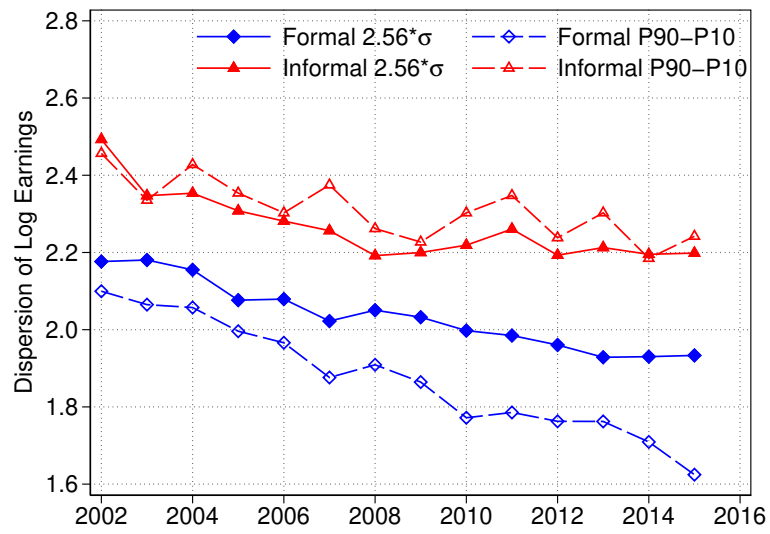

(B) Residual LOG EARNings

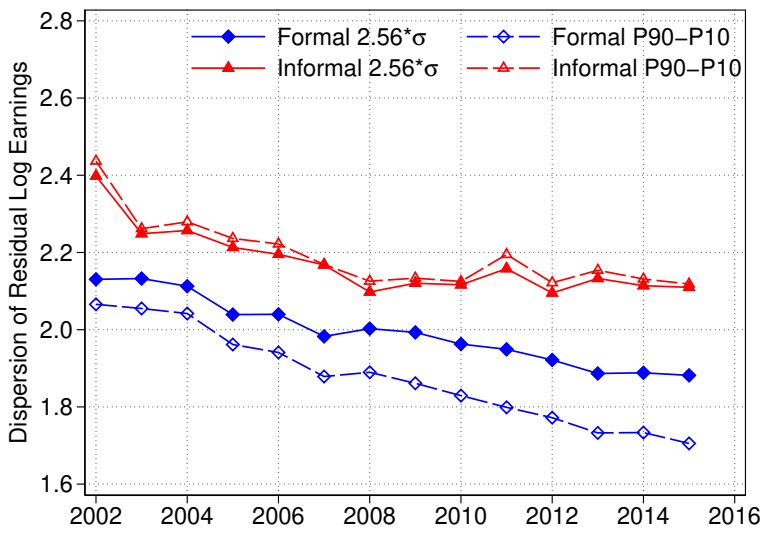

Note: Workers aged 25-55. Measures of dispersion of log earnings (Panel A) and residual log earnings (Panel B) in each sector. Residual log earnings are calculated controlling for age and survey wave fixed effects, separately by gender and year. Formal sector includes all employees with a work permit. Informal sector includes all employees without a work permit and the self-employed. Source: PME, $2002-2015$. 


\subsubsection{Earnings Dynamics in Brazil's Formal and Informal Sectors}

We next assess earnings dynamics in the presence of informality by analyzing the distribution of oneyear residual earnings changes by sectoral transition type. Because workers may change sector across years, we construct four mutually exclusive, collectively exhaustive groups: those who work in the formal sector both in year $t$ and in year $t+1$-henceforth "formal-formal" workers; those who work in the informal sector in both years- "informal-informal" workers; and those who work in the formal (informal) sector in year $t$ but in the informal (formal) sector in year $t+1$ - "formal-informal" and "informalformal," respectively.

Densities of residual earnings changes. Figure 18 shows the estimated densities of residual earnings changes by transition type. Informal-informal workers have more volatile earnings than formal-formal workers, with a higher prevalence of large negative and positive earnings changes. Of course, this pattern should not be interpreted in a causal sense, as workers are likely not randomly assigned to sector. Formal-informal workers tend to experience earnings losses, while the opposite is true among informalformal workers. The fact that a given worker experiences an earnings change when switching sectors suggests that the lower average earnings in the informal sector are not due purely to worker selection, consistent with the evidence presented above and that in Alvarez (2020). ${ }^{21}$

\section{Figure 18. Densities of One-Year Residual Log EARnings Change, by Sectoral TRANSITION}

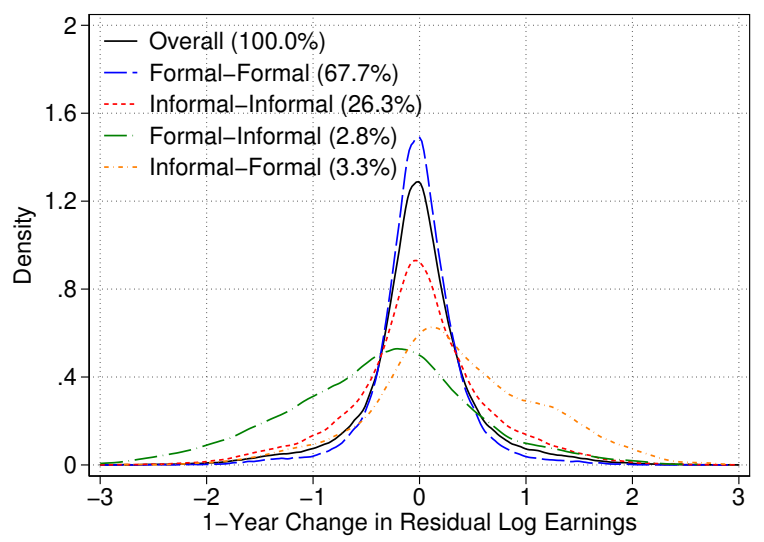

Note: Workers aged 25-55. Kernel densities of one-year change in residual log earnings by worker group. Residuals are calculated controlling for age and survey wave fixed effects, separately by gender and year. Different lines denote different combinations of a worker's current sector of employment and that in the next survey wave (e.g., "Formal-Informal" denotes current employment in the formal sector and employment in the informal sector in the next survey wave). Source: PME, 2002-2015.

\footnotetext{
${ }^{21}$ Figures A26 and A27 in Appendix A.3 show that a similar pattern to that in Figure 18 obtains for a range of demographic subgroups in 2002 (Figure A26) and 2015 (Figure A27). This points in the direction of greater dispersion in residual log earnings changes in the informal sector conditional on various dimensions of worker heterogeneity.
} 
Moments of the distribution of residual earnings changes. To put our estimates of earnings volatility in Brazil into context, Table 4 summarizes the first four moments of one-year residual earnings changes in the population and by sector transition. Recalling that year-on-year residual log earnings changes need not sum to zero in an unbalanced panel, we find a small mean change of -0.012 in the overall population. Mean changes are of similarly small magnitudes among formal-formal and informal-informal transitions, ranging from -0.015 to -0.010 . In contrast, sectoral switchers experience residual earnings changes that are large in magnitude and approximately symmetric, with estimated mean changes of -0.388 for formal-informal transitions and 0.361 for informal-formal transitions. At face value, this symmetry speaks against the view that comparative advantage drives worker mobility across sectors because, under such a view, the patterns of earnings gains and losses would be asymmetric.

Turning to the second standardized moment, the overall standard deviation of residual log earnings changes is 0.511 . As suggested by Figure 18, the standard deviation is significantly higher for informal sector stayers (0.652) than for formal sector stayers (0.380). While the overall standard deviation of earnings changes we find in Brazil is similar to that in the US, the standard deviation within the informal sector is closer to that among low-paid workers in the US (Guvenen et al., 2019). The standard deviation is even higher among workers who switch from formal to informal employment (0.880) and from informal to formal employment (0.809).

In terms of higher-order moments, a few points are worth noting. Starting with the third moment, the overall Kelley skewness and excess Crow-Siddiqui kurtosis of earnings changes are 0.017 and 2.451, respectively, indicating that earnings changes are lightly right-skewed and notably leptokurtic. The Kelley skewness is the most negative for formal-informal transitions $(-0.100)$ and takes on positive values for all other types of transitions, with the highest positive Kelley skewness observed for informal-to-formal transitions (0.112). Moving on to the fourth moment, the excess Crow-Siddiqui kurtosis is 2.451 overall, well above the excess Crow-Siddiqui kurtosis value of zero associated with a Gaussian distribution. While all the distribution of earnings changes is leptokurtic for all transition types, it is highest among formal-formal transitions (1.683) and lowest among formal-informal transitions (0.418). ${ }^{22}$

Formal decomposition of earnings volatility. Altogether, these results suggest that earnings are significantly more volatile within Brazil's informal sector than within the formal sector, and even more volatile and (positively or negatively) skewed for sector switchers. The higher volatility in Brazil's informal sector may, in turn, be accounted for by a different type of individual working in the informal sector, who

\footnotetext{
${ }^{22}$ Since reliably estimating higher order moments requires large datasets, we caution against attaching too much weight to these statistics, given the modest sample size of the PME household survey data in comparison to the administrative RAIS data.
} 


\section{TAble 4. Moments of the Distribution of One-YeAR Log EARnings Changes, By SECTORAL TRANSITION}

\begin{tabular}{|c|c|c|c|c|c|}
\hline & Overall & Formal-Formal & Informal-Informal & Formal-Informal & Informal-Formal \\
\hline Mean & -0.012 & -0.015 & -0.010 & -0.388 & 0.361 \\
\hline Standard deviation & 0.511 & 0.380 & 0.652 & 0.880 & 0.809 \\
\hline Kelley skewness & 0.017 & 0.030 & 0.013 & -0.100 & 0.112 \\
\hline Excess Crow-Siddiqui kurtosis & 2.451 & 1.683 & 1.470 & 0.418 & 0.448 \\
\hline Observations (weighted) & $140,059,975$ & $94,829,458$ & $36,769,712$ & $3,883,017$ & $4,577,788$ \\
\hline Observations (unweighted) & 323,916 & 216,716 & 86,212 & 9,786 & 11,202 \\
\hline
\end{tabular}

may experience more volatile earnings dynamics regardless of sector. Alternatively, earnings volatility may be higher in the informal sector also conditional on workers' type.

To assess the relative importance of differences in worker composition separately from the volatility of earnings for a given type of workers, we consider a shift-share analysis in the spirit of Kitagawa, Oaxaca, and Blinder. Specifically, we first compute one-year residual earnings changes, controlling for sector interacted with demographic subgroups. Here, we define demographic subgroups based on the intersection of three age groups, gender, two education groups, three industry groups and two occupation groups. ${ }^{23}$ Subsequently, we compute the variance of residual earnings changes in sector $s=\{i, f\}$ specific to demographic group $d, \sigma_{d, s}^{2}$. Finally, we compute a demographic group's share of employment in sector $s, \omega_{d, s}=N_{d, s} / N_{s}$, where $N_{d, s}$ is the number of individuals in demographic subgroup $d$ in sector $s$ and $N_{S}$ is the total number of individuals in sector $s$, both weighted by the provided survey weights.

Since the mean of the residual earnings changes in sector $s$ for demographic group $d$ is zero by construction, the overall variance of residual earnings changes in sector $s, \sigma_{s}^{2}$, can be written as

$$
\sigma_{s}^{2}=\frac{1}{N^{s}} \sum_{i \in s}\left(\Delta w_{i}\right)^{2}=\sum_{d} \frac{N_{d, s}}{N_{s}}\left(\frac{1}{N_{d, s}} \sum_{i \in d \times s}\left(\Delta w_{i}\right)^{2}\right)=\sum_{d} \omega_{d, s} \sigma_{d, s}^{2}
$$

We use equation (3) to run a series of counterfactual shift-share decompositions. First, we compute the counterfactual variance of residual earnings changes that would arise if the only difference across sectors were within-group differences in volatility, but demographic composition was the same. To that end, we hold the weights $\omega_{d, s}=\omega_{d, f}$, for $s=\{f, i\}$, fixed at their formal sector values, but let the within-group variances vary as in the data across sectors, $\sigma_{d, s}^{2}$. We label this the returns channel since it isolates the

\footnotetext{
${ }^{23}$ Specifically, the age groups we consider are 25-34, 35-44, 45-55, the education groups are less than high school or high school or more, the industry groups are manufacturing, services and agriculture/other, and the occupation groups are blue or white collar. The size of our data prohibits a reliable estimation of the within-group variance of earnings changes in more detailed subgroups.
} 
effect of within-group differences in volatility holding composition fixed.

Second, we hold within-group differences in volatility fixed at their formal sector values, $\sigma_{d, s}^{2}=\sigma_{d, f}^{2}$, for $s=\{f, i\}$, but let demographic composition, $\omega_{d, s}$, change as in the data. We label the resulting counterfactual variance of residual earnings changes in the informal sector the composition channel, since it isolates the effect of differences in composition holding within-group differences in volatility fixed. We also compute the counterfactual variance of residual earnings changes in the informal sector letting only composition adjust in one of the dimensions, holding within-group variances as well as the demographic composition in all other dimensions fixed at their formal sector level, as $\sum_{d} \tilde{w}_{d, s} \sigma_{d, f}^{2}$. We compute the counterfactual weights $\tilde{w}_{d, s}$ such that the marginal distribution of the particular demographic characteristic in focus corresponds to that in the informal sector, while the marginal distributions in all other demographic dimensions remain those in the formal sector.

Table 5 presents the results from this shift-share analysis. Little of the higher volatility in the informal sector is accounted for by differences in workforce composition, at least not in the relatively coarse characteristics that we consider. Instead, the great majority of the higher volatility in the informal sector takes place conditional on such worker characteristics, i.e. a higher within-group volatility of earnings in the informal sector.

\section{TABle 5. Shift-Share Decomposition of Relative Earnings Volatility Across Sectors}

\begin{tabular}{lccccccccc}
\hline \hline & & & \multicolumn{5}{c}{ Composition } \\
\cline { 5 - 9 } & Formal & Informal & Returns & Total & Age & Educ. & Gender & Ind. & Occ. \\
\hline Earnings volatility, $\sigma_{s}^{2}$ & 0.174 & 0.449 & 0.493 & 0.178 & 0.174 & 0.173 & 0.174 & 0.177 & 0.175
\end{tabular}

Min. observations $\quad 127 \quad 46$

Max. observations $\quad 4,969 \quad 3,594$

Total observations $\quad 107,972 \quad 47,063$

Note: Variance of residual earnings changes within the formal and informal sectors, as well as a shift-share decomposition of the differences in the variance of residual earnings changes by sector. Returns: Counterfactual variance of residual earnings changes in the informal sector holding fixed demographic composition at its formal sector values, but letting the within-group variance of residual earnings changes vary across sectors as in the data. Composition: Counterfactual variance of residual earnings changes in the informal sector holding the within-group variance of residual earnings changes fixed at its formal sector values, but letting the demographic composition vary across sectors as in the data. Total: Joint analysis of the impact of differences in demographic composition along all dimensions (age, gender, education, industry and occupation). Age/Educ./Gender/Ind./Occ.: Impact of differences in one composition along one demographic attribute (age, education, gender, industry, and occupation) at a time, holding fixed composition in all other dimensions. Min. (max) observations: Number of observations in the sector-demographic subgroup with the fewest (most) observations. All statistics are for workers aged 25-55. Source: PME, $2002-2015$.

\subsubsection{Dissecting the Process of Labor Market Formalization in Brazil}

Between 2002 and 2015, the Brazilian economy underwent a rapid transformation, both politically and economically. A notable aspect of this transformation has been the marked decline in informal employment rates over this period. 
Evolution of informality shares. The evolution of informality shares is illustrated in Figure 19. Panel A shows that the informal share has declined over the past 10-15 years, dropping from 39 percent in 2002 to 25 percent in 2015. Panel B dissects the decline across the earnings distribution. In the bottom quartile of the earnings distribution, almost three-quarters of workers were in the informal sector in 2002, while the corresponding figure in the top quartile was 17 percent. Over time, the decline in informality was particularly pronounced at the bottom of the distribution-the share of the first quartile working in the informal sector fell by 19 percentage points from 2002 to 2015 . Yet, the process of labor market formalization was widespread throughout the earnings distribution, with the share of the top quartile working in the informal sector also declining by seven percentage points. Despite the marked decline in informality overall, informal employment continues to account for over half of employment among workers in the bottom quartile of the earnings distribution. ${ }^{24}$

Figure 19. EVOlution of Informal EMPloyment SHARES

(A) OVERALL

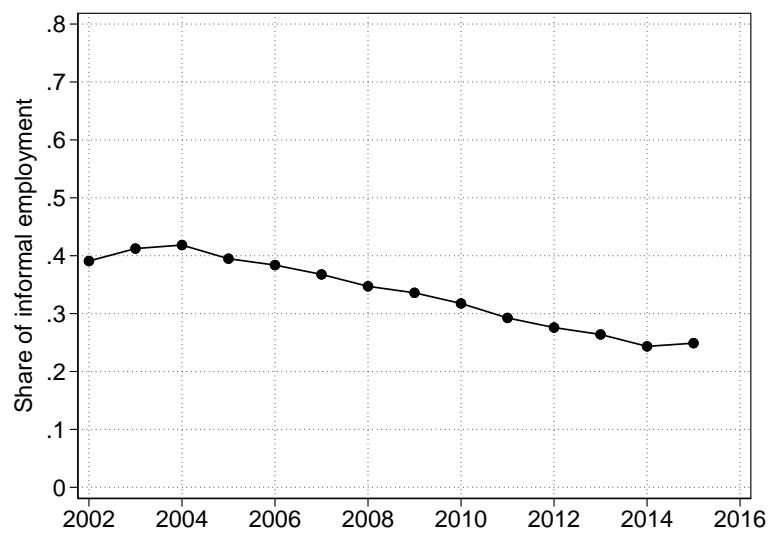

(B) BY EARNINGS QUARTILE

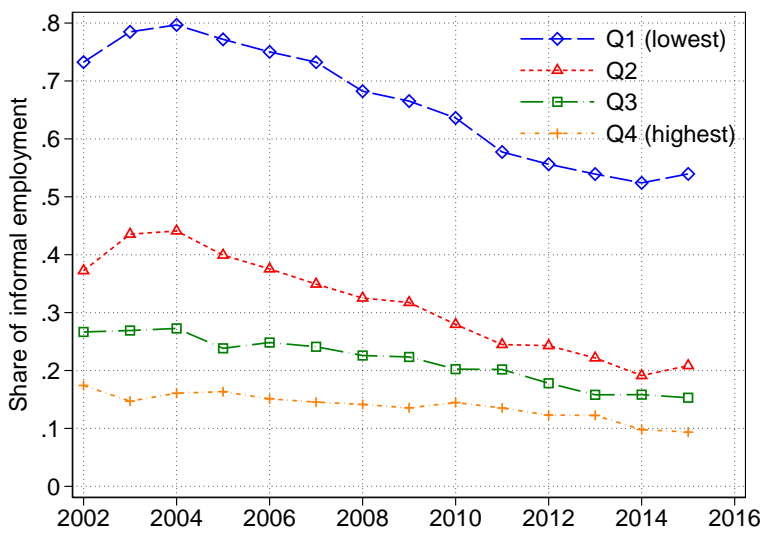

Note: All statistics are for workers aged 25-55. Residual earnings flexibly control for age and survey wave fixed effects, separately by gender and year. Source: PME, 2002-2015.

Relation to sectoral flow rates. The decrease in informality in Brazil between 2002 and 2015 is closely related to the evolution of labor market flow rates over this period. Figure 20 provides a high-level overview of sectoral transition rates within and between Brazil's formal and informal sectors. ${ }^{25}$

While a majority of workers remain attached to the same-formal or informal—sector between consecutive years, sector switchers and leavers are of particular interest in assessing the evolution of sectoral shares. To dig deeper into sector switchers and leavers, Figure 21 shows the one-year-forward transition

\footnotetext{
${ }^{24}$ As additional robustness, Appendix A.4 shows that multiple job holdings are quantitatively not relevant for understanding formality rates in the cross section or over time.

${ }^{25}$ Figures A20 and A21 in Appendix A.3 show the evolution of the composition of formal-formal and informal-informal transition rates by workers' educational attainment (Figure A20) and age (Figure A21) over time.
} 


\section{Figure 20. TRANSITION RATES Within AND BETWEEN THE Formal AND INFORMAL SECTORS}

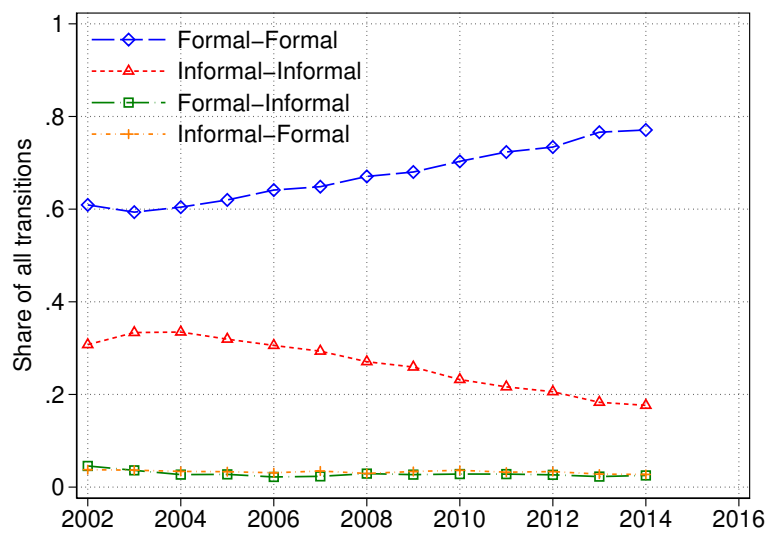

Note: Workers aged 25-55. "Formal-formal" corresponds to workers staying employed in the formal sector between consecutive years. Similarly, "informal-informal" corresponds to workers staying employed in the informal sector. "Formal-informal" corresponds to workers switching from formal to informal employment between years. "Informal-formal" corresponds to workers switching from informal to formal employment between years. Source: PME, 2002-2015.

rates out of the formal sector (Panel A) and out of the informal sector (Panel B). Sector transitions are categorized as either sector switchers (i.e., from formal to informal in Panel A, and from informal to formal in Panel B) or sector leavers (i.e., workers moving into nonemployment). For this purpose, we define "nonemployment" as no employment in either the formal or the informal sector (i.e., including unemployed workers and those out of the labor force).

Several results are noteworthy. A striking observation is that transition rates out of the formal sector (Panel A) are around four times smaller than transition rates out of the informal sector (Panel B). Given that between 2002 and 2015, the formal sector was only between one-and-a-half and three times as large as the informal sector, a balance-flow-equation logic implies that there must have been a net inflow into formality over this period. A second striking observation is that the formal-to-informal transition rate has approximately halved, from around 2.5 percent to around 1.2 percent, over this period. At the same time, the informal-to-formal transition rate has slightly increased. Exit rates into nonemployment have been U-shaped in both sectors over this period. We conclude from this analysis that persistently asymmetric flow rates have contributed toward the decline in informal employment in Brazil over this period.

Heterogeneity in flow rates by earnings rank. While in the aggregate, asymmetric flow rates have contributed toward Brazil's process of formalization, we document significant heterogeneity in sectoral flows across the earnings distribution. Figure 22 plots the mean transition rates as a function of population earnings rank for formal sector workers in panel A and for informal sector workers in panel 


\section{Figure 21. Evolution of Sectoral Flow Rates, by Origin Sector}

\section{(A) Flow Rates From Formal SeCtor}

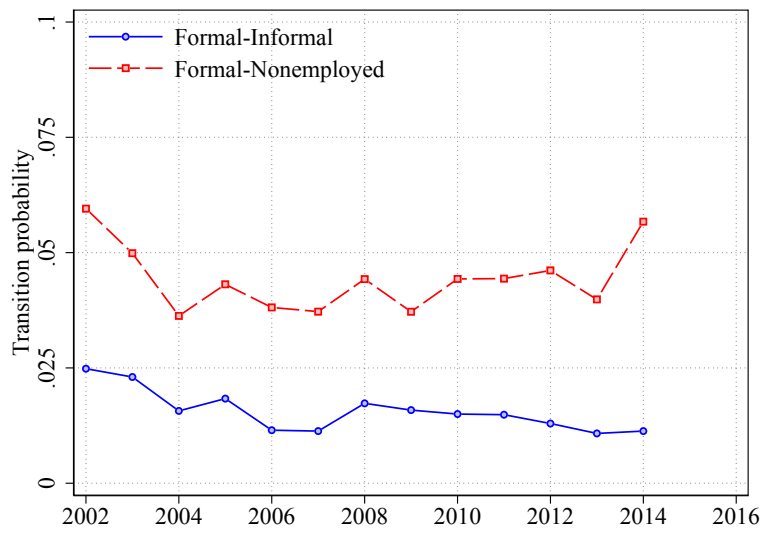

(B) FLOW RATES FROM INFORMAL SECTOR

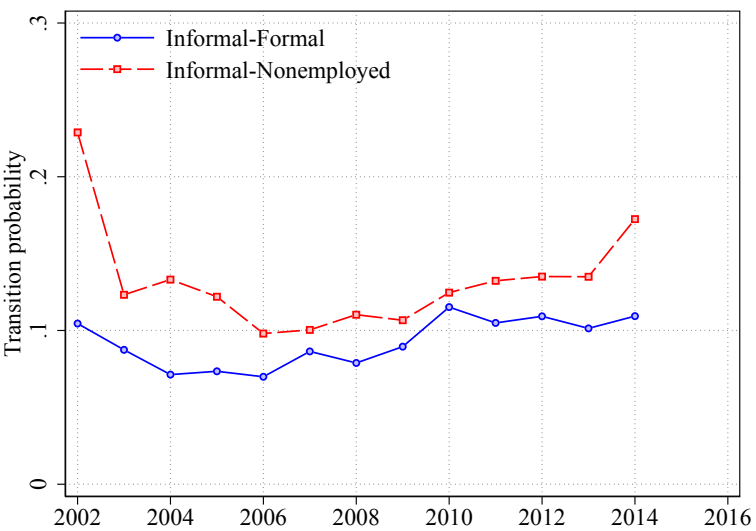

Note: Workers aged 25-55. Source: PME, 2002-2015.

B.

A few points are noteworthy. First, for both formal and informal workers, the probability of staying in the same sector in consecutive years (the omitted category in each panel of Figure 22) far outweighs that of switching sectors or leaving employment altogether. Second, formal workers are relatively more attached to their sector than informal workers are. Third, there is a marked decrease in exit rates from the formal sector toward informality and nonemployment but an increase in exit rates from the informal sector toward formality and nonemployment toward higher earnings percentiles.

Figure 22. Cross-Sectional Heterogeneity in Sectoral Flow Rates, by Origin Sector

(A) Flow RATES From Formal SECTOR

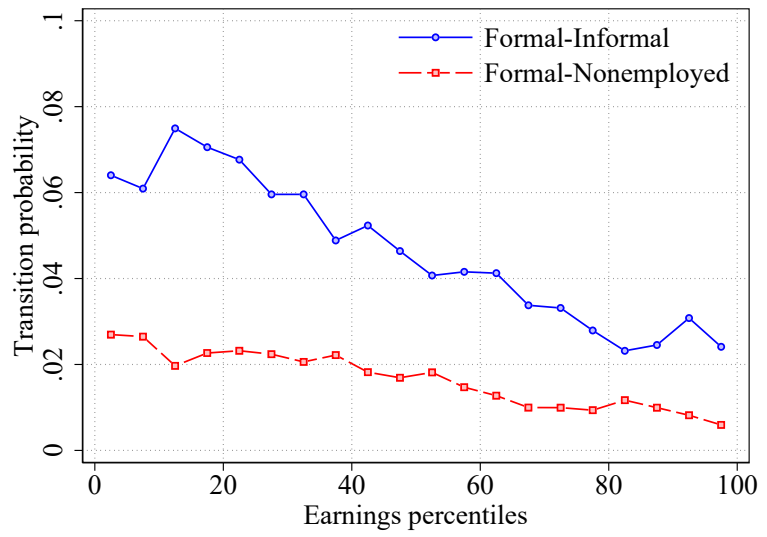

Note: Workers aged 25-55. Source: PME, 2002-2015.
(B) FLOW RATES FROM INFORMAL SECTOR

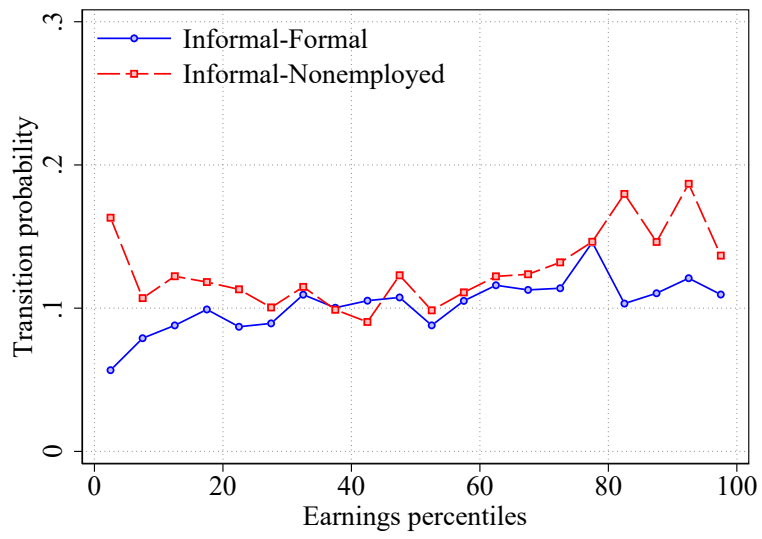




\subsubsection{Understanding the Decline in Earnings Volatility in Brazil}

While it is well known that earnings inequality declined in Brazil since the early 2000s (Alvarez et al., 2018; Firpo and Portella, 2019), less is known about the evolution of earnings volatility in Brazil's formal and informal sectors.

Aggregate time series. Figure 23 shows that, over the period from 2002 to 2015, there has been a marked decline in earnings volatility in Brazil. Pooling the formal and informal sectors, the figure shows that earnings volatility fell in the early 2000s and subsequently remained relatively stable from around 2006 onwards.

Figure 23. Overall Dispersion in One-Year Residual Log EARnings Changes

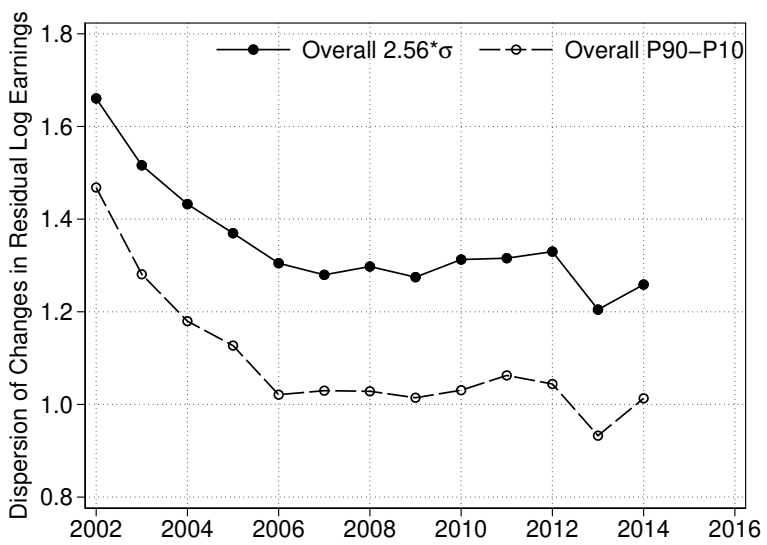

Note: Workers aged 25-55. Residual earnings control for age and survey wave fixed effects, separately by gender and year. Source: PME, 2002-2015.

Besides the evolution of sectoral transition rates documented above, the aggregate decline in earnings volatility in Brazil depends on two additional factors. First, the mean earnings change associated with each type of sectoral transition and, second, the dispersion in earnings changes associated with each type of sectoral transition.

Trends in mean earnings changes by sectoral transition. First, to understand the evolution of mean earnings changes by sectoral transition, Figure 24 plots the evolution of mean earnings changes by a worker's type of sectoral transition. There was a marked decline in the mean change in residual earnings for workers transitioning from the informal to the formal sector between 2002 and 2014. Driven by this decline and relatively stable means for other sectoral transition groups, the between-group dispersion in means was significantly lower in 2014 than it was in 2002. 
Figure 24. Evolution of Mean EARnings Changes by Sectoral Transition

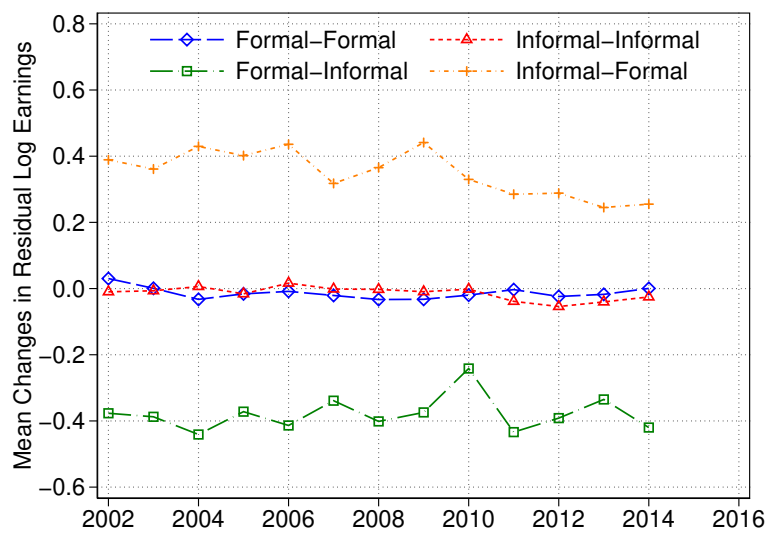

Note: Workers aged 25-55. Source: PME, 2002-2015.

Trends in dispersion of earnings changes by sectoral transition. Second, to understand the role of within-sector changes in earnings volatility, Figure 25 plots the evolution of the scaled standard deviation (Panel A) and the P90-P10 percentile ratio of changes in residual log earnings separately by worker transition. As in Figure 20, we distinguish between four transition categories: formal-formal, informal-informal, formal-informal, and informal-formal. The largest decline in earnings volatility occurred within the informal sector stayers. There were less pronounced declines in earnings volatility for formal sector stayers as well as for switchers from the formal into the informal sector. In contrast, the earnings volatility of switchers from the informal to the formal sector actually increased. Qualitatively, these insights are similar across both measures of dispersion of earnings changes.

Figure 25. EVOlution OF EARNings Volatility by SECTORAL TRANSITION

(A) SCAlED Standard DEviation

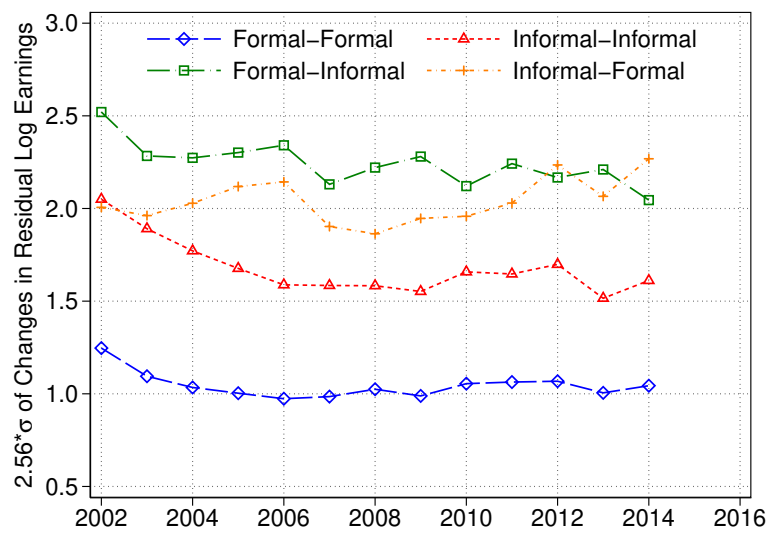

(B) P90-P10 Log Percentile Ratio

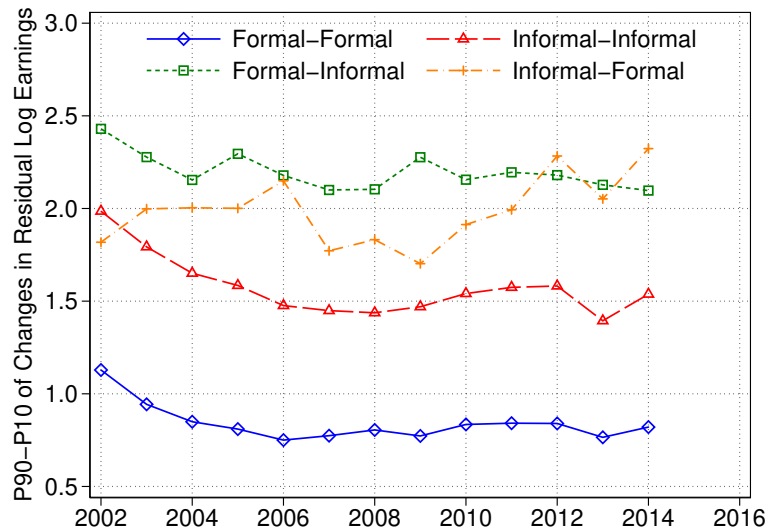

Note: Workers aged 25-55. Source: PME, 2002-2015. 
Formal decomposition of earnings volatility. Combining our analysis of sectoral transition shares from Section 4.1 .3 with the evolution of means and dispersion of earnings volatility documented above, we now conduct a between- versus within-group decomposition of the variance of one-year changes in residual log earnings by type of sectoral transition groups (i.e., formal-formal, informal-informal, formal-informal, and informal-formal transitions). At any point in time, the total variance of residual earnings changes, $g_{i t}$, can be decomposed into two terms, namely a between-group component and a within-group component:

$$
\overbrace{\frac{1}{N_{t}} \sum_{i}\left(g_{i t}-\bar{g}_{t}\right)^{2}}^{\text {total variance }}=\overbrace{\sum_{s \in S} \frac{N_{s t}}{N_{t}}\left(\bar{g}_{s t}-\bar{g}_{t}\right)^{2}}^{\text {between component }}+\overbrace{\sum_{s \in S} \underbrace{\frac{N_{s t}}{N_{t}}}_{\text {composition channel }} \times \underbrace{\frac{1}{N_{s t}} \sum_{i \in s}\left(g_{i t}-\bar{g}_{s t}\right)^{2}}_{\text {returns channel }}}^{\text {within component }},
$$

where $\bar{g}_{t}=\frac{1}{N_{t}} \sum_{i} g_{i t}$ is the grand average residual in year $t$ and $\bar{g}_{s t}=\frac{1}{N_{s t}} \sum_{i \in s} g_{i t}$ is the average residual within group $s$ in year $t$. Note that $\bar{g}_{t}$ is not identically equal to zero, because our analysis residualizes earnings instead of earnings changes together with the fact that we work with an unbalanced panel. In a balanced panel, if residual earnings have mean zero each year, then earnings changes also have mean zero. But since our panel is unbalanced, the same is not necessarily true in our case, depending on the pattern of household survey responses. ${ }^{26}$ Note that $\bar{g}_{s t}$ is not identically equal to zero, both because the age and education effects do not vary by group and also because the panel is not balanced.

Since different groups are characterized by different volatilities of earnings, two factors in turn contribute to changes in the within component in (4) over time. ${ }^{27}$ First, changes in the employment weights, $\frac{N_{s t}}{N_{t}}$, of groups in (4) by themselves lead to changes in overall volatility through a composition channel. Second, within-group changes in volatility, $\frac{1}{N_{s t}} \sum_{i \in s}\left(g_{i t}-\bar{g}_{s t}\right)^{2}$, lead to changes in overall volatility, holding composition fixed, which we refer to as the returns channel.

Panel A of Figure 26 decomposes the overall change in the variance of earnings changes into its between and within components based on (4). Changes within groups in the volatility of earnings account

${ }^{26}$ That the distribution of earnings changes must have mean zero in a balanced panel, but need not have mean zero in an unbalanced panel, is straightforward to verify. The average change in the residuals between year $t$ and $t+1$ is

$$
\frac{1}{N_{t}} \sum_{i} g_{i t}=\frac{1}{N_{t}} \sum_{i}\left(w_{i t+1}-w_{i t}\right)=\frac{N_{t+1}}{N_{t}} \frac{1}{N_{t+1}} \sum_{i} w_{i t+1}-\frac{1}{N_{t}} \sum_{i} w_{i t} .
$$

In a balanced panel, this expression equals zero because both $\frac{1}{N_{t+1}} \sum_{i} w_{i t+1}=0$ and $\frac{1}{N_{t}} \sum_{i} w_{i t}=0$ by the nature of their both being the sum of mean-zero residuals in a balanced panel. Since neither summand need to evaluate to zero in an unbalanced panel, the grand average also need not be zero in that case.

${ }^{27}$ While the same is true also for the between component in (4), we focus on the within component, since that accounts for the great majority of the changes in volatility over this period. 
for the great majority of the fall in earnings volatility over this period.

Panel B of Figure 26 further dissects the within component from the previous decomposition in equation (4) into a composition channel and a returns channel. We isolate the role of these two forces using a shift-share approach (as standard in shift-share analysis, the two components do not add up to the total change). That is, to compute the composition channel, we hold the within-group variances fixed at their initial level and only change the employment weights as in the data. To compute the returns channel, we hold the employment weights fixed at their initial level and only change the within-group variances as in the data. Within-group account for a larger decline in volatility than compositional shifts, although the effect of the latter is also significant. The composition effect arises primarily because employment has gravitated toward formal-formal workers over this period, a shift that is characterized by lower volatility of earnings. ${ }^{28}$

\section{FIgURE 26. DECOMPOSITION OF CHANGE IN VOLATILITY}

(A) BETWEEN VERSUS WITHIN COMPONENTS

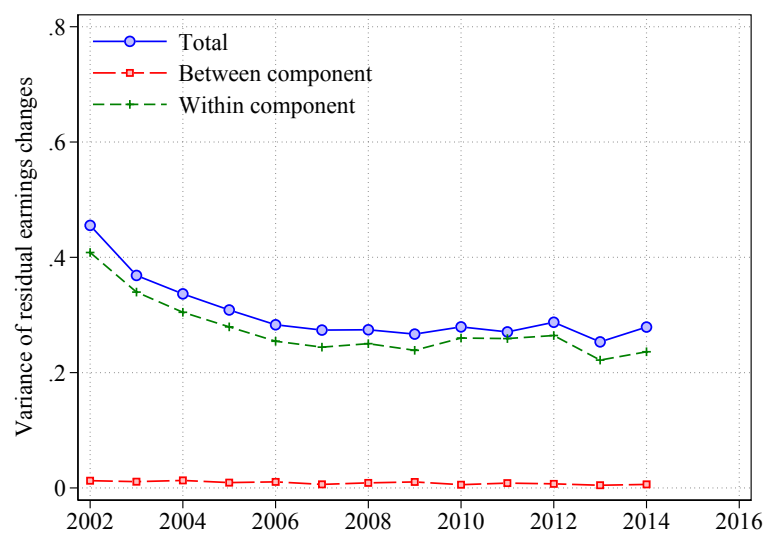

(B) DeCOMPOSING THE WITHIN COMPONENT

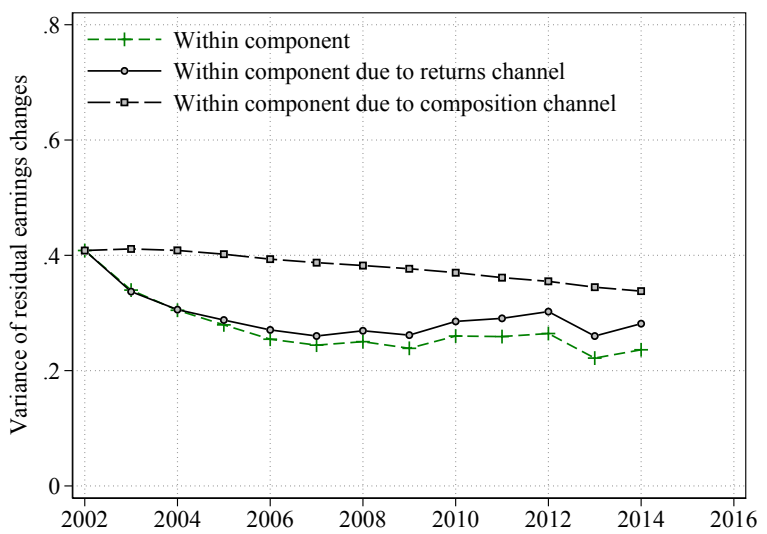

Note: Workers aged 25-55. Panel A shows a between- versus within-group decomposition of the variance of earnings changes based on (4). Panel B shows a shift-share analysis of the within component of (4). The returns channel holds the sector composition fixed at its initial level and letting the within-group variances evolve as in the data. The composition channel holds the within-group variances fixed at their initial level and letting the sector composition evolve as in the data. Source: PME, 2002-2015.

\section{Conclusion}

In this paper, we document new facts on earnings inequality, dynamics, and mobility in Brazil. Among workers in Brazil's formal sector, there has been a remarkable decrease in earnings inequality, driven by bottom-led growth in real earnings, since the late 1990s. At the same time, the dispersion of earnings

\footnotetext{
${ }^{28}$ As an additional robustness check, in Appendix A.5 we present a between- versus within-group decomposition of the overall variance of earnings changes by worker education groups. Consistent with the results presented here, we find that most of the decline in the overall variance of earnings changes occurs within, rather than between, education groups.
} 
changes decreased markedly. Higher-order moments of the distribution of earnings changes differ in levels but show cyclical movements similar to those previously documented in developed countries such as the US. Earnings mobility is comparatively high in Brazil, especially at the bottom of the distribution.

We leverage detailed household survey data to study earnings inequality and dynamics in Brazil's formal and informal sectors. Compared with formal sector workers, there is significantly higher dispersion of earnings changes among informal sector workers and significantly (positively or negatively) skewed earnings changes among sector switchers. Finally, we find a large decrease in the economywide dispersion of earnings changes, which is driven mostly by the within-sector evolution of earnings volatility.

Our work points to two interesting avenues for future research. The first avenue is to shed further light onto the microeconomic sources of Brazil's decline in earnings inequality and volatility that we document. The second avenue is to assess the macroeconomic consequences of this decline as well as its implications for social insurance and other policies. 


\section{References}

Almeida, Rita and Pedro Carneiro, "Enforcement of Labor Regulation and Informality," American Economic Journal: Applied Economics, 2012, 4 (3), 64-89.

Alvarez, Jorge A., "The Agricultural Wage Gap: Evidence from Brazilian Micro-Data," American Economic Journal: Macroeconomics, 2020, 12 (1), 153-173.

Alvarez, Jorge, Felipe Benguria, Niklas Engbom, and Christian Moser, "Firms and the Decline of Earnings Inequality in Brazil," American Economic Journal: Macroeconomics, 2018, 10 (1), 149-189.

Ayres, João, Márcio Garcia, Diogo A. Guillén, and Patrick J. Kehoe, “The Monetary and Fiscal History of Brazil, 1960-2016," NBER Working Paper No. 25421, 2019.

Babina, Tania, Wenting Ma, Christian Moser, Paige Ouimet, and Rebecca Zarrutskie, "Pay, Employment, and Dynamics of Young Firms," Working Paper, 2019.

Barros, Ricardo, Mirela de Carvalho, Samuel Franco, and Rosane Mendonça, "Markets, the State, and the Dynamics of Inequality in Brazil," in Luis F. López-Calva and Nora Lustig, eds., Declining Inequality in Latin America: A Decade of Progress?, Washington, D.C.: Brookings Institution Press, 2010, pp. 134174.

Benguria, Felipe, Felipe Saffie, and Sergio Urzúa, "The Transmission of Commodity Price SuperCycles," NBER Working Paper No. 24560, 2021.

Blanco, Andres, Bernardo Diaz de Astarloa, Andres Drenik, Christian Moser, and Danilo Trupkin, "The Evolution of the Earnings Distribution in a Volatile Economy: Evidence from Argentina," Working Paper, 2021.

Bloom, Nicholas, Fatih Guvenen, Luigi Pistaferri, John Sabelhaus, Sergio Salgado, and Jae Song, "The Great Micro Moderation," Working Paper, 2017.

Bosch, Mariano and Julen Esteban-Pretel, "Job Creation and Job Destruction in the Presence of Informal Markets," Journal of Development Economics, 2012, 98 (2), 270-286.

Bowlus, Audra, Émilien Gouin-Bonenfant, Huju Liu, Lance Lochner, and Youngmin Park, "Four Decades of Canadian Earnings Inequality and Dynamics Across Workers and Firms," Working Paper, 2021.

Busch, Christopher, David Domeij, Fatih Guvenen, and Rocio Madera, "Skewed Idiosyncratic Income Risk over the Business Cycle: Sources and Insurance," Working Paper, 2020.

Calderón, Mariana, Alfonso Cebreros, Leó Fernández, Jose A. Inguanzo, David Jaume, and Daniela Puggioni, “Global Income Dynamics: Mexico," Working Paper, 2021.

Dix-Carneiro, Rafael and Brian K. Kovak, "Trade Liberalization and the Skill Premium: A Local Labor Markets Approach," American Economic Review, 2015, 105 (5), 551-557.

_ and _ , "Trade Liberalization and Regional Dynamics," American Economic Review, 2017, 107 (10), 2908-46.

_ and _ , "Margins of Labor Market Adjustment to Trade," Journal of International Economics, 2019, 117 (C), 125-142.

_ , Pinelopi Koujianou Goldberg, Costas Meghir, and Gabriel Ulyssea, "Trade and Informality in the Presence of Labor Market Frictions and Regulations," Working Paper, 2021.

Engbom, Niklas and Christian Moser, "Earnings Inequality and the Minimum Wage: Evidence from Brazil," Working Paper, 2021.

_, , , and Jan Sauermann, “Firm Pay Dynamics," Working Paper, 2021.

Fairris, David and Erik Jonasson, "Determinants of Changing Informal Employment in Brazil, 20002010," Journal of Development Economics, 2020, 1(1), 1-43.

Ferreira, Francisco H. G., Phillippe G. Leite, and Matthew Wai-Poi, “Trade Liberalization, Employment Flows, And Wage Inequality In Brazil," Working Paper, United Nations University, 2007.

_, Sergio P. Firpo, and Julián Messina, "Ageing Poorly?: Accounting for the Decline in Earnings Inequality in Brazil, 1995-2012," IDB Working Paper Series No. 792, 2017.

Firpo, Sergio and Alysson Portella, "Decline in Wage Inequality in Brazil: A Survey," Policy Research Working Paper 9096, The World Bank, 2019. 
Gomes, Diego B.P., Felipe S. Iachan, and Cezar Santos, "Labor Earnings Dynamics in a Developing Economy with a Large Informal Sector," Journal of Economic Dynamics and Control, 2020, 113.

Gonzaga, Gustavo, Naércio Menezes Filho, and Cristina Terra, "Trade Liberalization and the Evolution of Skill Earnings Differentials in Brazil," Journal of International Economics, 2006, 68 (2), 345-367.

Guvenen, Fatih, Fatih Karahan, Serdar Ozkan, and Jae Song, "What Do Data on Millions of U.S. Workers Reveal about Life-Cycle Earnings Dynamics?," FRB of New York Staff Report, 710, 2019.

_ , Serdar Ozkan, and Jae Song, "The Nature of Countercyclical Income Risk," Journal of Political Economy, 2014, 122 (3), 621-660.

Haanwinckel, Daniel, "Supply, Demand, Institutions, and Firms: A Theory of Labor Market Sorting and the Wage Distribution," Working Paper, 2020.

- and Rodrigo R. Soares, "Workforce Composition, Productivity, and Labor Regulations in a Compensating Differentials Theory of Informality," Review of Economic Studies, forthcoming.

Hoffmann, Eran B. and Davide Malacrino, "Employment time and the cyclicality of earnings growth," Journal of Public Economics, 2019, 169, 160-171.

Martínez, Tomás and Ursula Mello, "Trade Shocks and Higher-Order Earnings Risk in Local Labor Markets," Working Paper, 2021.

McKinney, Kevin L. and John M. Abowd, “Global Income Dynamics: United States,” Working Paper, 2021.

Meghir, Costas, Renata Narita, and Jean-Marc Robin, "Wages and Informality in Developing Countries," American Economic Review, 2015, 105 (4), 1509-1546.

Moffitt, Robert A. and Peter Gottschalk, "Trends in the Variances of Permanent and Transitory Earnings in the U.S. and Their Relation to Earnings Mobility," Boston College Working Papers in Economics, 1995.

Morchio, Iacopo and Christian Moser, "The Gender Gap: Micro Sources and Macro Consequences," Working Paper, 2020.

Ponczek, Vladimir and Gabriel Ulyssea, "Enforcement of Labor Regulation and the Labor Market Effects of Trade: Evidence from Brazil," Economic Journal, forthcoming.

Ribas, Rafael Perez and Sergei Suarez Dillon Soares, "Sobre o Painel da Pesquisa Mensal de Emprego (PME) do IBGE," IPEA Discussion Paper 1348, 2008.

Sabelhaus, John and Jae Song, "The Great Moderation in Micro Labor Earnings," Journal of Monetary Economics, 2010, 57 (4), 391-403.

Seminario-Amez, Cristhian, "Informal Rungs on the Job Ladder: Theory and Evidence from Brazil," Working Paper, 2021.

Shorrocks, Anthony, "Income Inequality and Income Mobility," Journal of Economic Theory, 1978, 19 (2), 376-393.

Ulyssea, Gabriel, "Regulation of Entry, Labor Market Institutions and the Informal Sector," Journal of Development Economics, 2010, 91 (1), 87-99.

_ , "Firms, Informality, and Development: Theory and Evidence from Brazil," American Economic Review, 2018, 108 (8), 2015-2047.

- , "Informality: Causes and Consequences for Development," Annual Review of Economics, 2020, 12, 525-546. 
A Appendix

A.1 Additional Summary Statistics 
જ! ๙

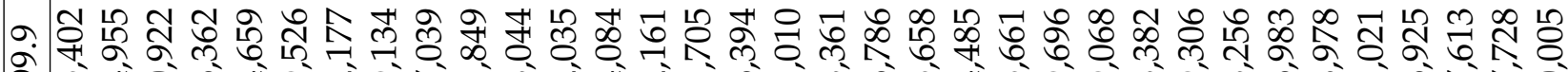
হे

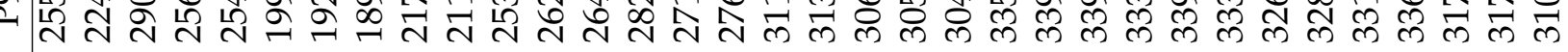

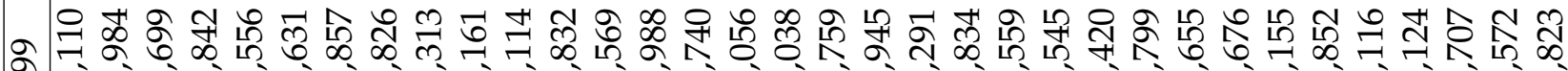

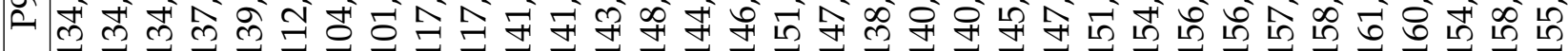

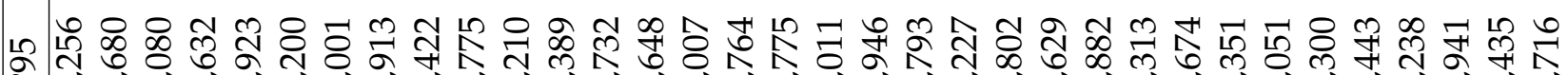

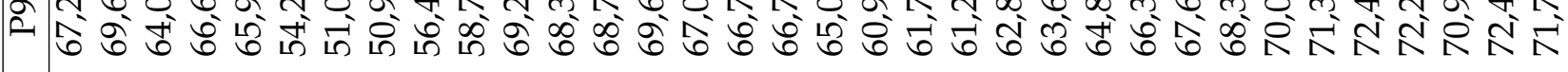

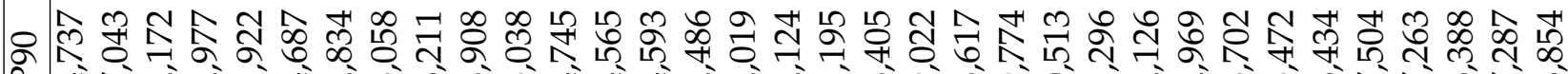
凤 ผ สิ

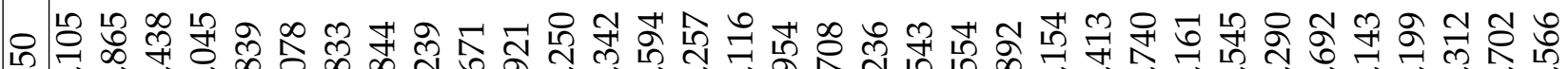
F 슈

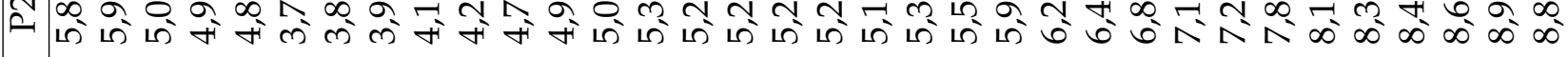
이

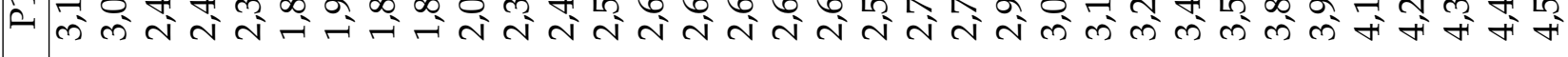

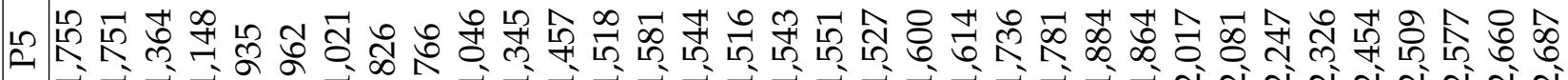
1 프 .

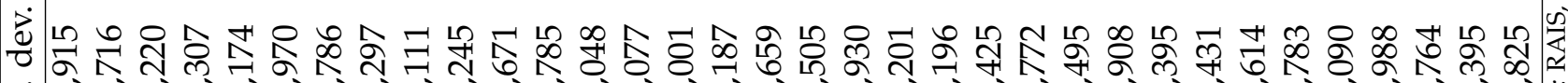

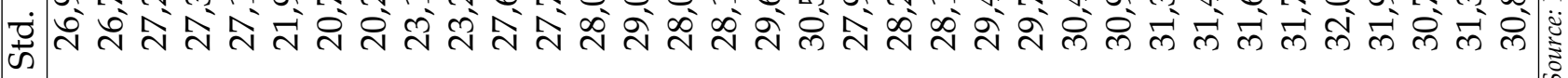

च

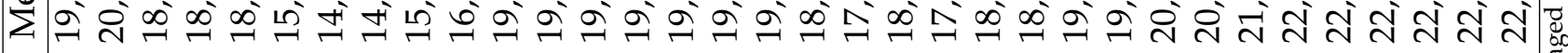

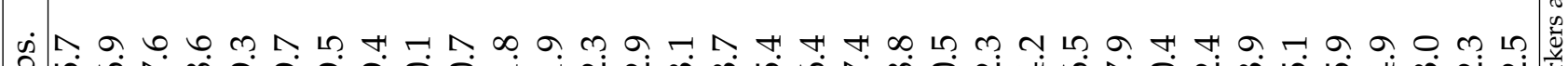
ठ윰 च む্خ 


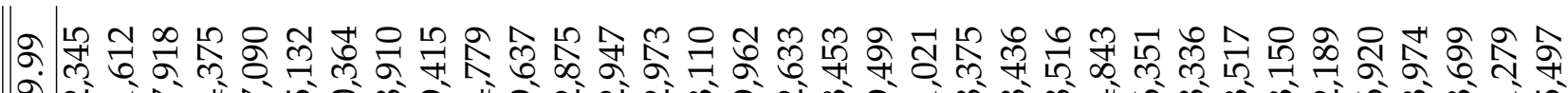

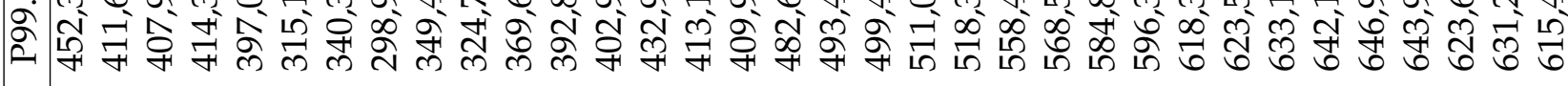

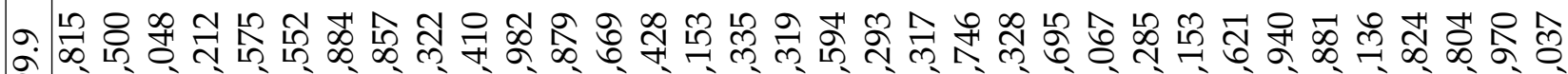
సิ

๙

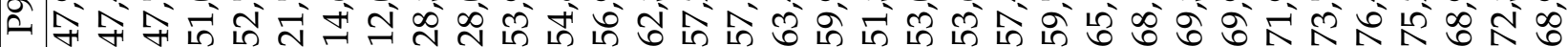

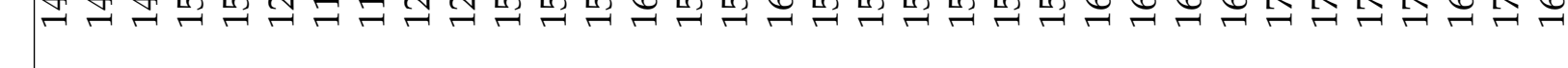
낭

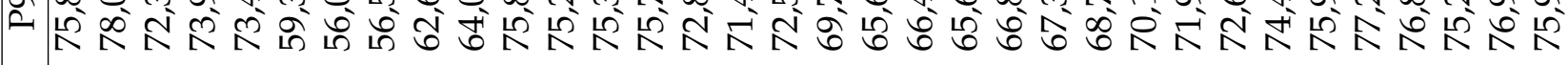
감

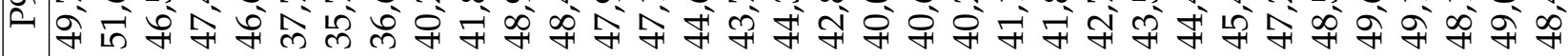

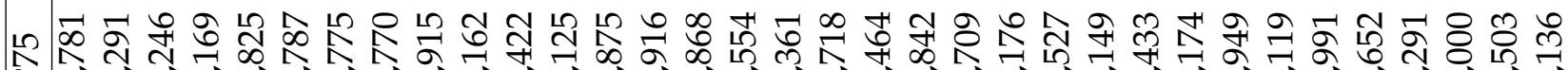

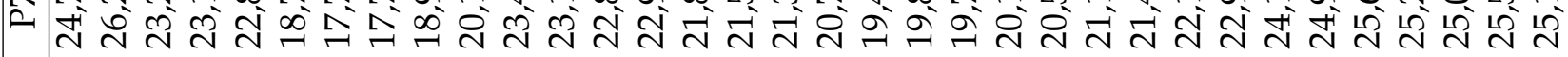

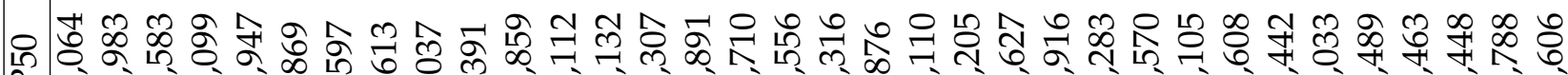
云

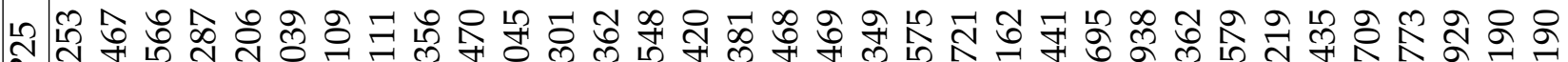

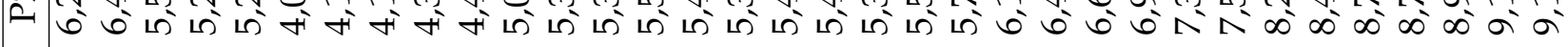
궁 ले 는 웅

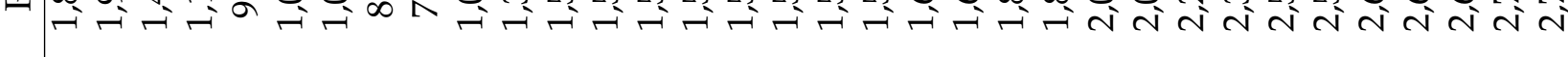
స A 宅央

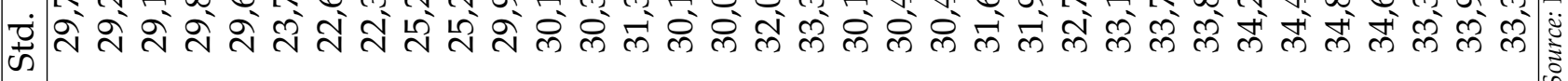
च

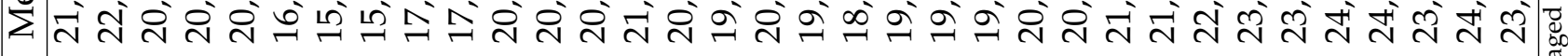

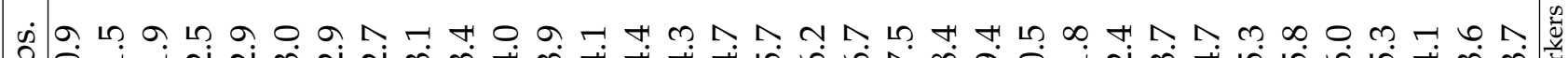

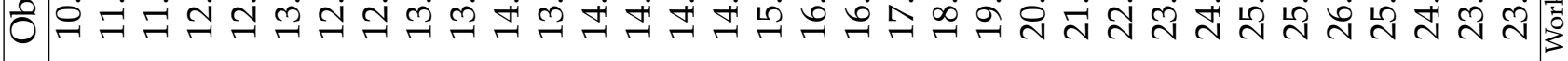
๘ ¿্ৰ 
б.

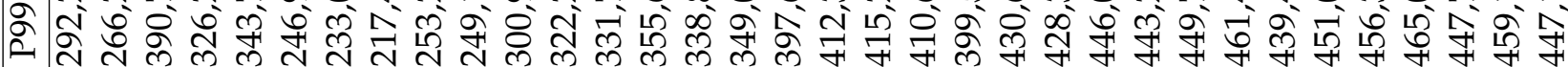

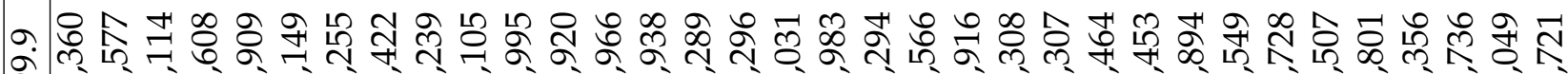

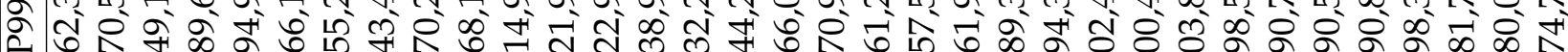

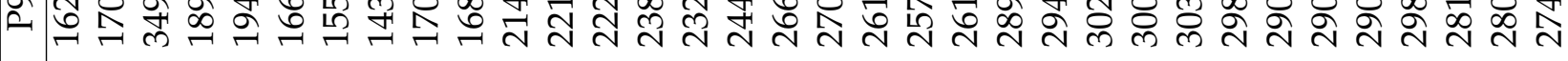

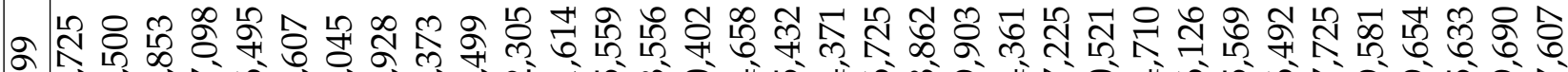

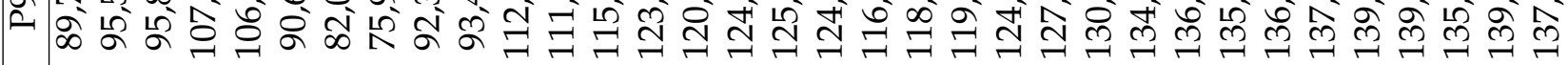
L

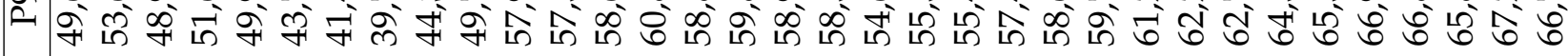
\&

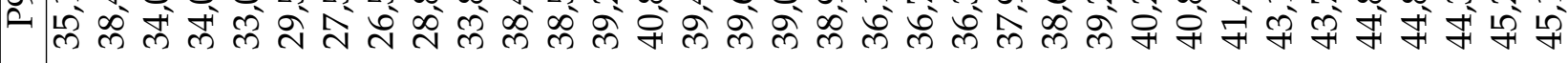

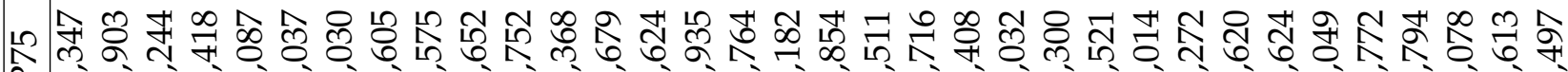

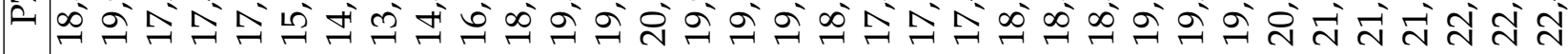

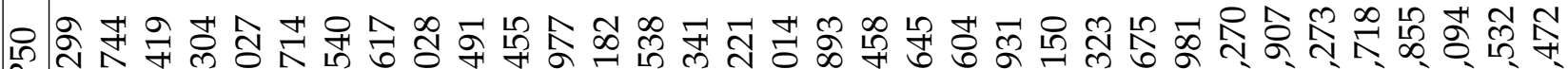

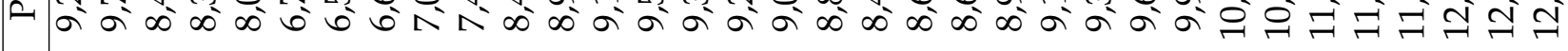

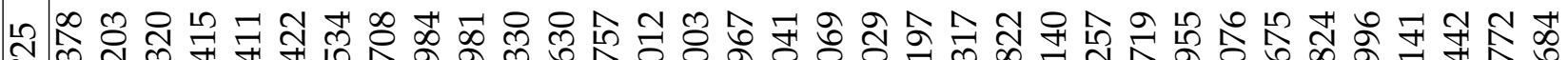

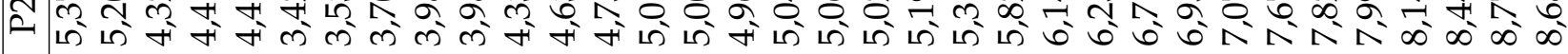
응 웡

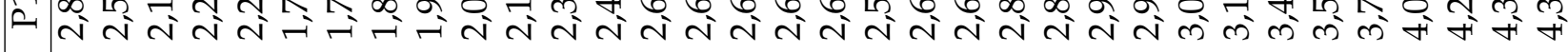

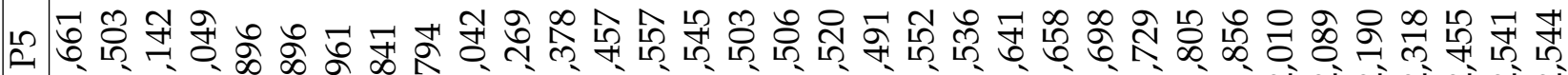
A- I-

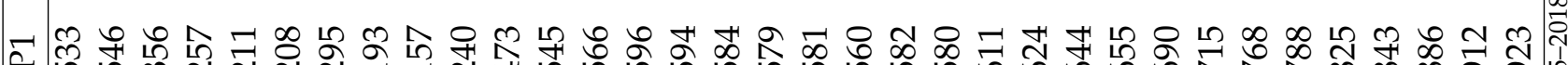
ज फ़

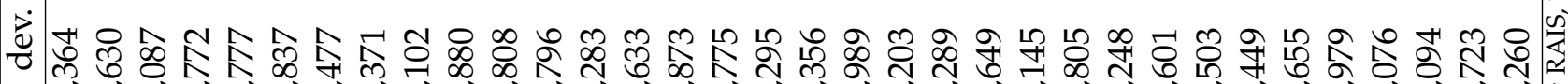

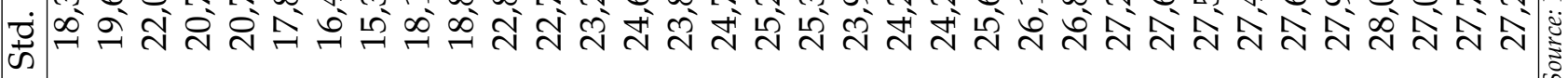

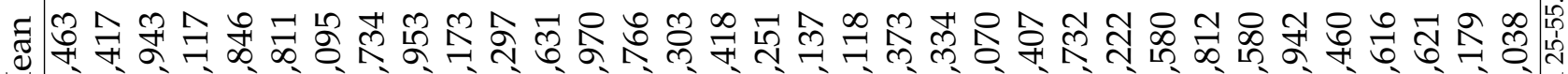

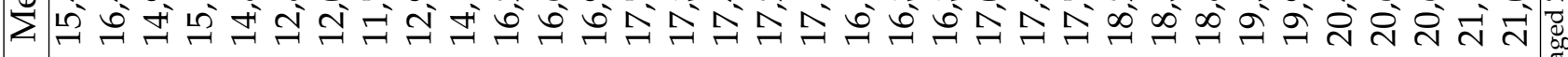

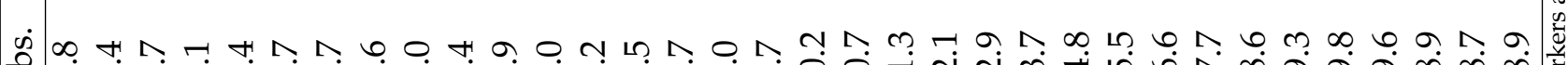

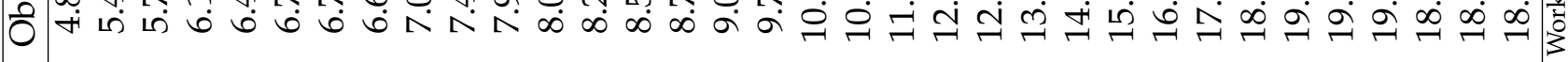

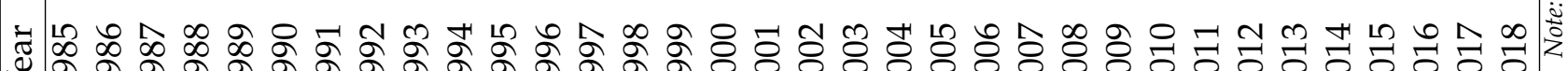
ฮ্خ 


\section{A.2 Additional Figures for Brazil's Formal Sector}

Figure A1. Evolution of Earnings Percentiles, Men and Women Pooled

(A) Percentiles

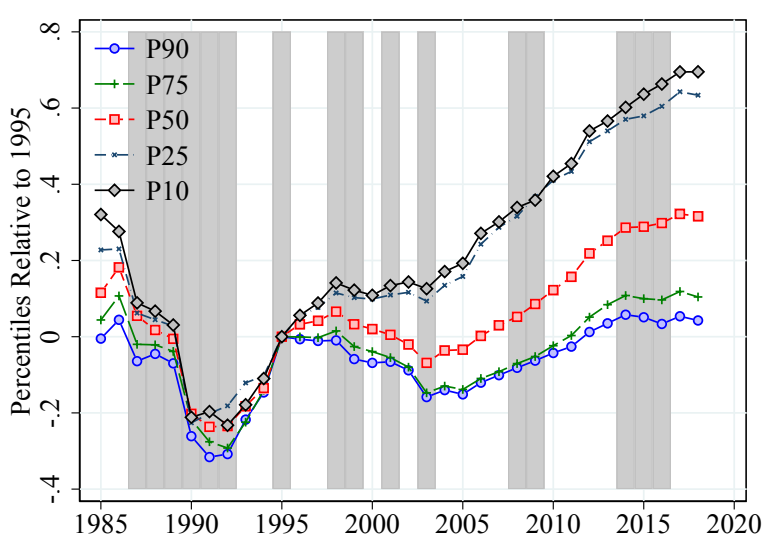

(C) OVERALl INEQUALITY

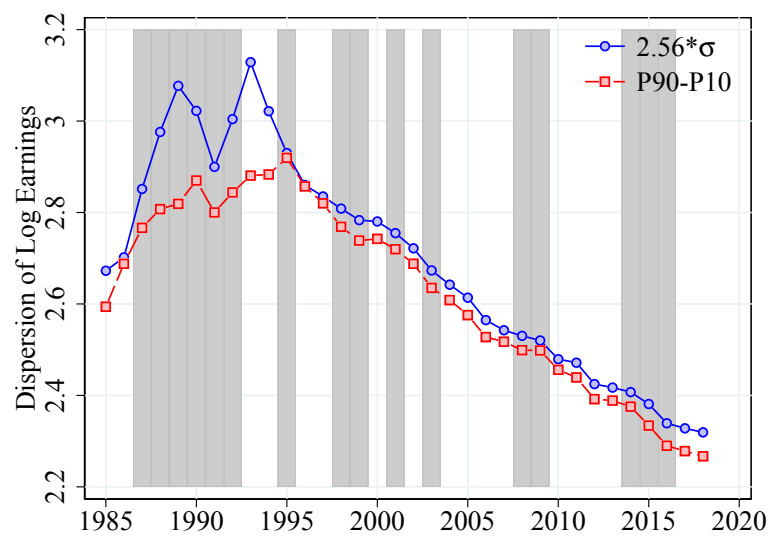

(B) TOP PERCENTILES

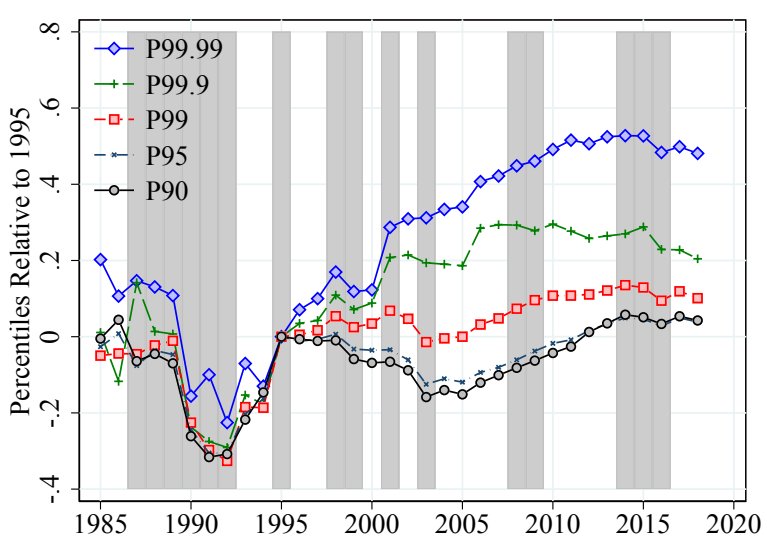

(D) RIgHT- AND LEFT-TAIL INEQUALITY

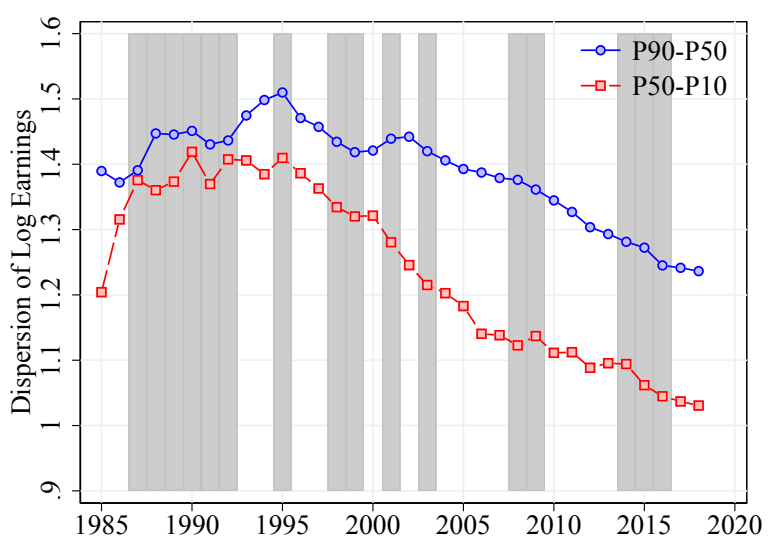

Note: Workers aged 25-55. Source: RAIS, 1985-2018. 
Figure A2. Evolution of Earnings Percentiles, Men And Women Pooled And CONTROLLING FOR AGE

(A) Percentiles

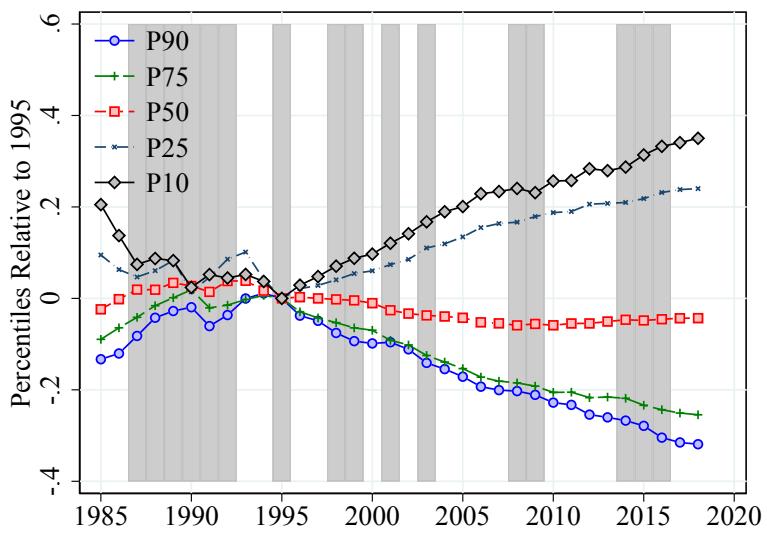

(C) Overall Inequality

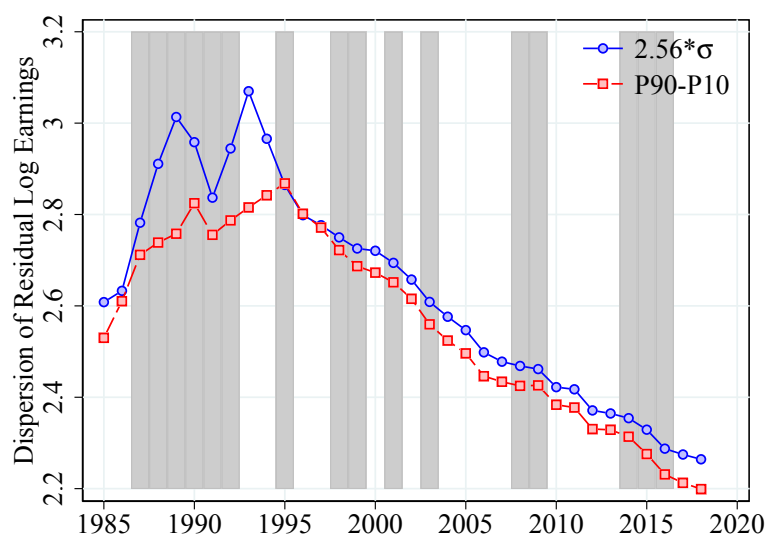

(B) TOP PERCENTILES

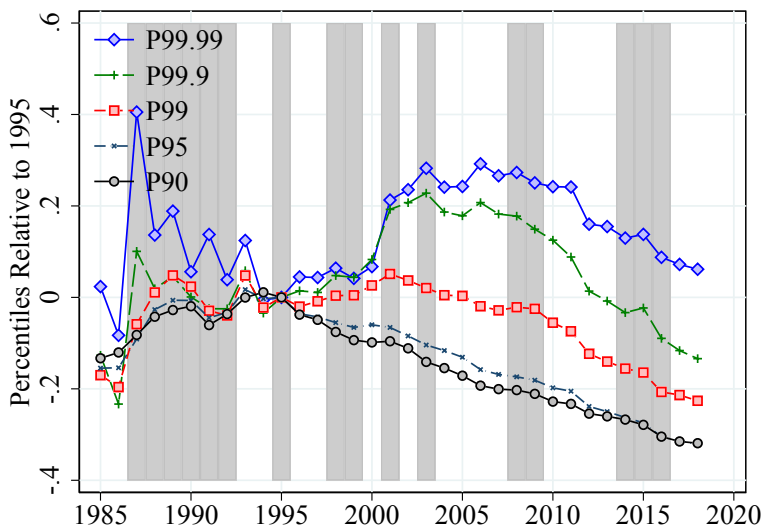

(D) RIgHT- AND LEFT-TAIL INEQUALITY

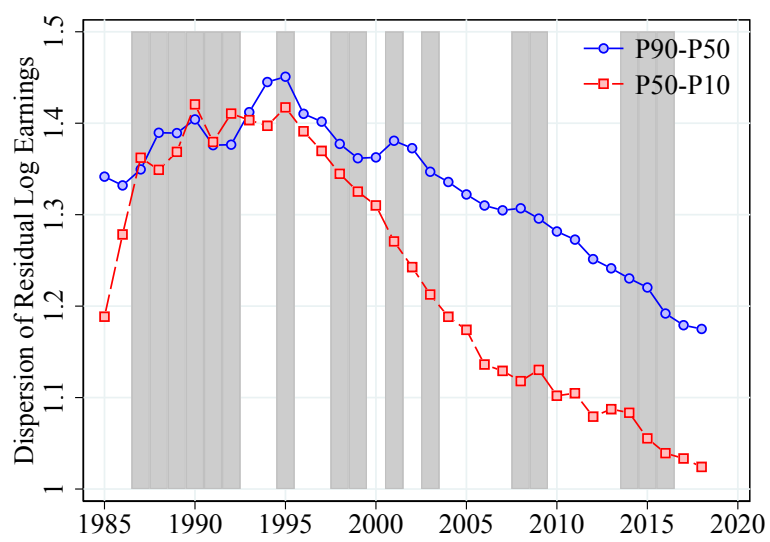

Note: Workers aged 25-55. Source: RAIS, 1985-2018. 
Figure A3. Evolution of Residual Earnings Percentiles, Men and Women Pooled AND CONTROLLING FOR AGE AND EDUCATION

(A) Percentiles

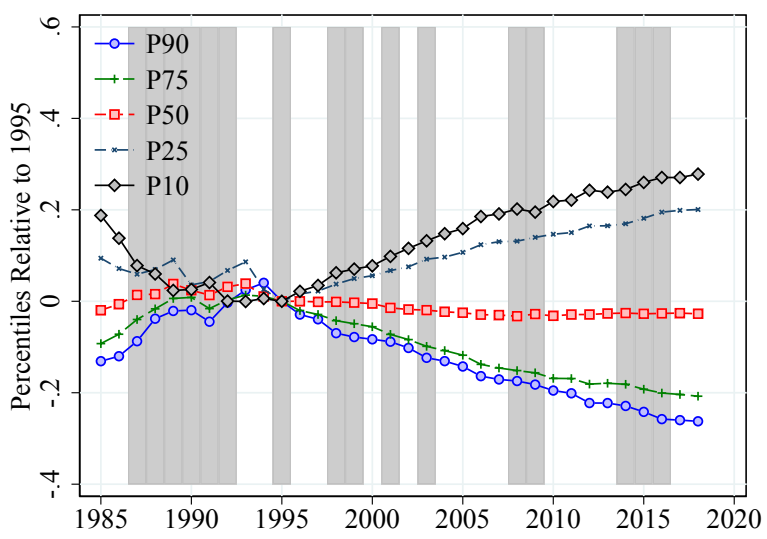

(C) OVERALl INEQuALity

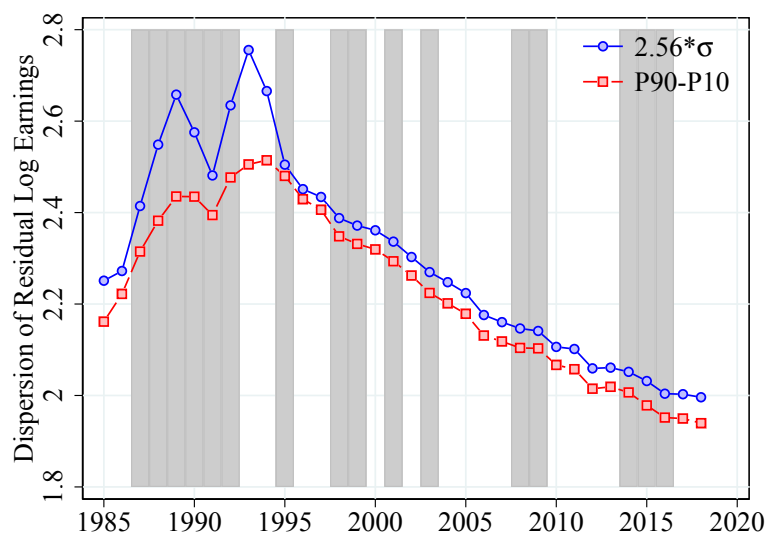

(B) TOP PERCENTILES

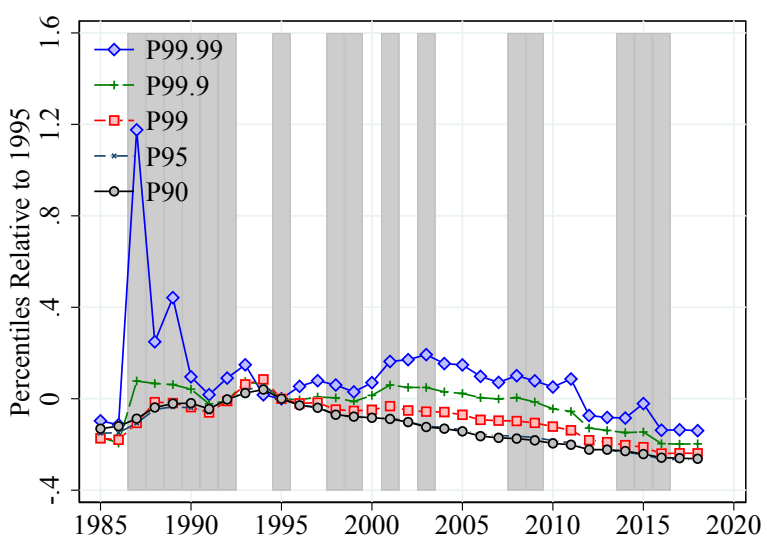

(D) RIgHT- AND LEFT-TAIL INEQUALITY

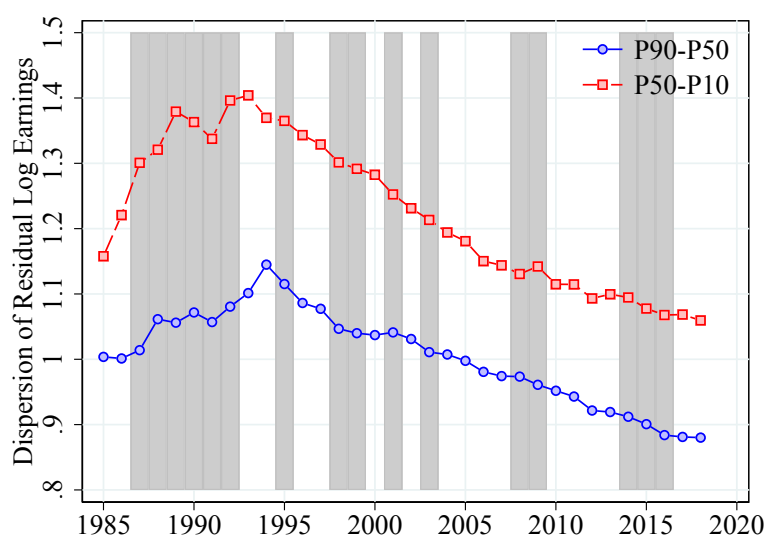

Note: Workers aged 25-55. Source: RAIS, 1985-2018.

Figure A4. Pareto Tail Within Top 1 Percent, by Gender

(A) MEN

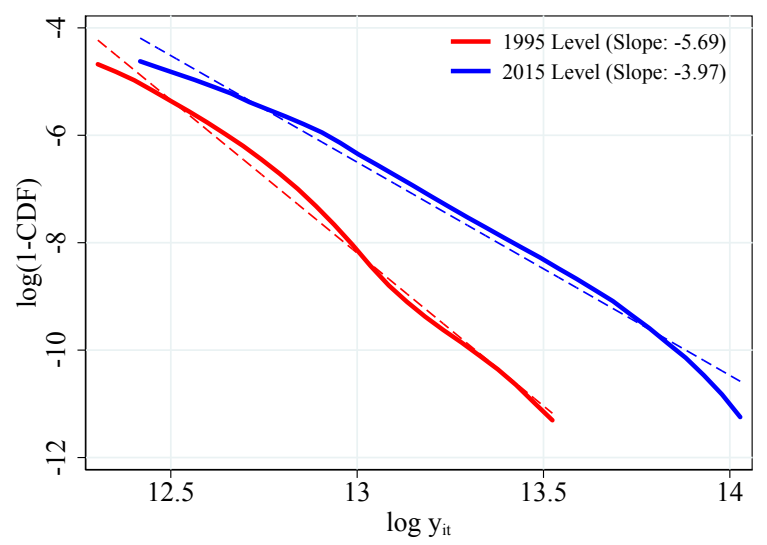

(B) WOMEN

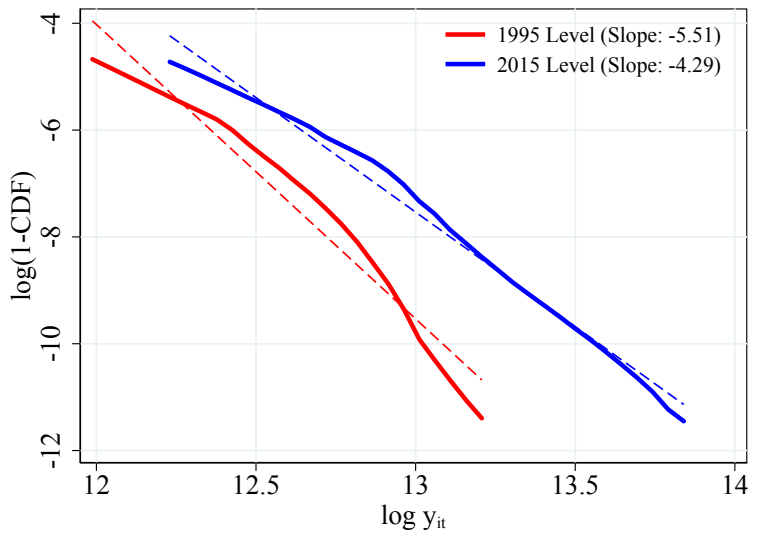

Note: Workers aged 25-55. Source: RAIS, 1985-2018. 
Figure A5. Pareto Tail within top 5 Percent, by Gender

(A) MEN

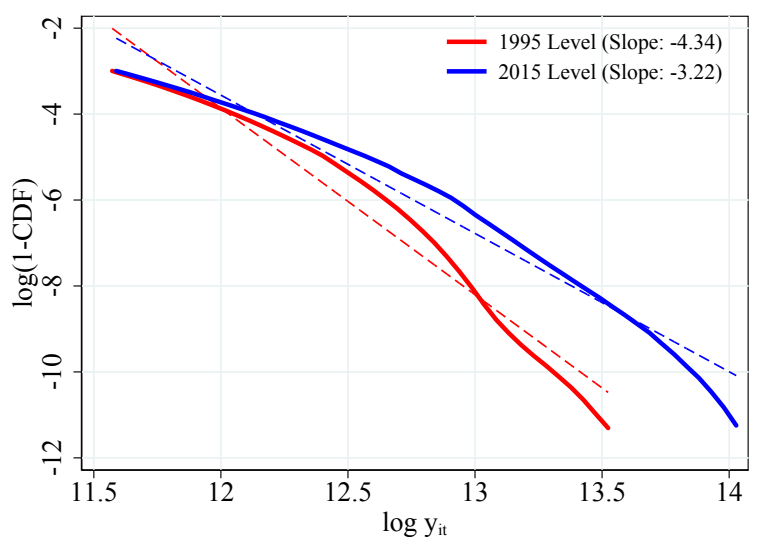

(B) WOMEN

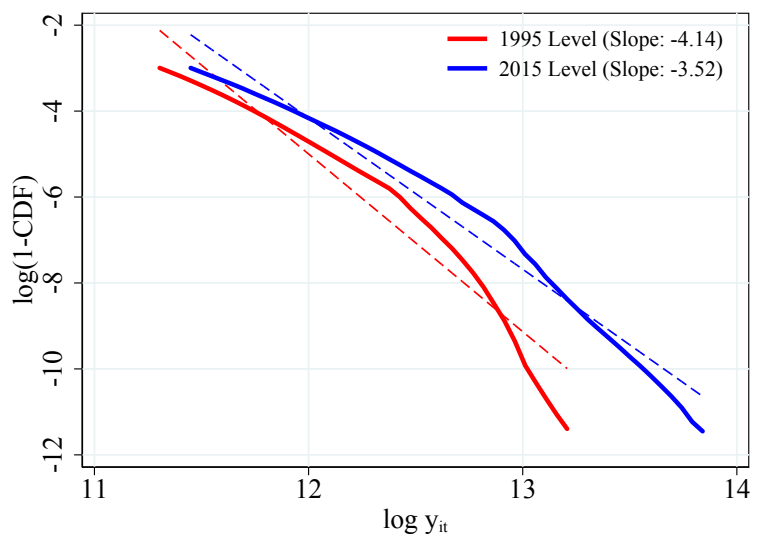

Note: Workers aged 25-55. Source: RAIS, 1985-2018.

Figure A6. EVolution of EARNings Shares, Relative to 1995

(A) INCOME SHARES OF QUINTILES

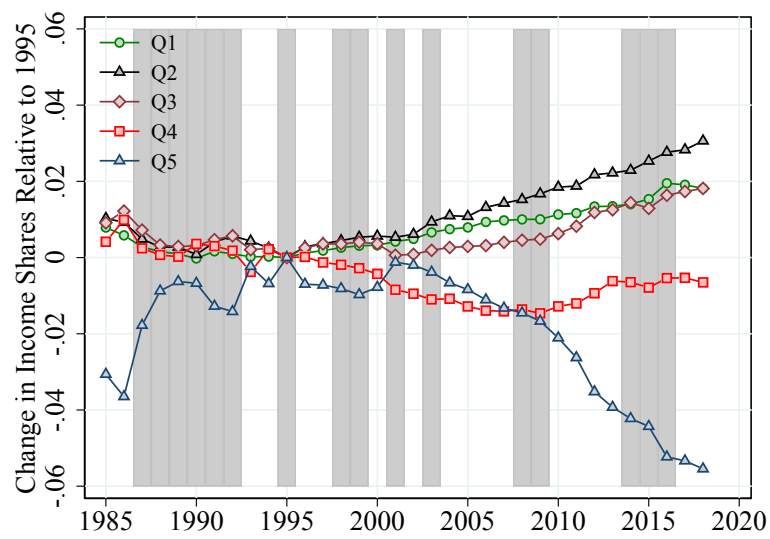

(B) SELECTED INCOME SHARES

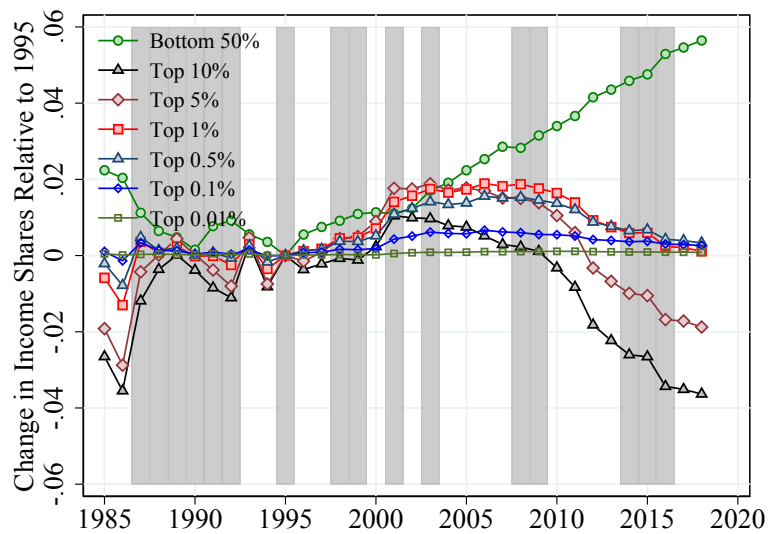

Note: Workers aged 25-55. Source: RAIS, 1985-2018.

Figure A7. Gini COEFFICIENT OF EARNINGS

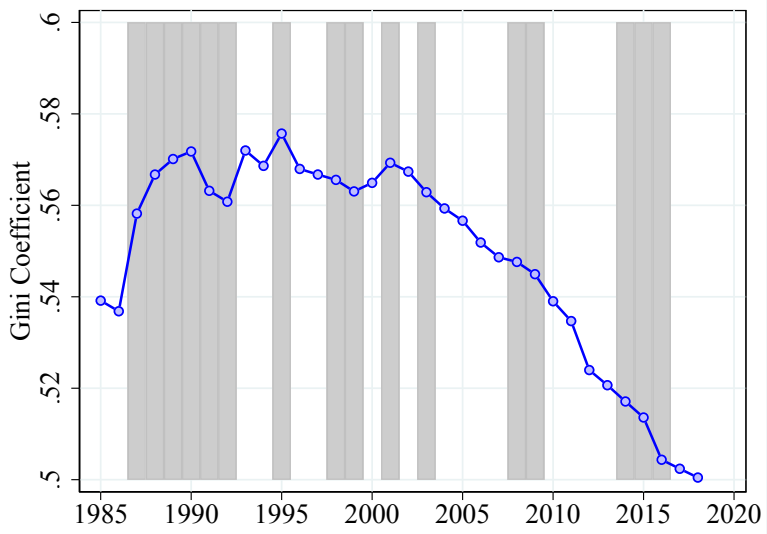

Note: Workers aged 25-55. Source: RAIS, 1985-2018. 
Figure A8. Dispersion in Five-Year Earnings Changes, by Gender

(A) MEN

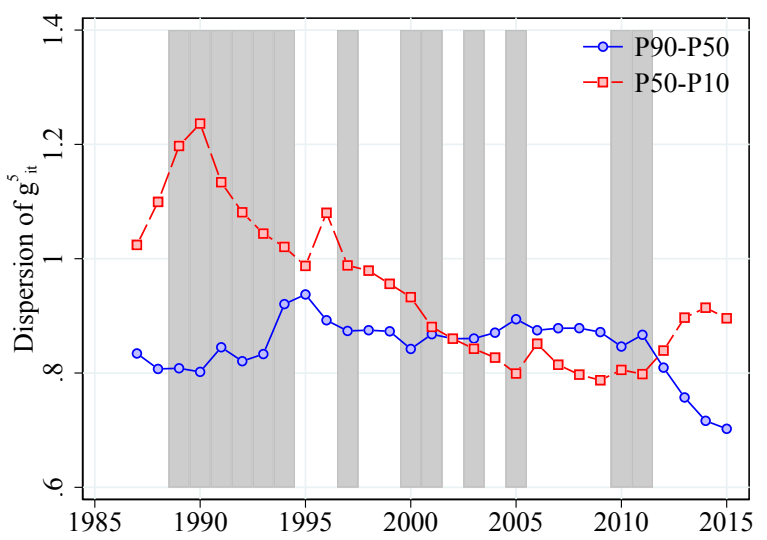

(B) WOMEN

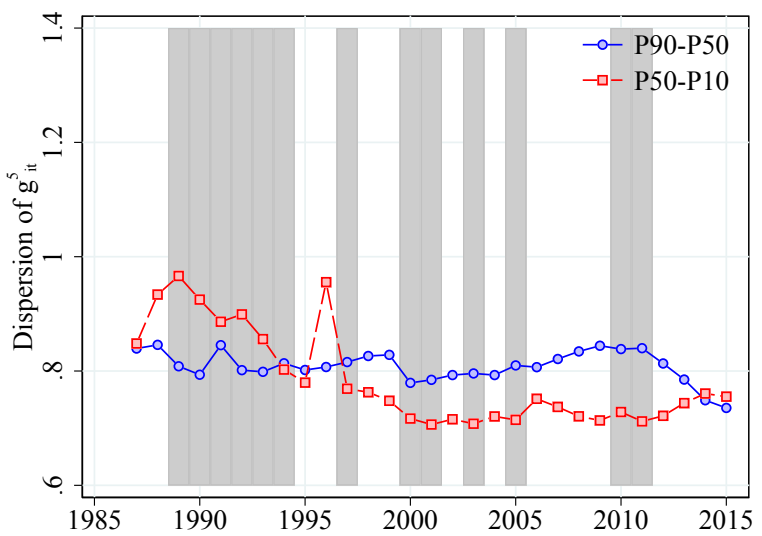

Note: Workers aged 25-55. Source: RAIS, 1985-2018.

Figure A9. Higher-Order Moments of the Five-Year EARnings Change Distribution, BY GENDER

(A) KeLley SKeWNeSS

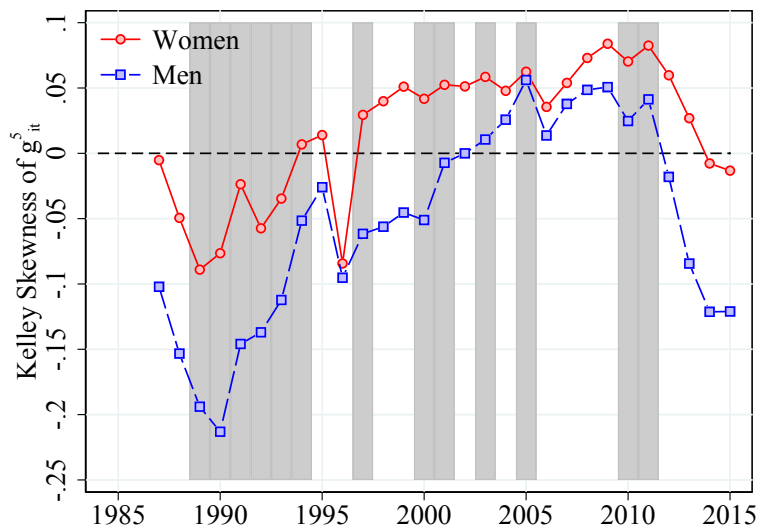

Note: Workers aged 25-55. Source: RAIS, 1985-2018. (в) EXCESS CROW-SidDiqui KuRTOSIS

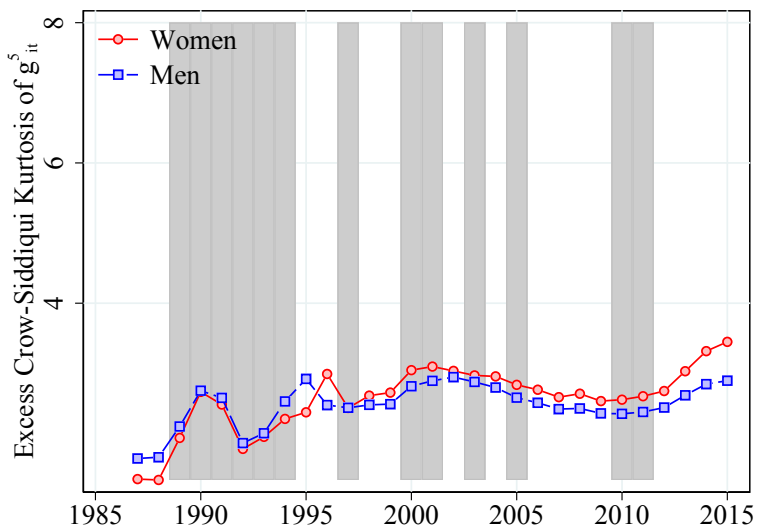


Figure A10. Moments of the Distribution of Five-Year Earnings Changes, by Gender

(A) P90-P10, MEN

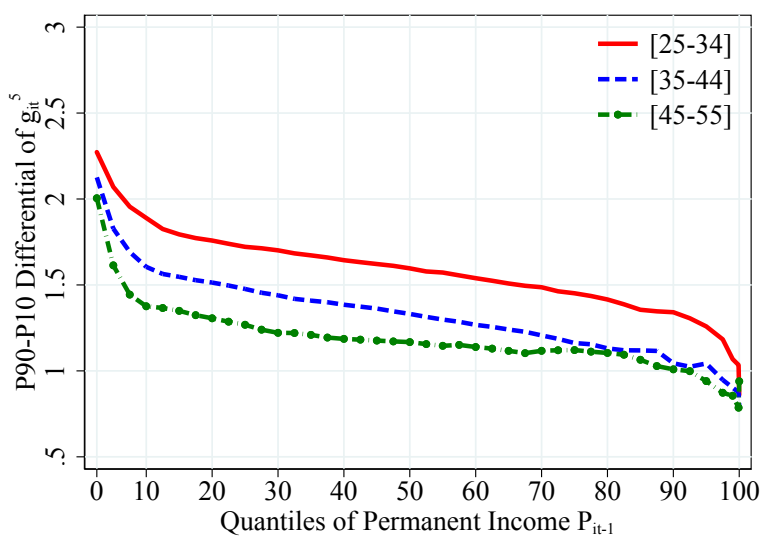

(C) Kelley SKeWness, MeN

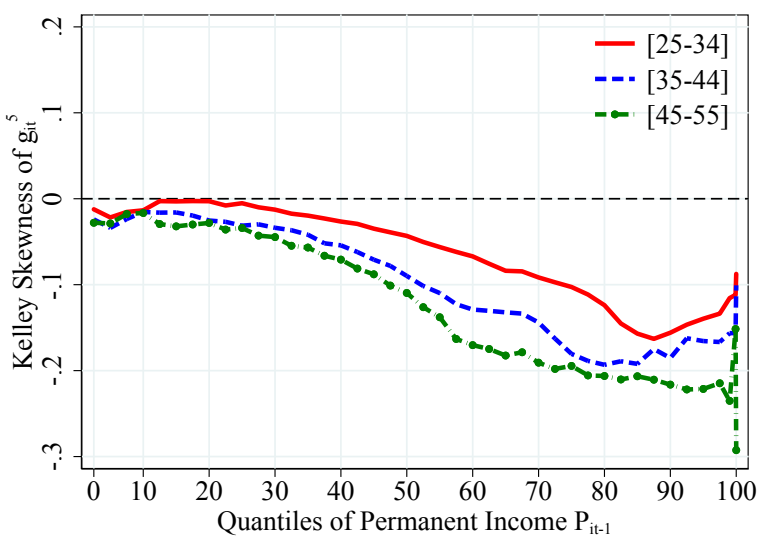

(E) Excess CROW-SidDiQui KuRTOSis, MEN

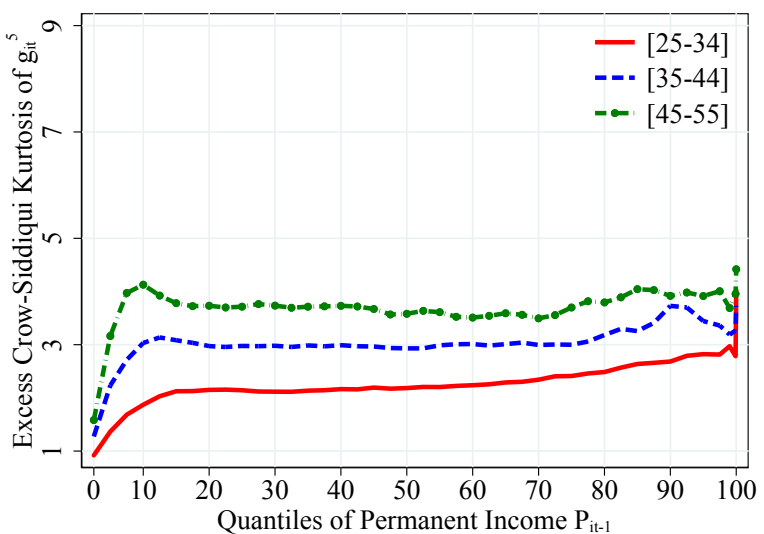

Note: Workers aged 25-55. Source: RAIS, 1999-2018.
(B) P90-P10, WOMEN

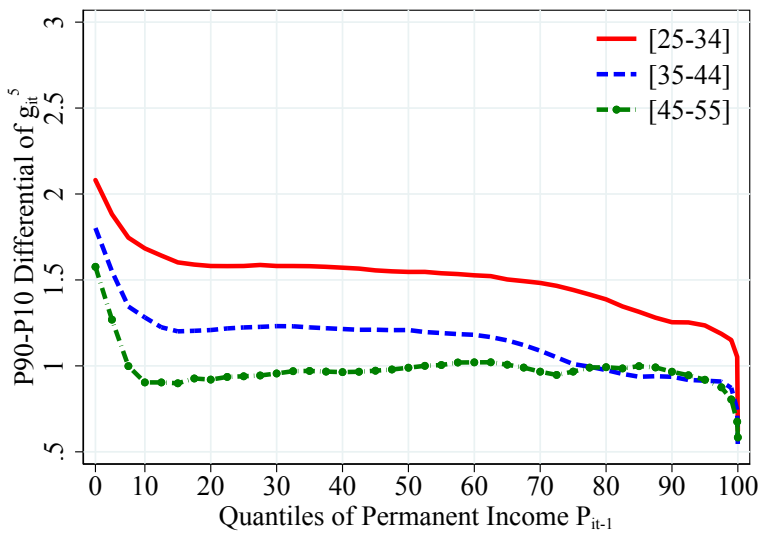

(D) Kelley SKewness, Women

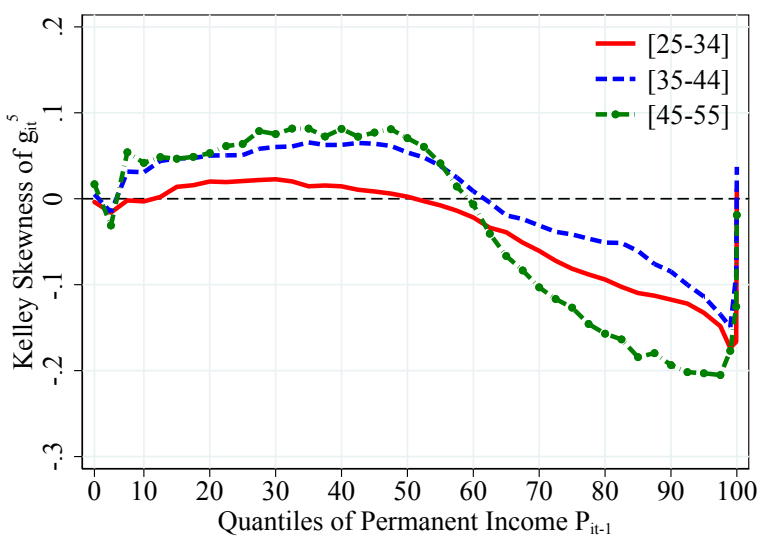

(F) Excess CROW-SidDiqui KuRTOSIS, WOMEN

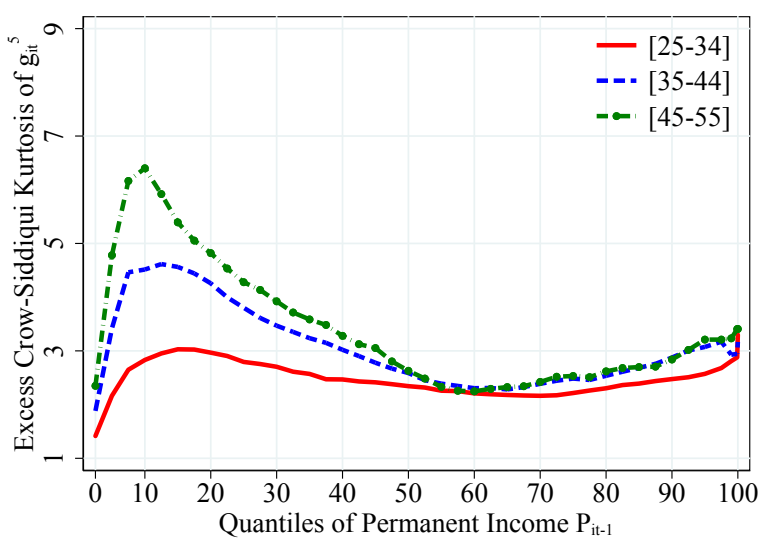




\section{Figure A11. Standardized Moments of the Distribution of One-YeAR EARnings CHANGES, BY GENDER}

(A) STANDARD DeViation, Men

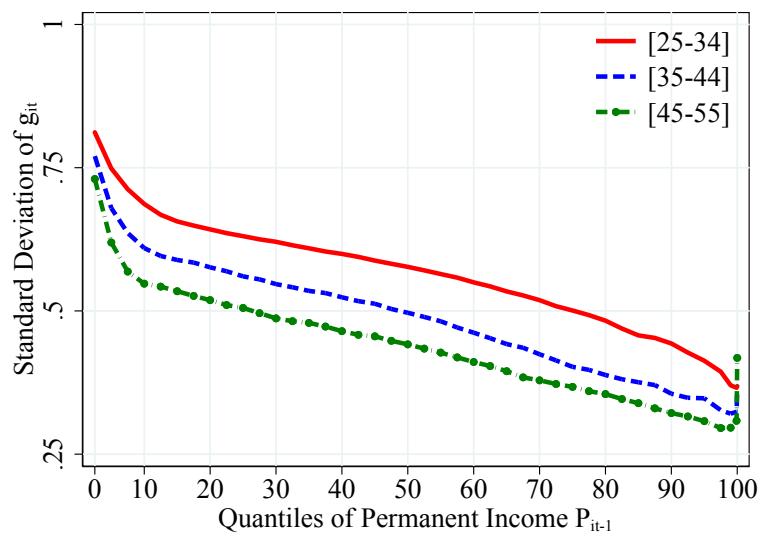

(C) SKEWNESS, MEN

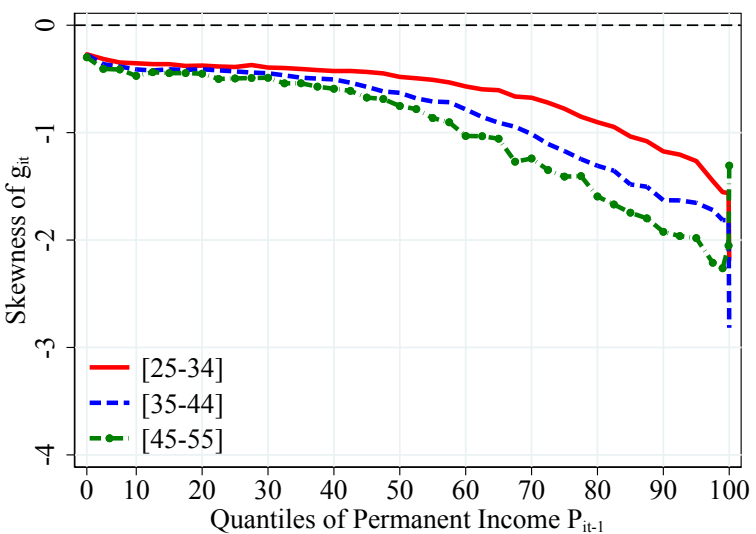

(E) ExCESs Kurtosis, MEN

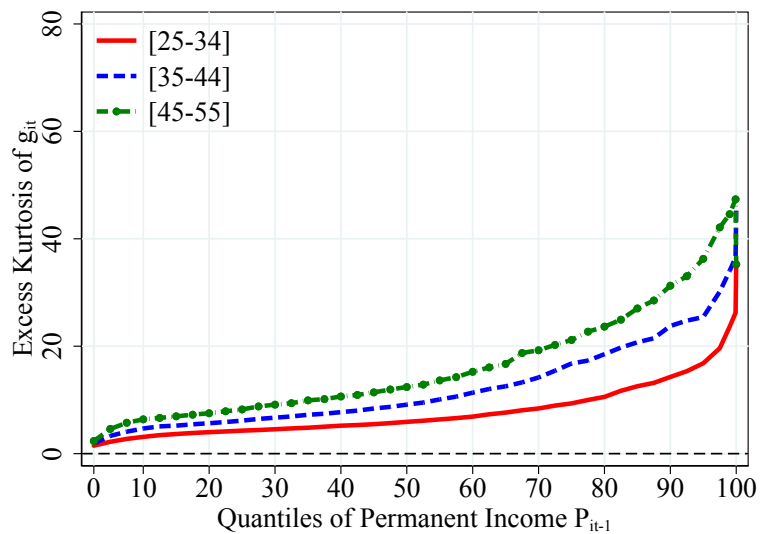

(B) STANDARD DEVIATION, WOMEN

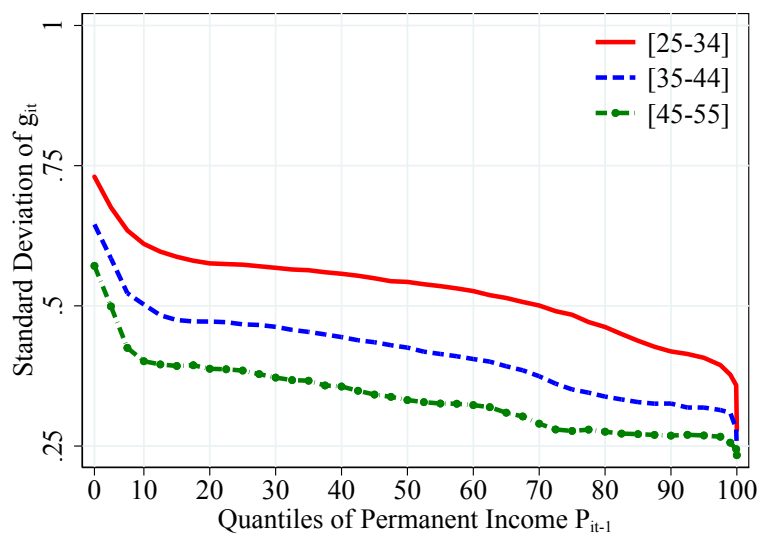

(D) SKEWNESS, WOMEN

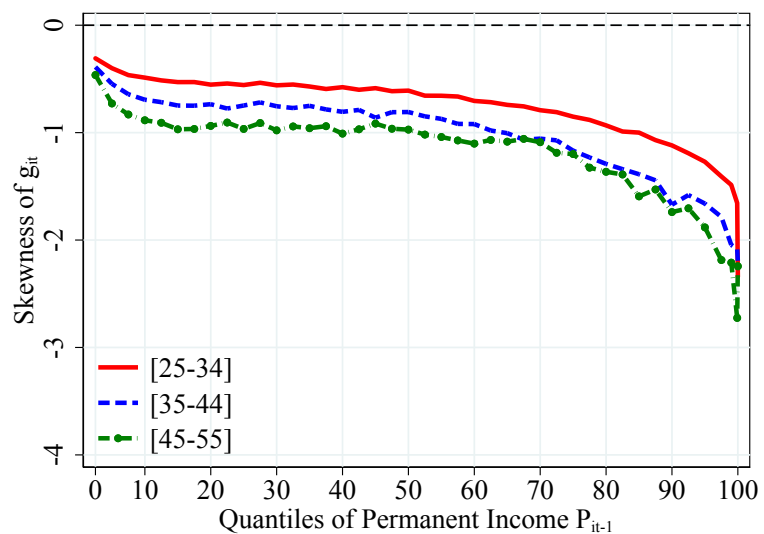

(F) EXCESS KuRTOSIS, WOMEN

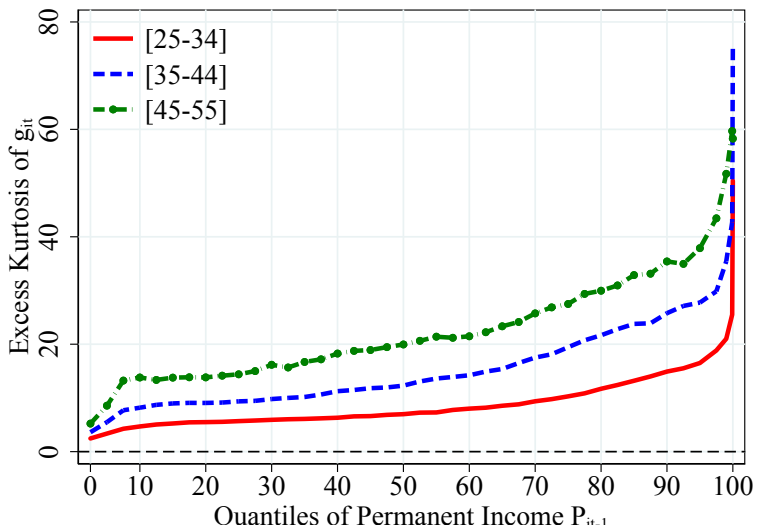

Note: Workers aged 25-55. Skewness corresponds to the standardized third moment of the distribution. Excess Kurtosis is defined as the standardized fourth moment of the distribution minus 3. Source: RAIS, 1999-2018. 
Figure A12. Moments of the Distribution of Five-Year EARnings Changes, by Gender

(A) P90-P10, MEN

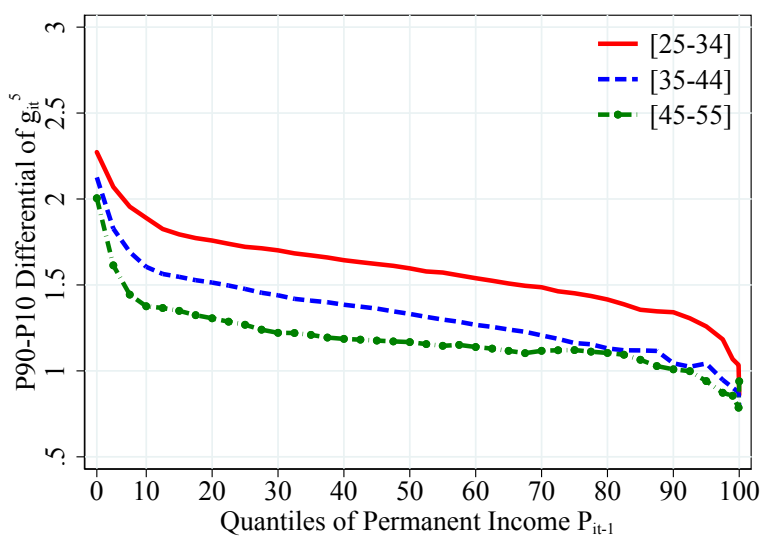

(C) Kelley SKewness, MeN

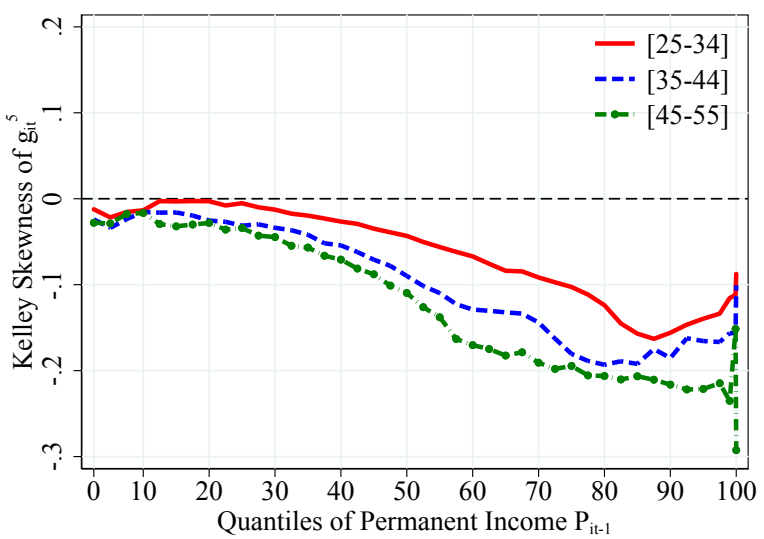

(E) Excess CRow-Siddiqui Kurtosis, MeN

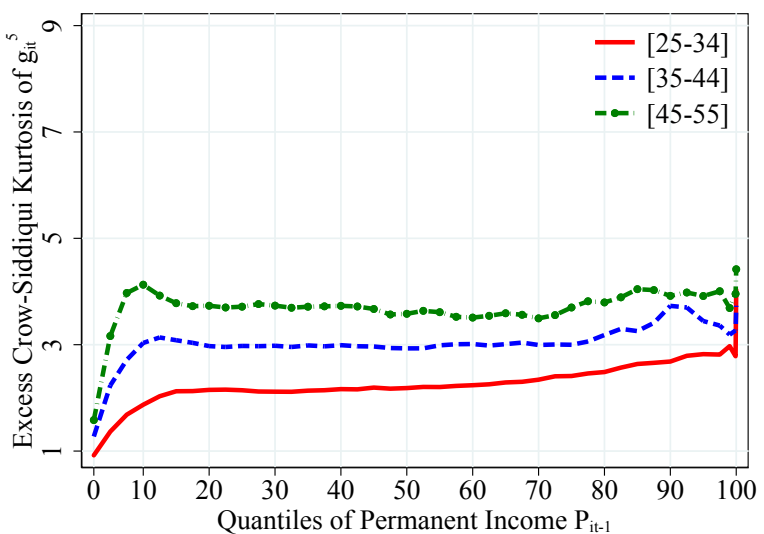

Note: Workers aged 25-55. Source: RAIS, 1999-2018.
(B) P90-P10, WOMEN

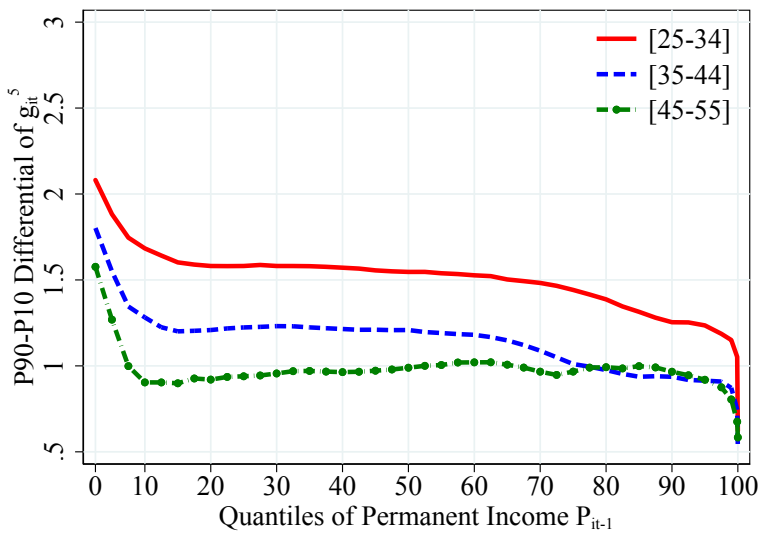

(D) Kelley Skewness, Women

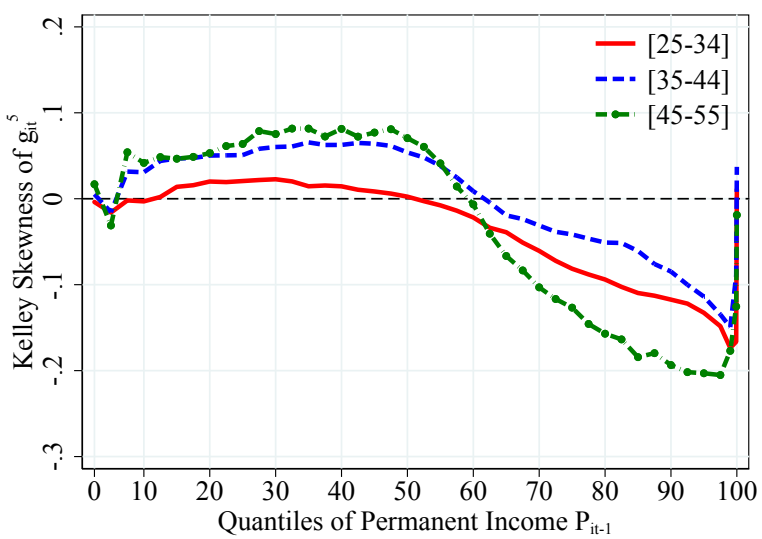

(F) Excess CROW-Siddiqui KuRtosis, WOMEN

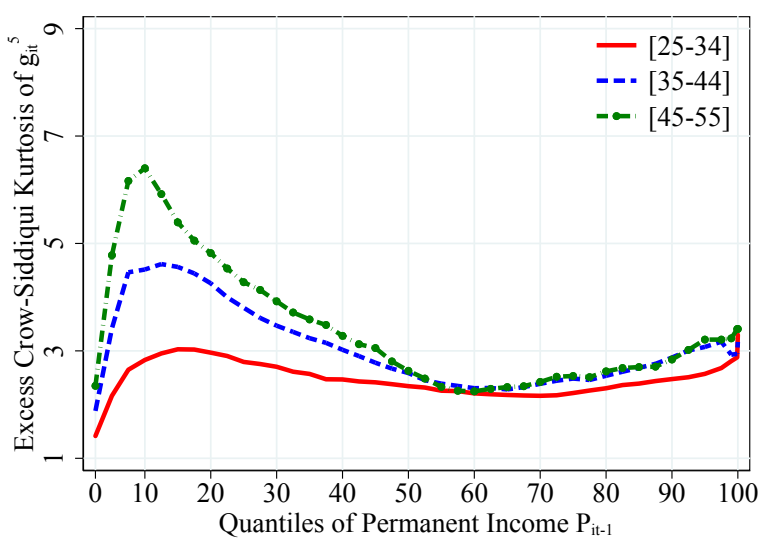




\section{Figure A13. Standardized Moments of the Distribution of Five-YeAR EARnings CHANGES, BY GENDER}

(A) STANDARD DeViation, Men

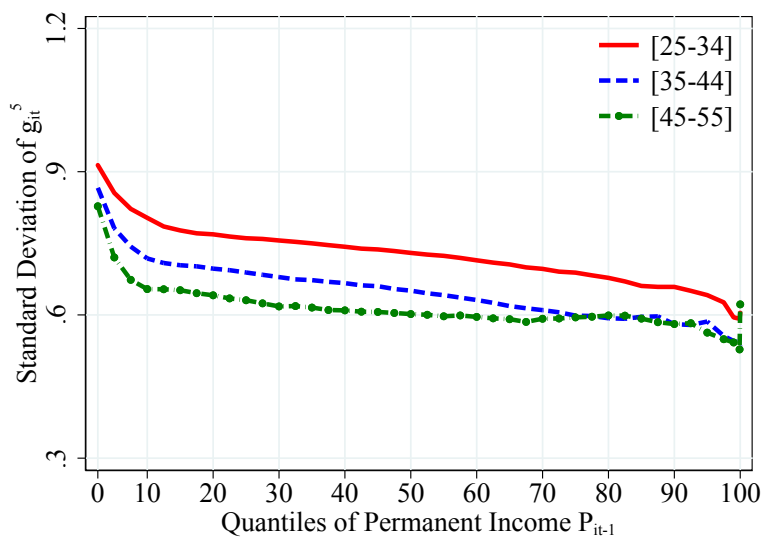

(C) SKEWNESS, MEN

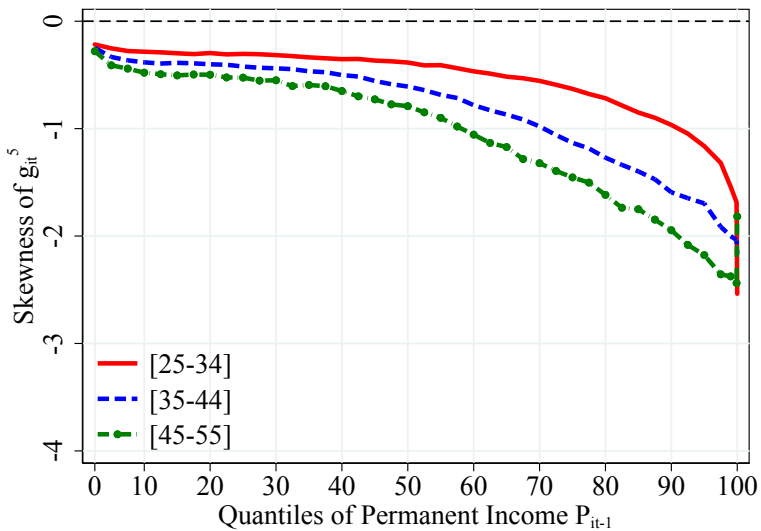

(E) Excess Kurtosis, MEN

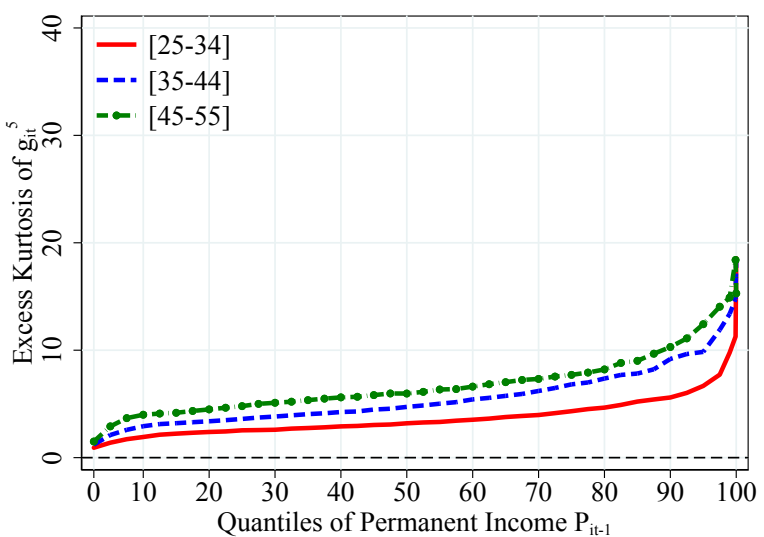

(B) STANDARD DEVIATION, WOMEN

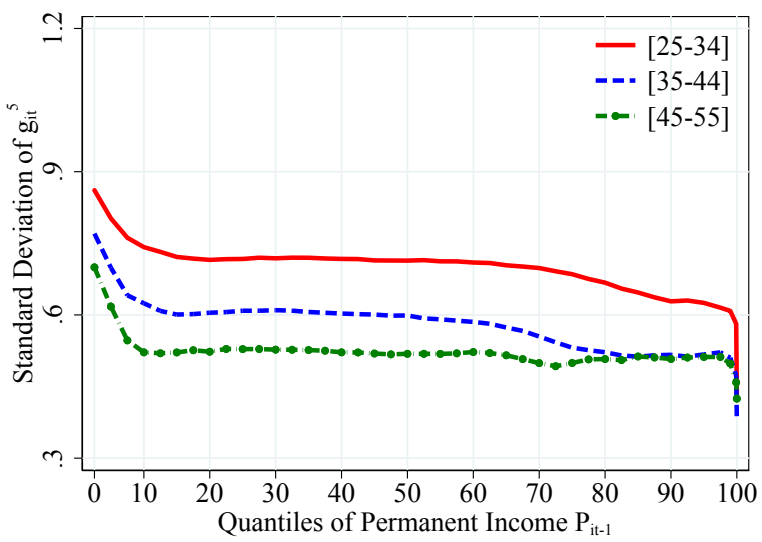

(D) SKEWNESS, WOMEN

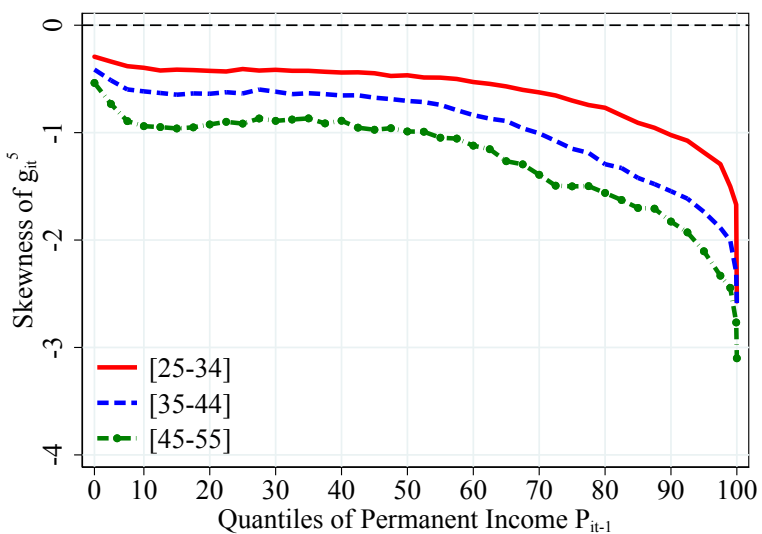

(F) EXCESS KuRTOSIS, WOMEN

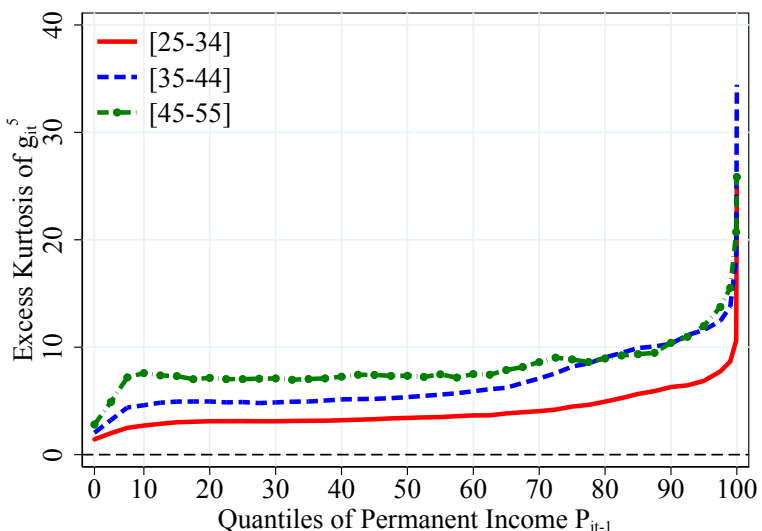

Note: Workers aged 25-55. Skewness corresponds to the standardized third moment of the distribution. Excess Kurtosis is defined as the standardized fourth moment of the distribution minus 3. Source: RAIS, 1999-2018. 
Figure A14. Evolution of Earnings Mobility over the Life CyCle, by Gender

(A) MEN

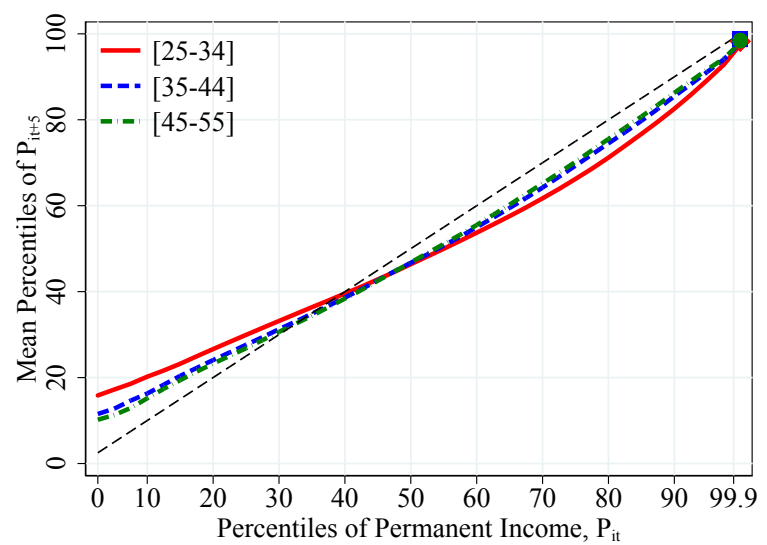

(B) WOMEN

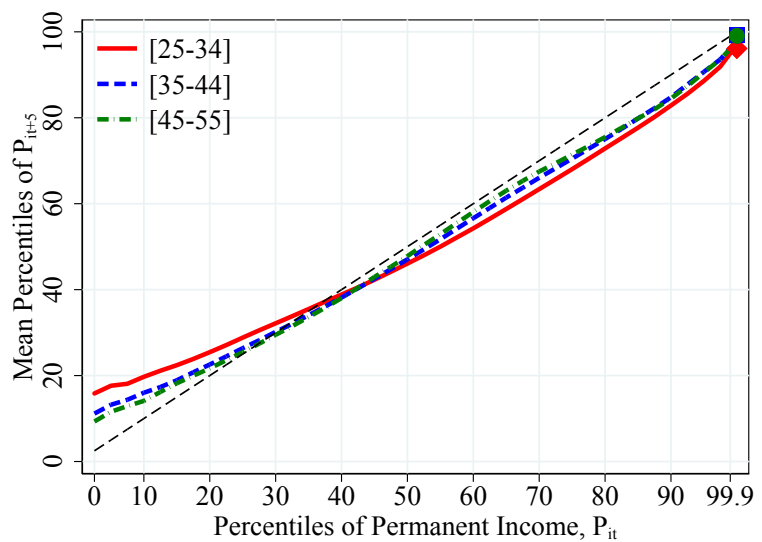

Note: Workers aged 25-55. Colored markers denote the top $0.1 \%$ of permanent income $P_{i t}$. Source: RAIS, 1985-2018.

\section{Figure A15. Evolution of EARNings Mobility OVER Time, By GENDER}

\section{(A) MEN}

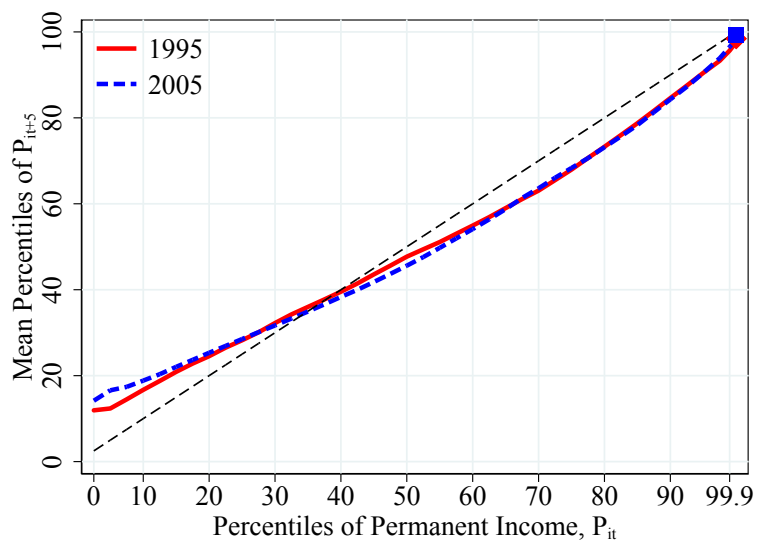

(B) WOMEN

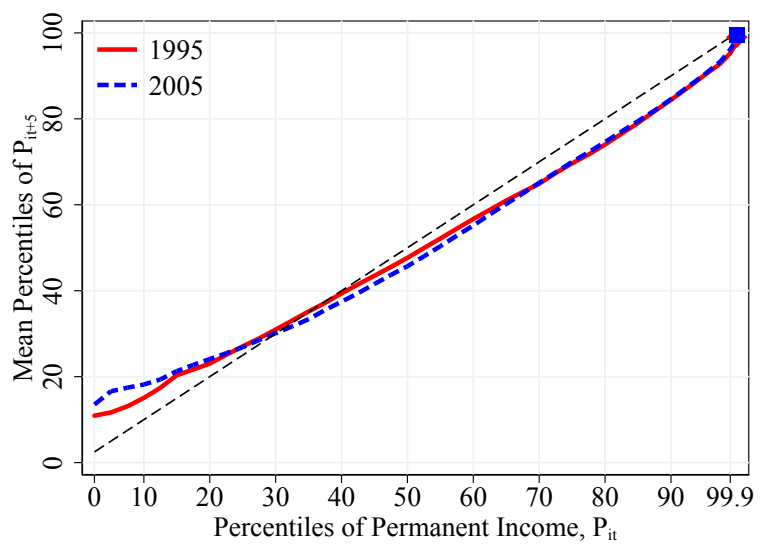

Note: Workers aged 25-55. Colored markers denote the top $0.1 \%$ of permanent income $P_{i t}$. Source: RAIS, $1985-2018$. 
Figure A16. Density of One-Year EARnings Changes, by Gender

(A) MEN

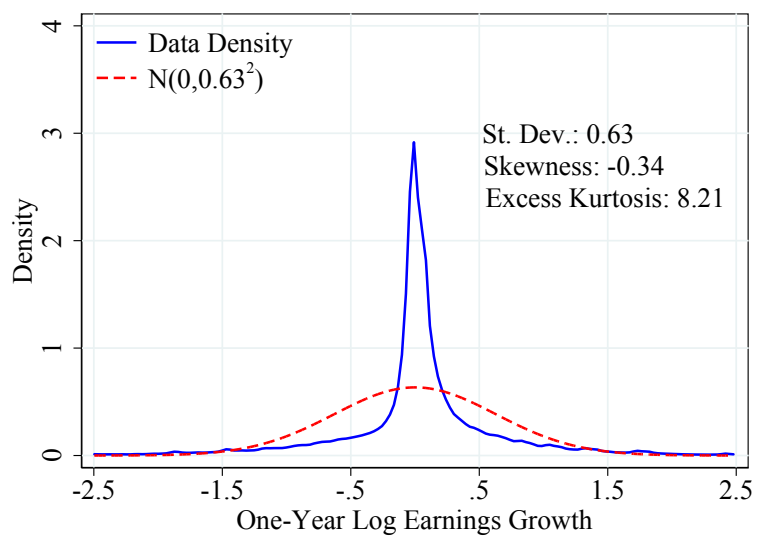

Note: Workers aged 25-55. Source: RAIS, 1985-2018.
(B) WOMEN

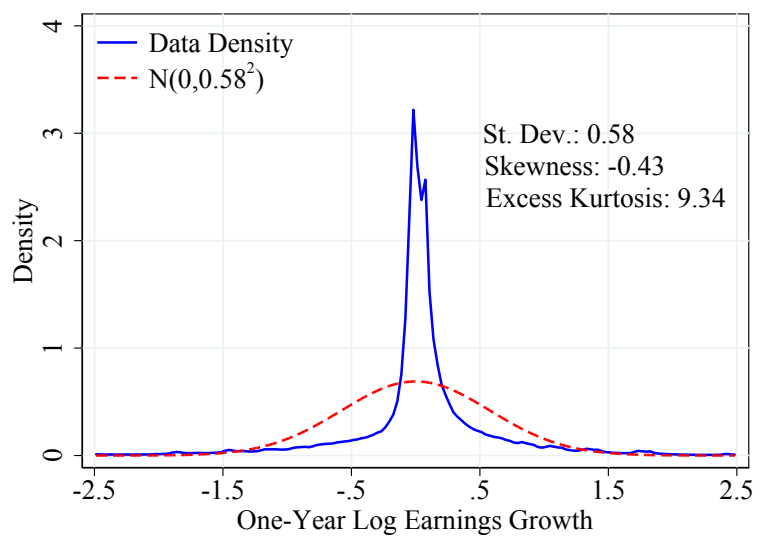

Figure A17. Density of Five-Year Earnings Changes, by Gender

(A) MEN

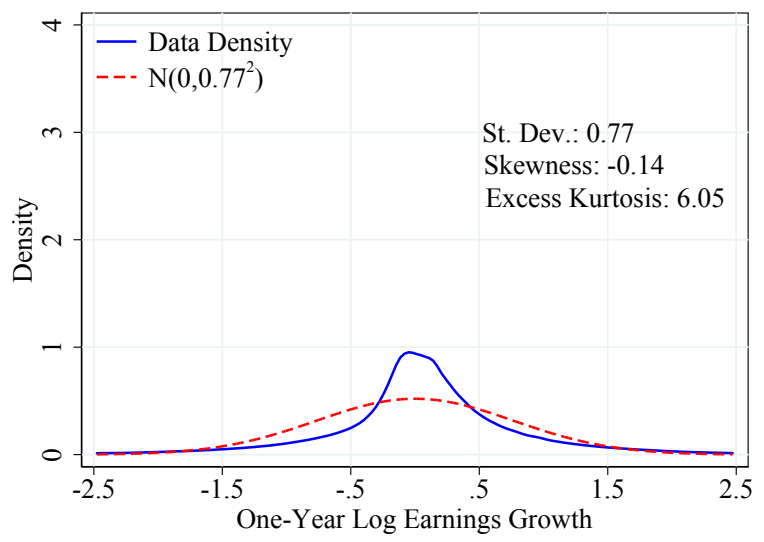

Note: Workers aged 25-55. Source: RAIS, 1985-2018.
(B) WOMEN

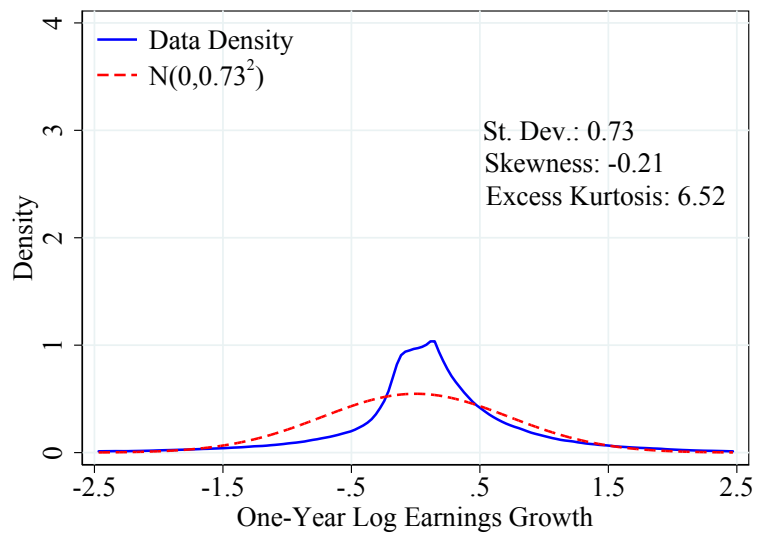


Figure A18. Log-Density of One-Year EARnings Changes, by Gender

(A) MEN

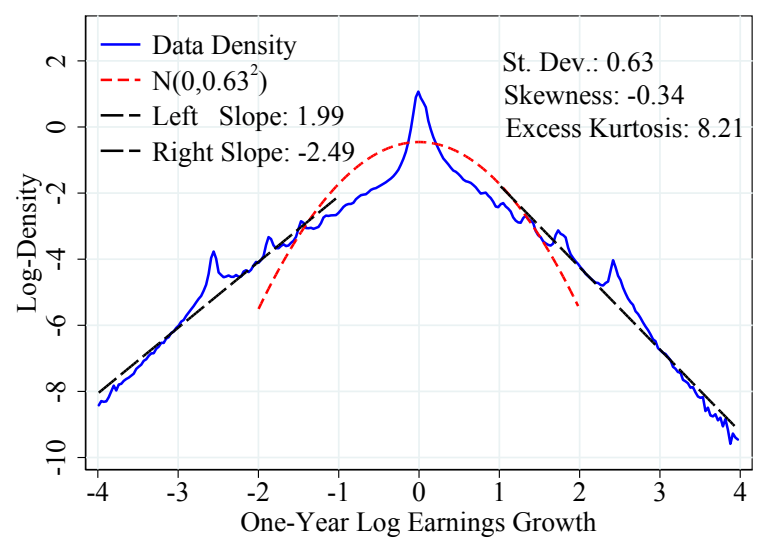

(B) WOMEN

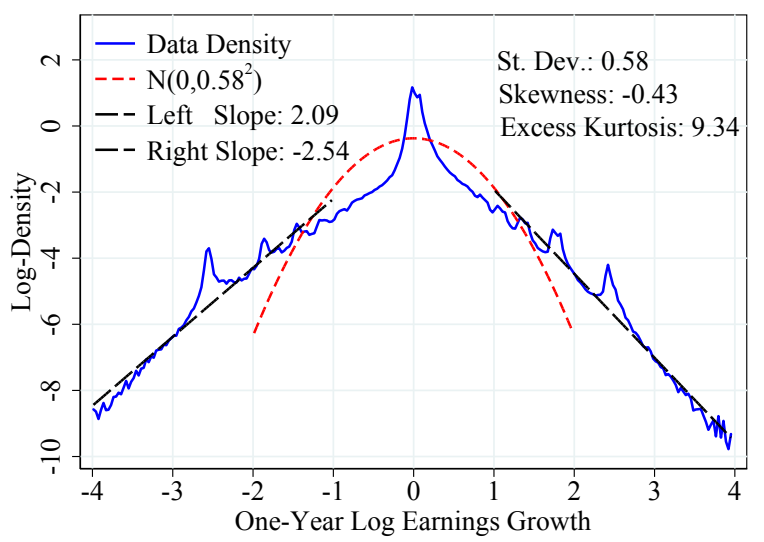

Note: Workers aged 25-55. Source: RAIS, 1985-2018.

Figure A19. Log-Density of Five-Year EARnings Changes, by Gender

(A) MEN

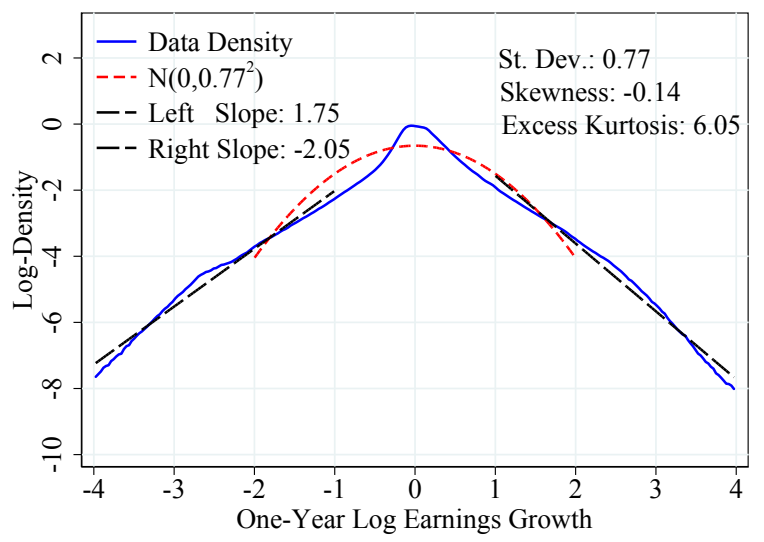

(B) WOMEN

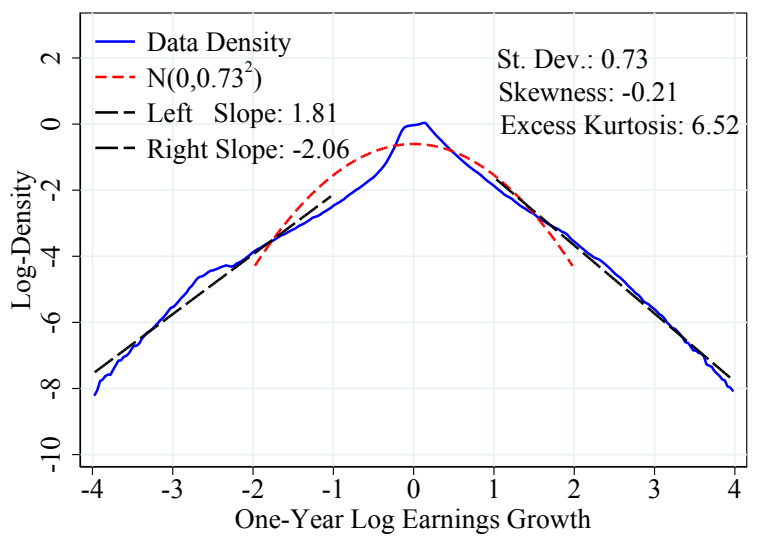

Note: Workers aged 25-55. Source: RAIS, 1985-2018. 


\section{A.3 Additional Figures for Brazil's Informal Sector}

Figure A20. Education Shares, by Origin ANd Destination Sector

(A) FORMAL-FORMAL TRANSITIONS

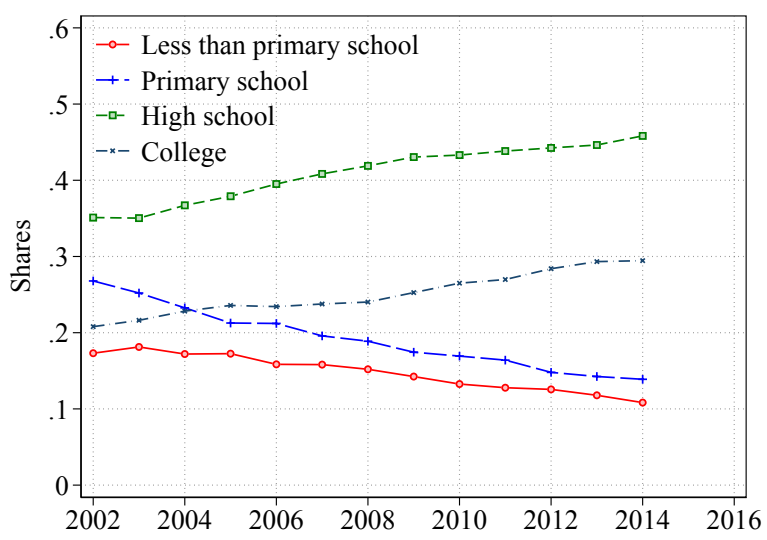

(B) INFORMAL-INFORMAL TRANSITIONS

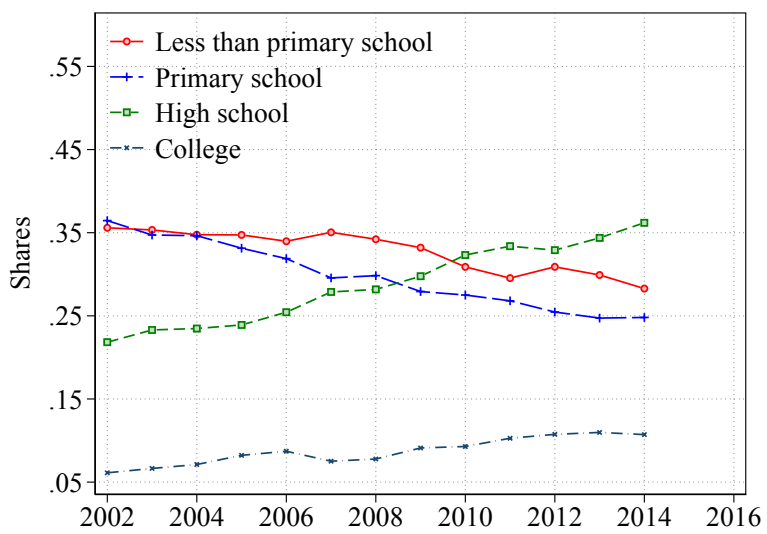

Note: Workers aged 25-55. Source: PME, 2002-2015.

Figure A21. Age Group Shares, by Origin and Destination Sector

(A) FORMAL-FORMAL TRANSITIONS

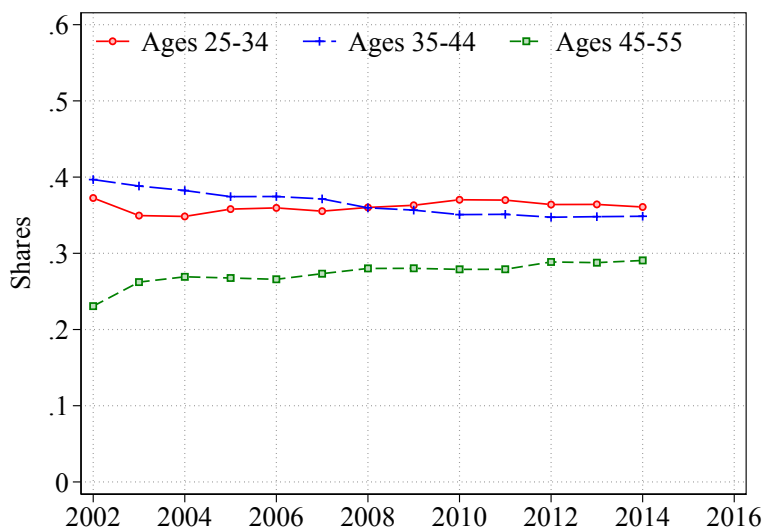

(B) INFORMAL-INFORMAL TRANSITIONS

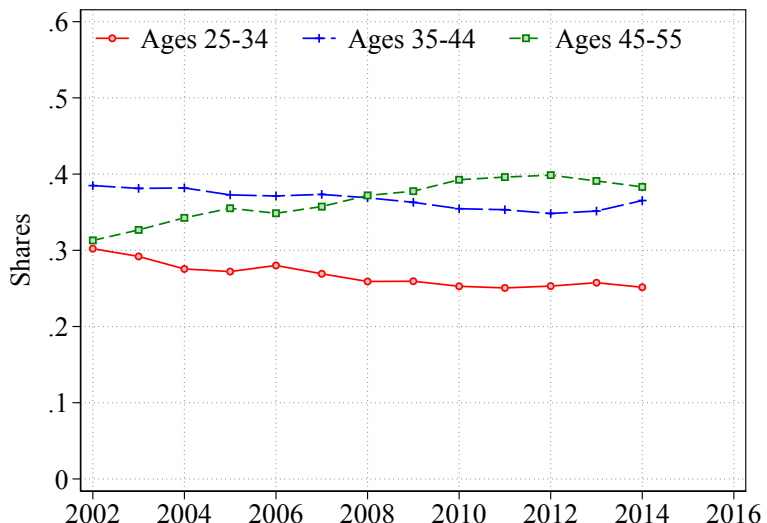

Note: Workers aged 25-55. Source: PME, 2002-2015. 
Figure A22. Densities of Log EARnings, by Sector And Population Subgroup in 2002

(A) MEN, <HS, AGE 25-34

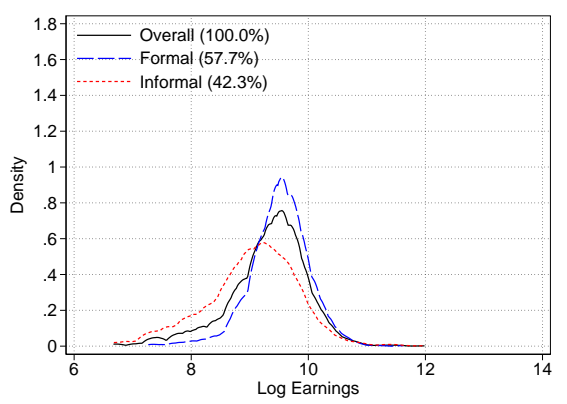

(D) MEN, $\geq$ HS, AGE 25-34

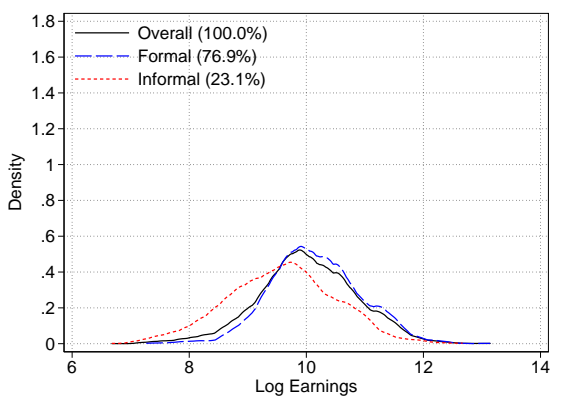

(G) WOMEN, <HS, AGE 25-34

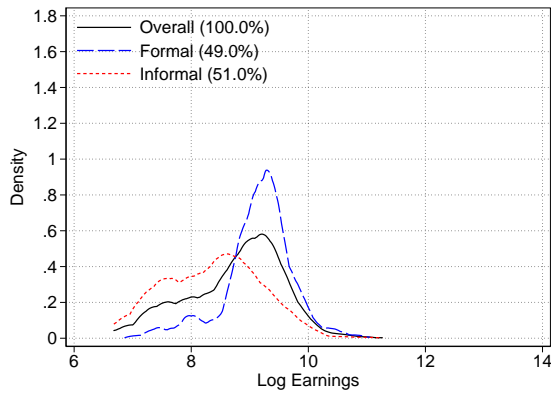

(J) WOMEN, $\geq$ HS, AGE 25-34

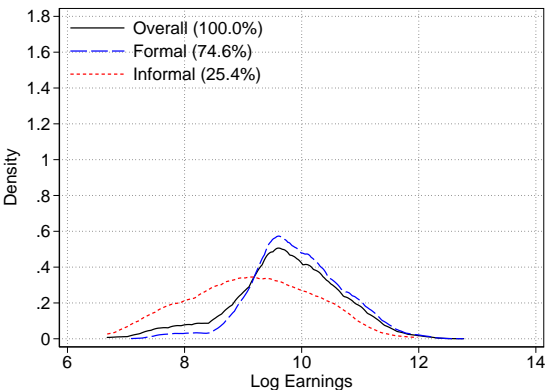

(B) MEN, <HS, AGE 35-44

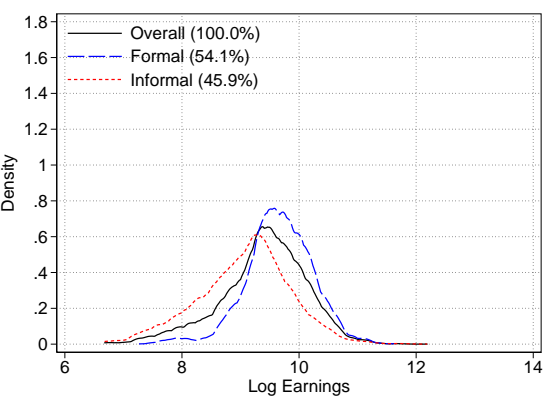

(E) MEN, $\geq$ HS, AGE 35-44

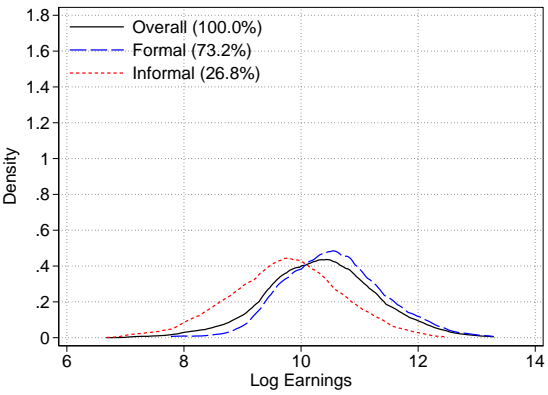

(H) WOMEN, <HS, AGE 35-44

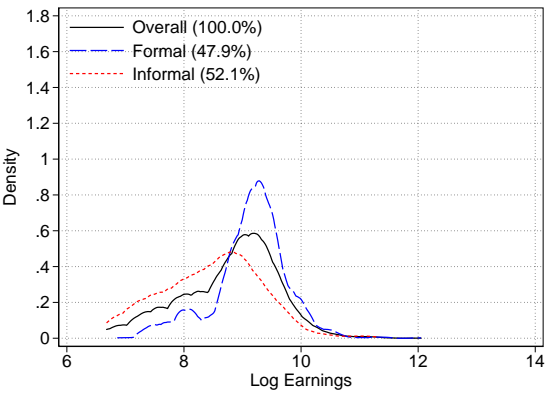

(K) WOMEN, $\geq$ HS, AGE 35-44

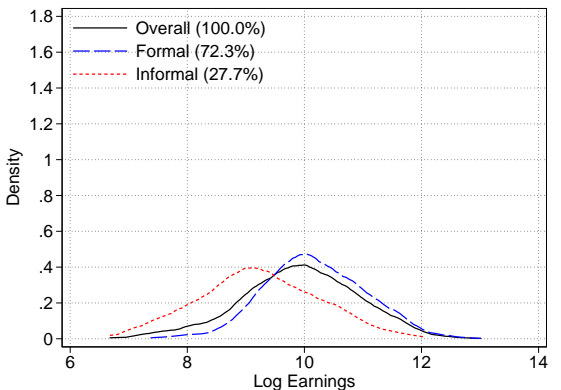

(C) MEN, <HS, AGE 45-55

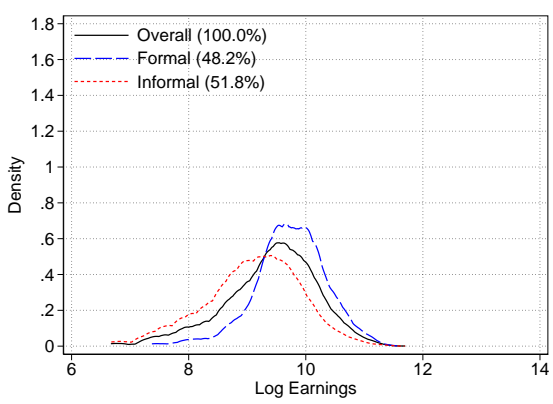

(F) MEN, $\geq$ HS, AGE 45-55

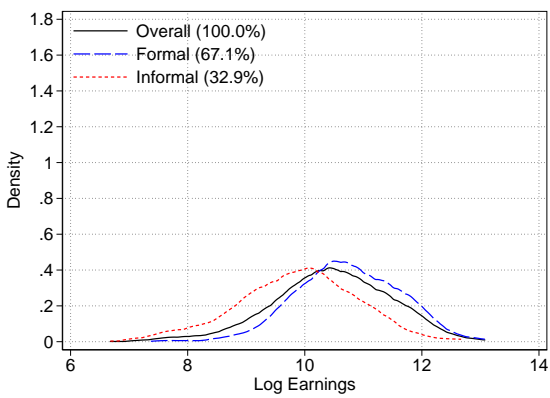

(I) WOMEN, <HS, AGE 45-55

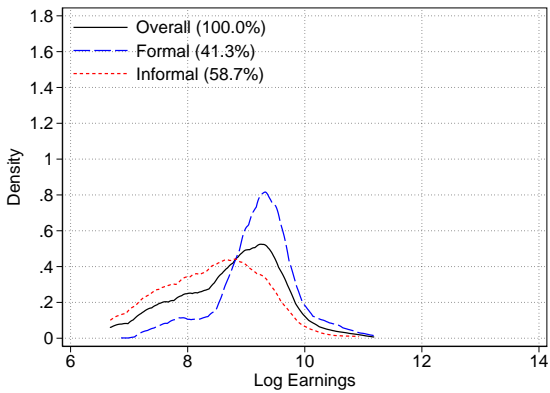

(L) WOMEN, $\geq$ HS, AGE 45-55

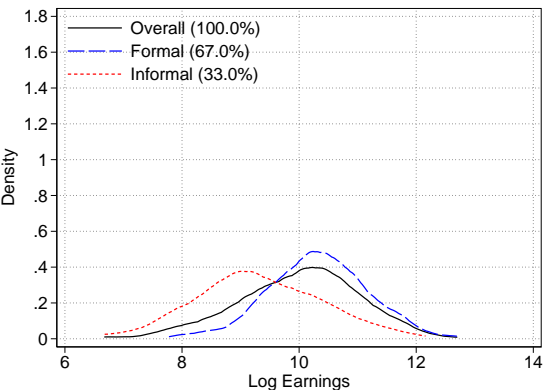

Note: Workers aged 25-55. Kernel densities of log earnings by worker group. Different lines show the overall distribution as well as that in the formal sector and that in the informal sector. Source: PME, 2002. 
Figure A23. Densities of Log EARnings, by Sector And Population Subgroup in 2015

(A) MEN, <HS, AGE 25-34

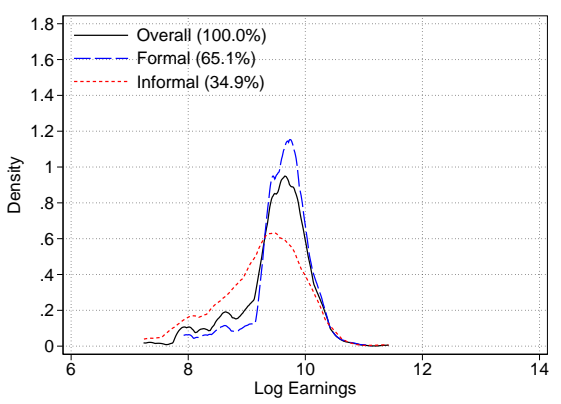

(D) MEN, $\geq$ HS, AGE 25-34

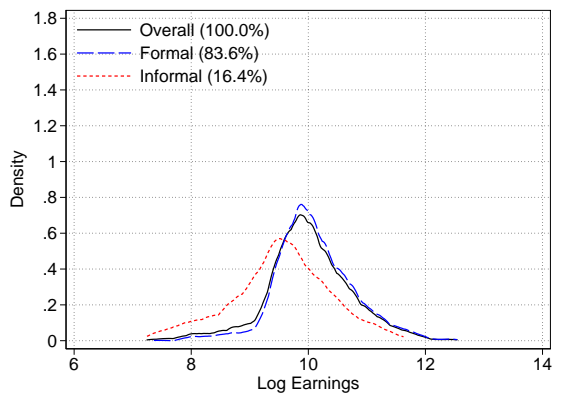

(G) WOMEN, <HS, AGE 25-34

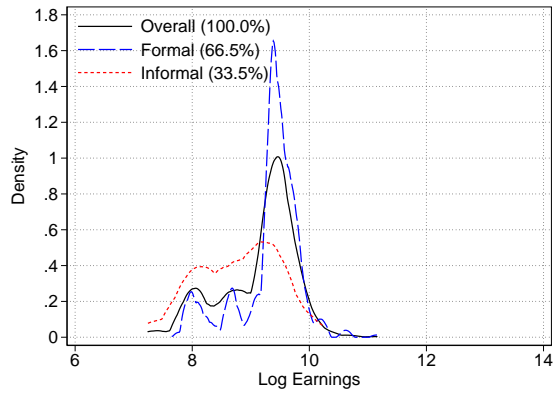

(J) WOMEN, $\geq$ HS, AGE 25-34

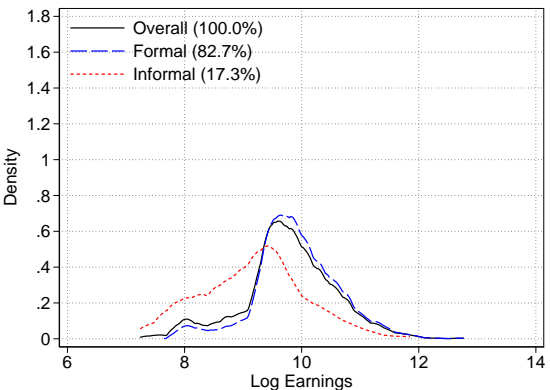

(B) MEN, <HS, AGE 35-44

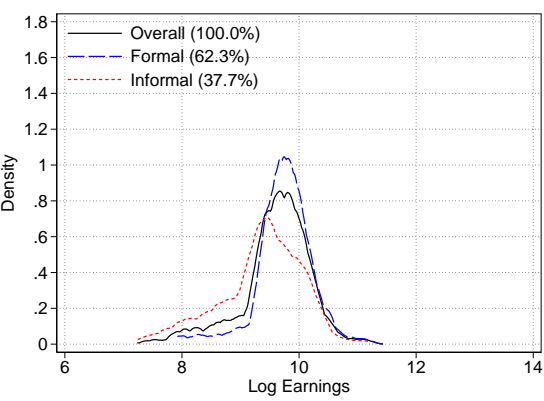

(E) MEN, $\geq$ HS, AGE 35-44

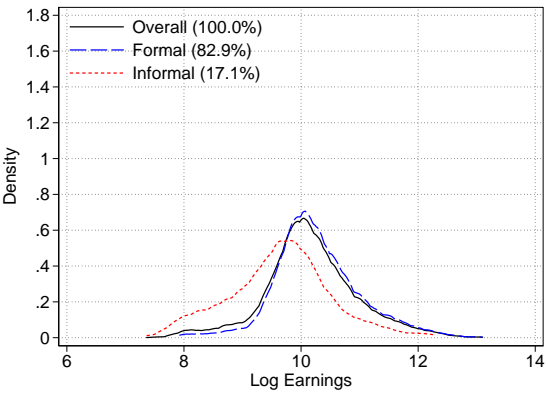

(H) WOMEN, <HS, AGE 35-44

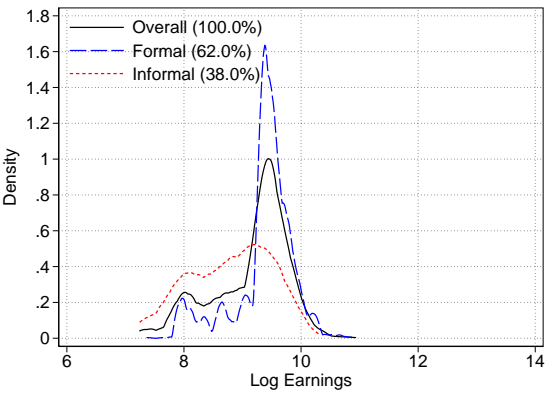

(K) WOMEN, $\geq$ HS, AGE 35-44

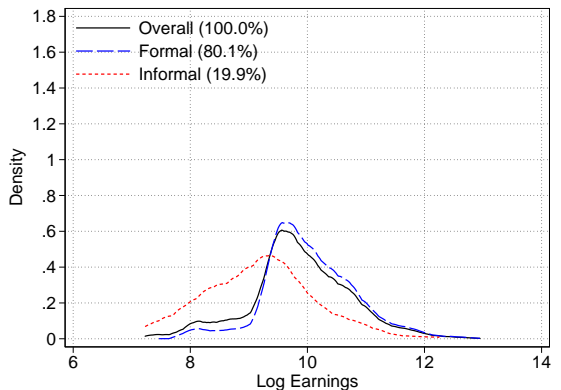

(C) MEN, <HS, AGE 45-55

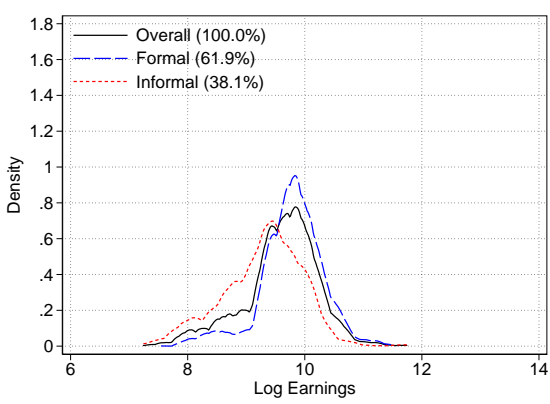

(F) MEN, $\geq$ HS, AGE 45-55

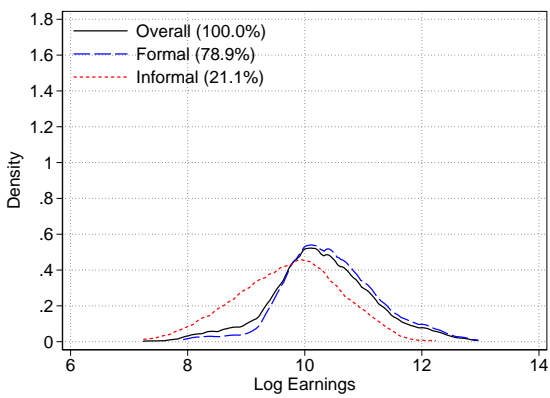

(I) WOMEN, <HS, AGE 45-55

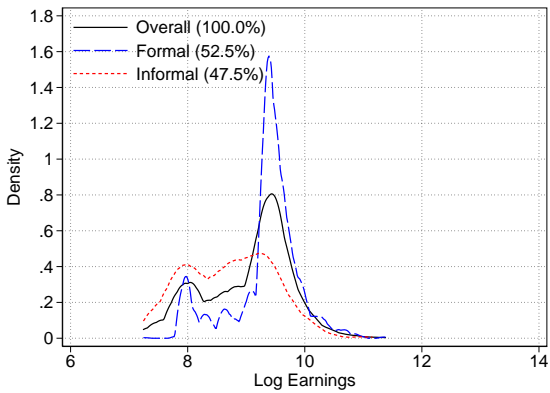

(L) WOMEN, $\geq$ HS, AGE 45-55

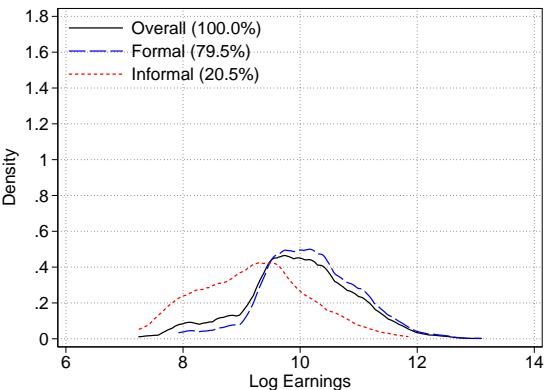

Note: Workers aged 25-55. Kernel densities of log earnings by worker group. Different lines show the overall distribution as well as that in the formal sector and that in the informal sector. Source: PME, 2015. 
Figure A24. Densities of Residual Log Earnings, by Sector and Population Subgroup IN 2002

(A) MEN, <HS, AGE 25-34

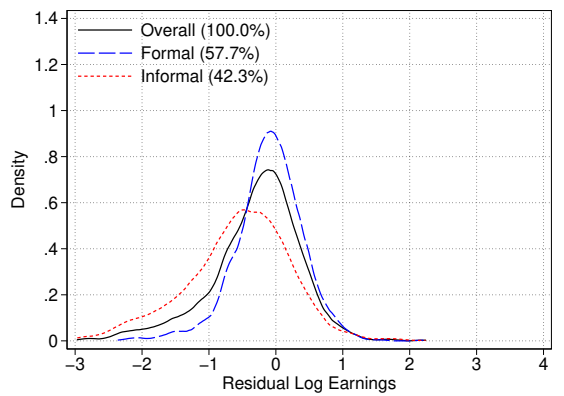

(D) MEN, $\geq$ HS, AGE 25-34

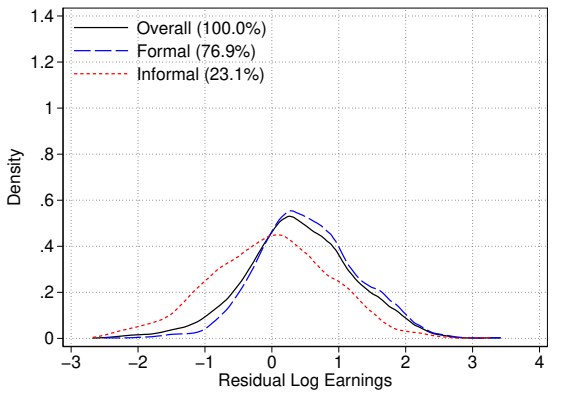

(G) WOMEN, <HS, AGE 25-34

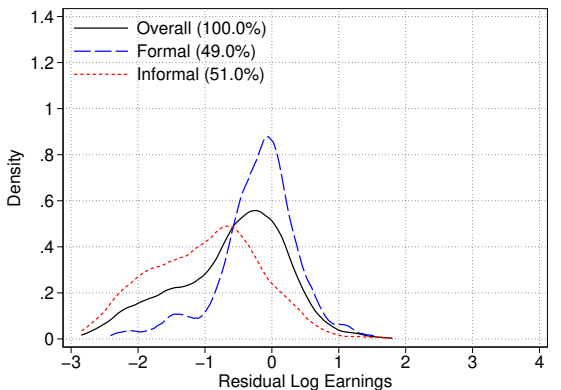

(J) WOMEN, $\geq$ HS, AGE 25-34

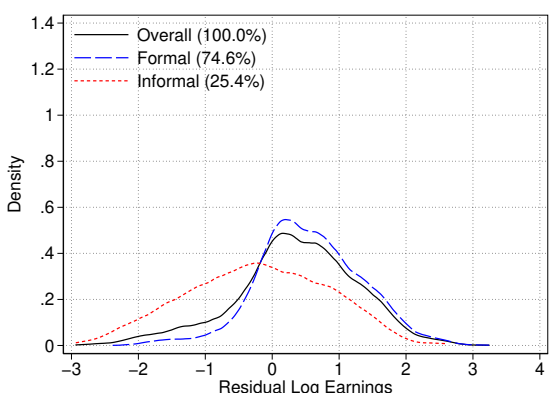

(B) MEN, <HS, AGE 35-44

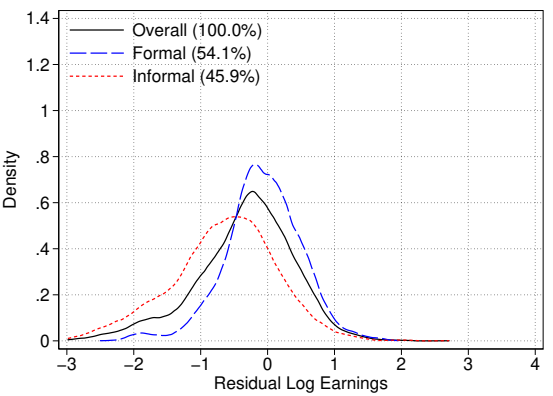

(E) MEN, $\geq$ HS, AGE 35-44

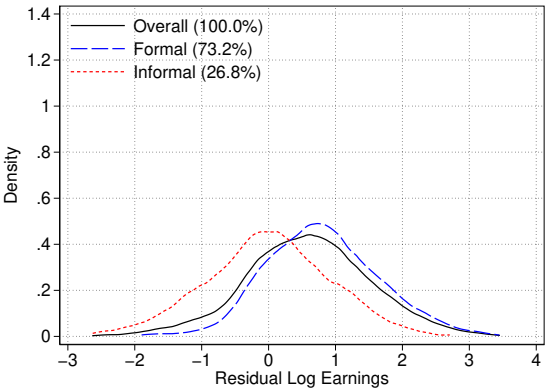

(H) WOMEN, <HS, AGE 35-44

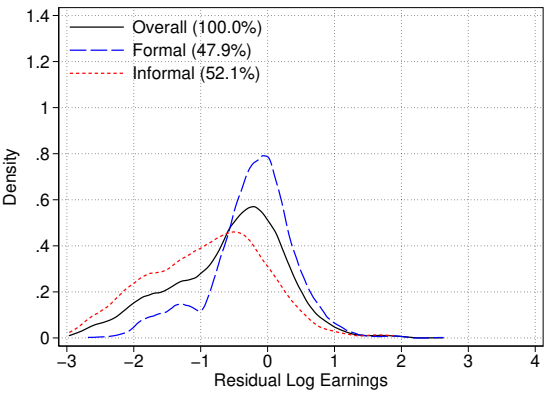

(K) WOMEN, $\geq$ HS, AGE 35-44

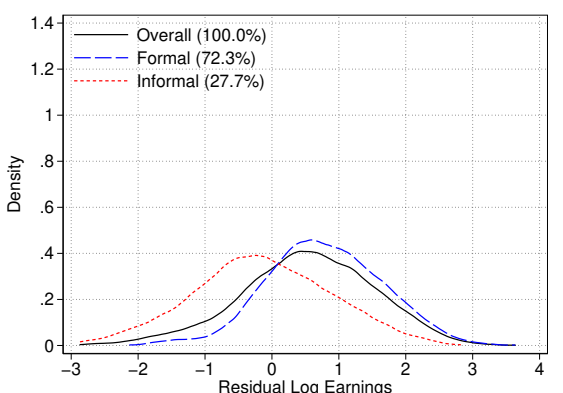

(C) MEN, <HS, AGE 45-55

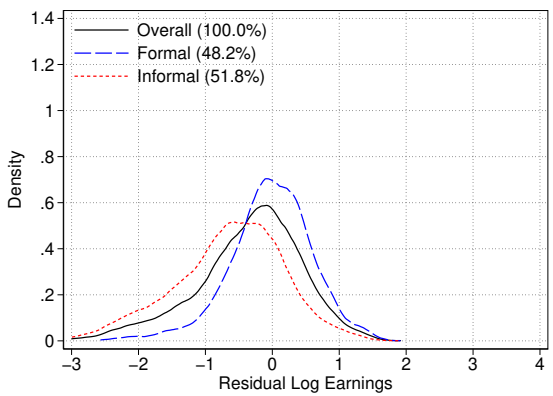

(F) MEN, $\geq$ HS, AGE 45-55

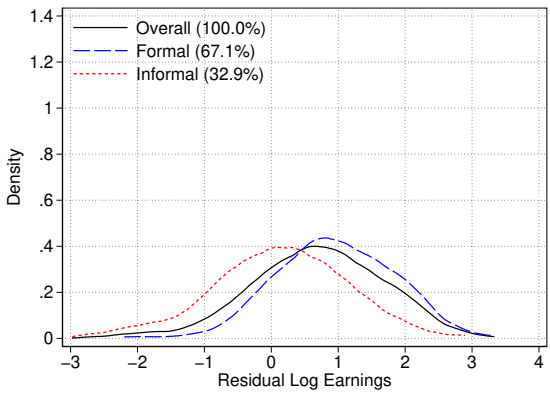

(I) WOMEN, <HS, AGE 45-55

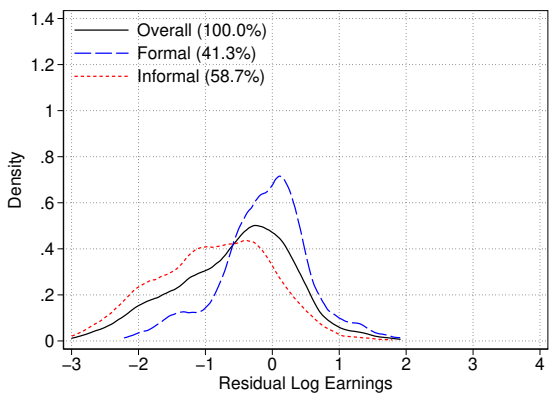

(L) WOMEN, $\geq$ HS, AGE 45-55

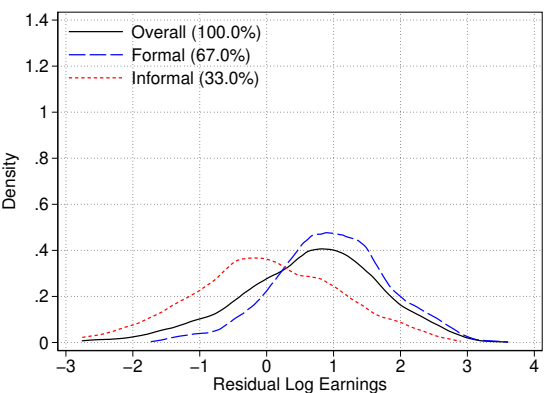

Note: Workers aged 25-55. Kernel densities of residual log earnings by worker group. Residuals are calculated controlling for age and survey wave fixed effects, separately by gender and year. Different lines show the overall distribution as well as that in the formal sector and that in the informal sector. Source: PME, 2002. 
Figure A25. Densities of Residual Log Earnings, by Sector and Population Subgroup IN 2015

(A) MEN, <HS, AGE 25-34

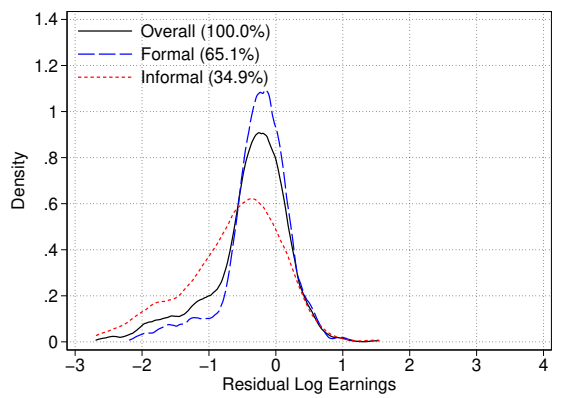

(D) MEN, $\geq$ HS, AGE 25-34

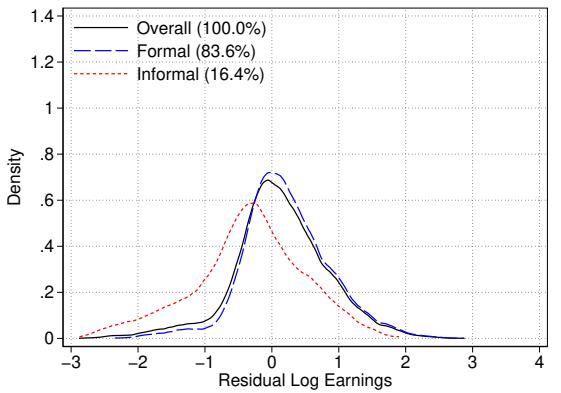

(G) WOMEN, <HS, AGE 25-34

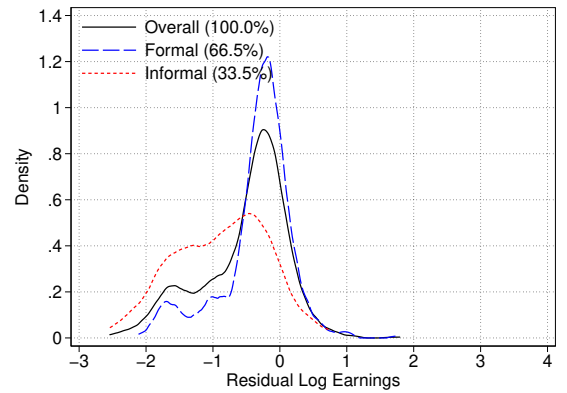

(J) WOMEN, $\geq$ HS, AGE 25-34

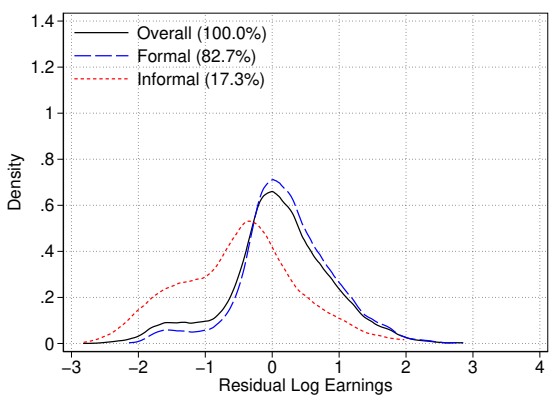

(B) MEN, <HS, AGE 35-44

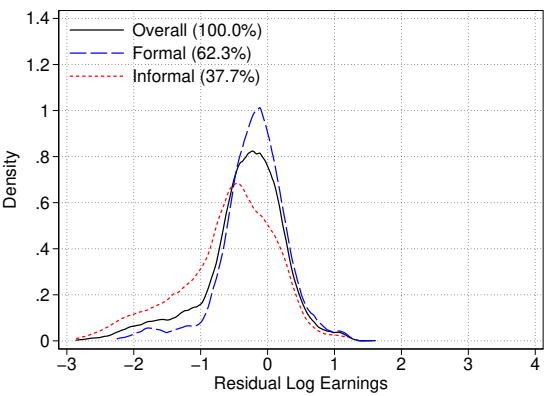

(E) MEN, $\geq$ HS, AGE 35-44

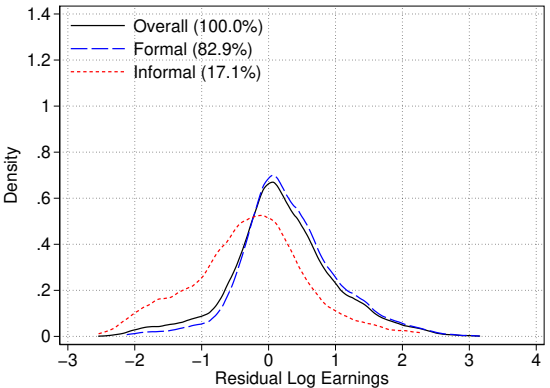

(H) WOMEN, < HS, AGE 35-44

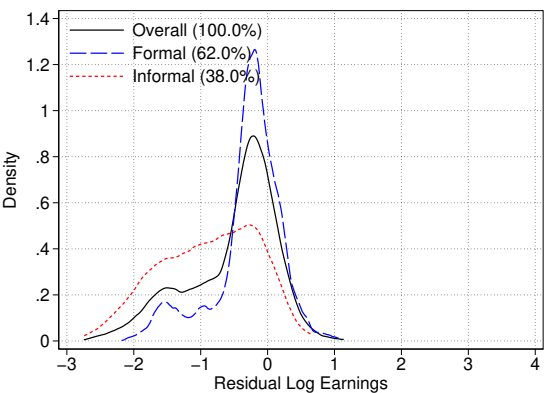

(K) WOMEN, $\geq$ HS, AGE 35-44

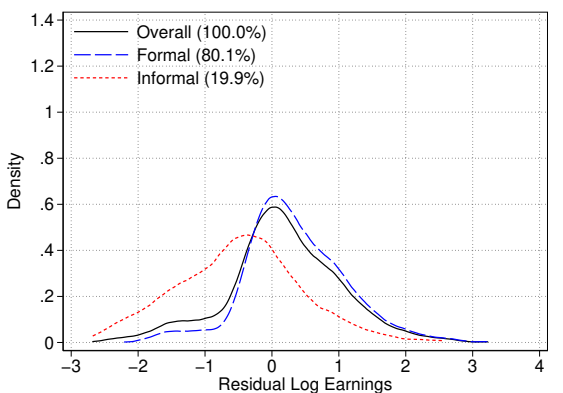

(C) MEN, <HS, AGE 45-55

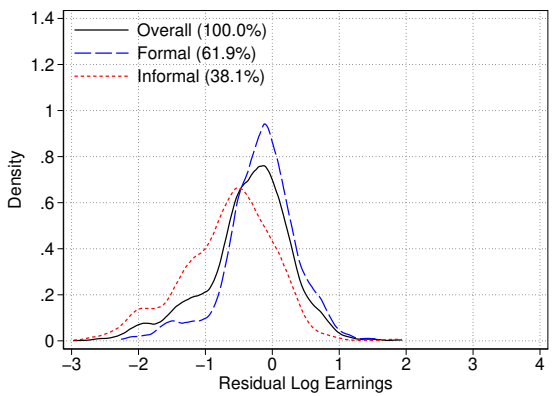

(F) MEN, $\geq$ HS, AGE 45-55

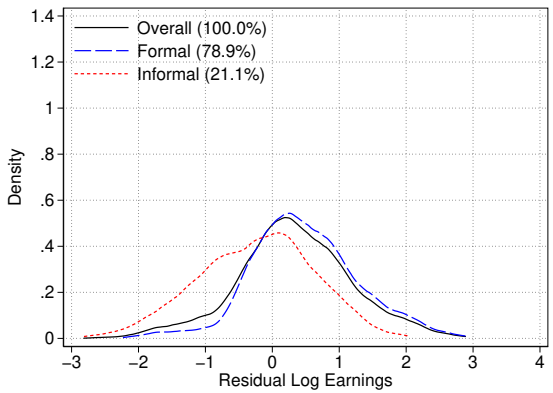

(I) WOMEN, <HS, AGE 45-55

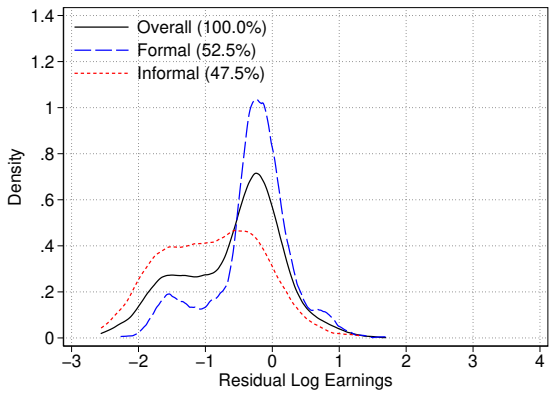

(L) WOMEN, $\geq$ HS, AGE 45-55

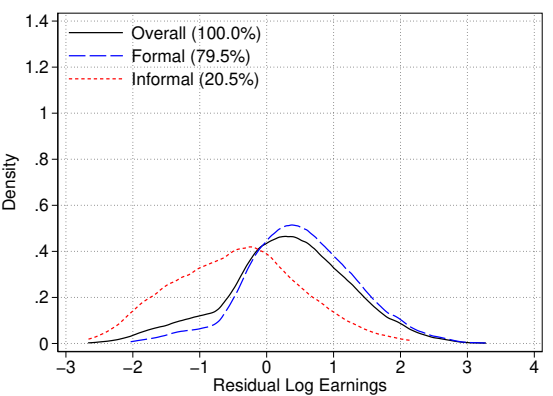

Note: Workers aged 25-55. Kernel densities of residual log earnings by worker group. Residuals are calculated controlling for age and survey wave fixed effects, separately by gender and year. Different lines show the overall distribution as well as that in the formal sector and that in the informal sector. Source: PME, 2015. 


\section{Figure A26. Densities of One-Year Residual Log EARnings Change, by Transition TYPE AND POPUlATION SUBGROUP IN 2002-2003}

(A) MEN, <HS, AGE 25-34

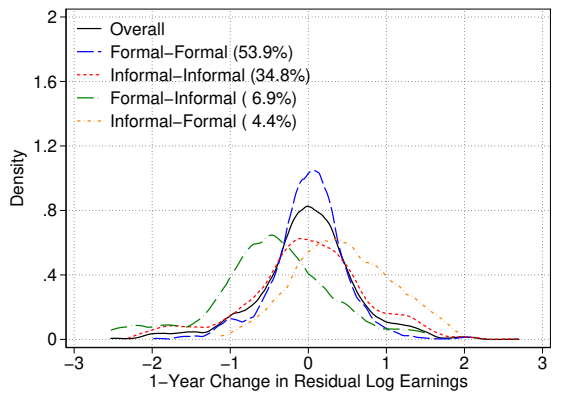

(D) MEN, $\geq$ HS, AGE 25-34

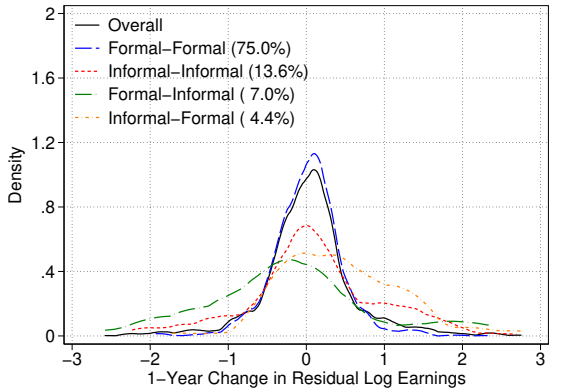

(G) WOMEN, <HS, AGE 25-34

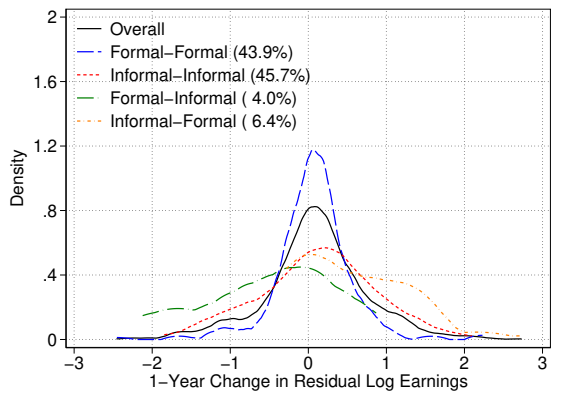

(J) WOMEN, $\geq$ HS, AGE 25-34

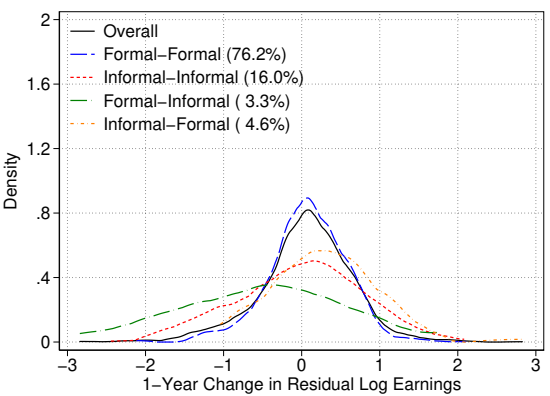

(B) MEN, <HS, AGE 35-44

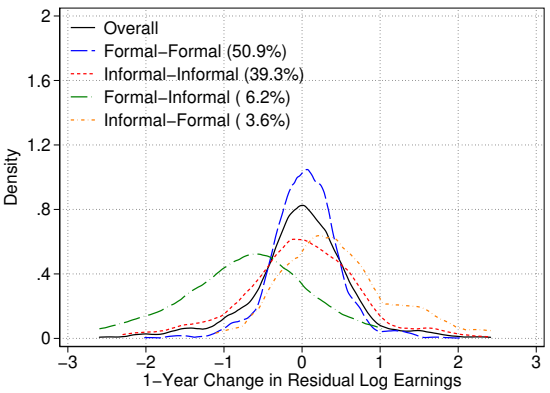

(E) MEN, $\geq$ HS, AGE 35-44

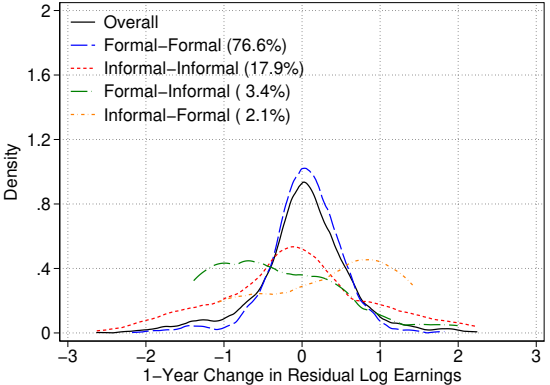

(H) WOMEN, < HS, AGE 35-44

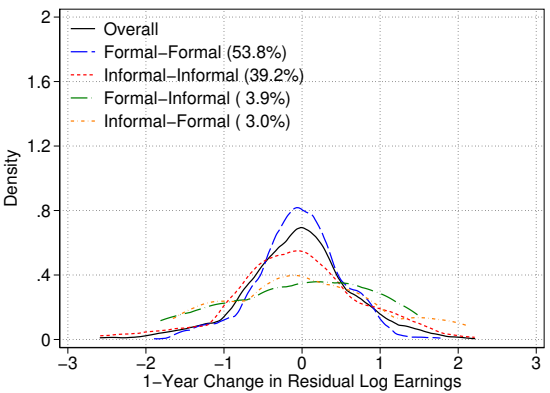

(K) WOMEN, $\geq$ HS, AGE 35-44

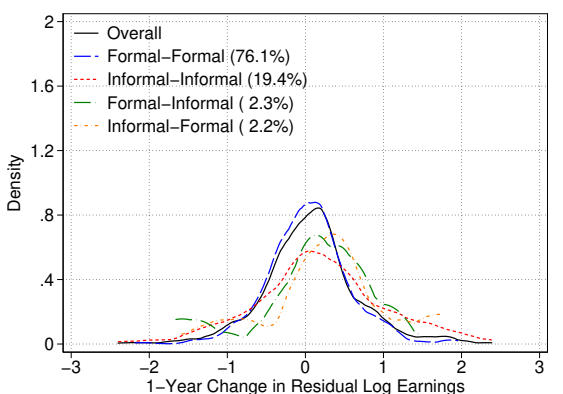

(C) MEN, <HS, AGE 45-55

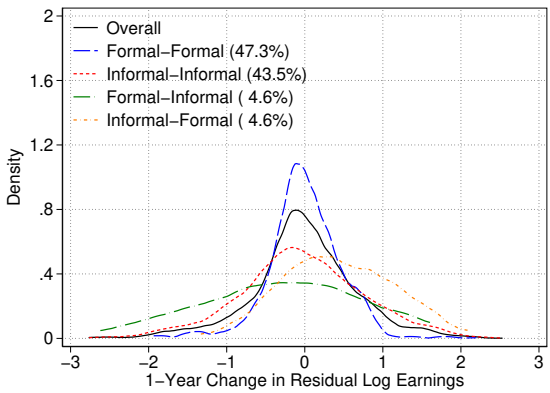

(F) MEN, $\geq$ HS, AGE 45-55

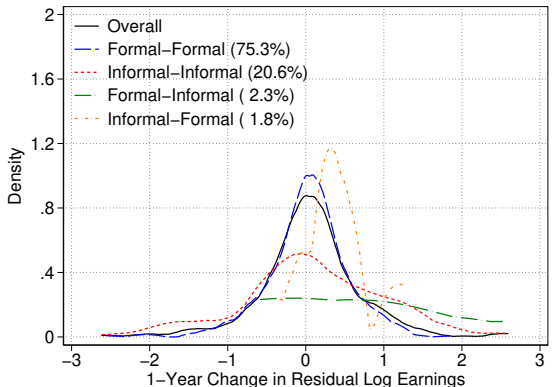

(I) WOMEN, <HS, AGE 45-55

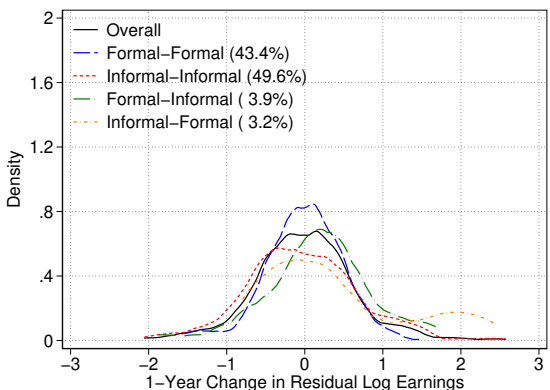

(L) WOMEN, $\geq$ HS, AGE 45-55

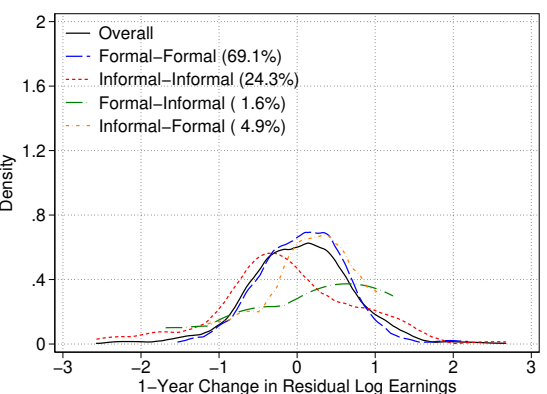

Note: Workers aged 25-55. Kernel densities of one-year change in residual log earnings by worker group. Residuals are calculated controlling for age and survey wave fixed effects, separately by gender and year. Different lines denote different combinations of a worker's current sector of employment and that in the next survey wave (e.g., "Formal-Informal" denotes current employment in the formal sector and employment in the informal sector in the next survey wave). Source: PME, 2002-2003. 


\section{Figure A27. Densities of One-Year Residual Log Earnings Change, by Transition TYPE AND POPUlATION SUbGROUP IN 2014-2015}

(A) MEN, <HS, AGE 25-34

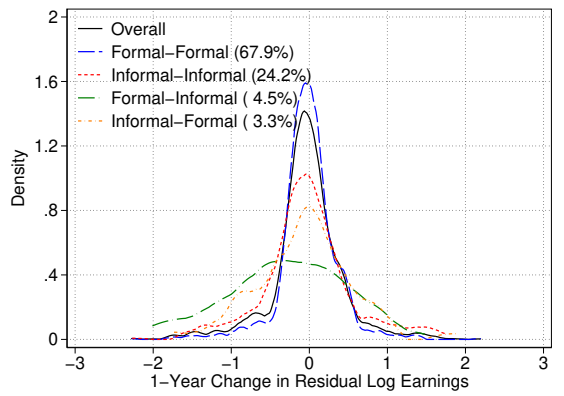

(D) MEN, $\geq$ HS, AGE 25-34

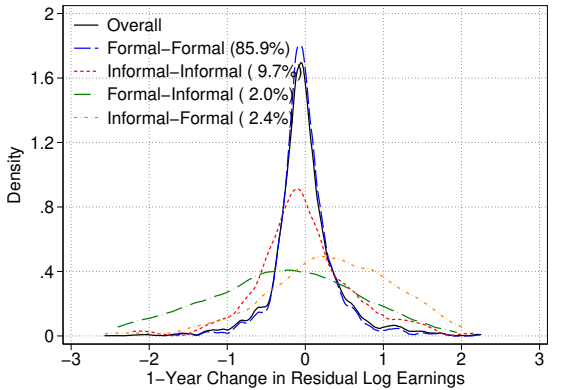

(G) WOMEN, <HS, AGE 25-34

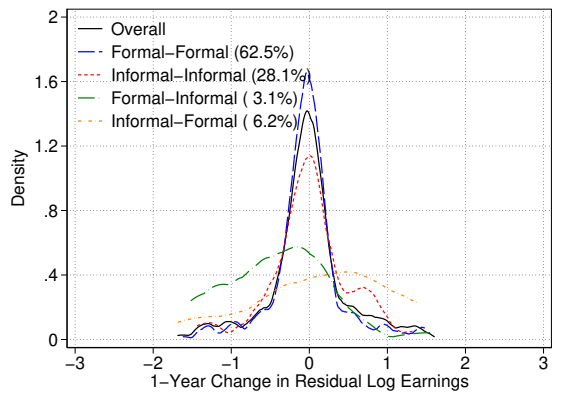

(J) WOMEN, $\geq$ HS, AGE 25-34

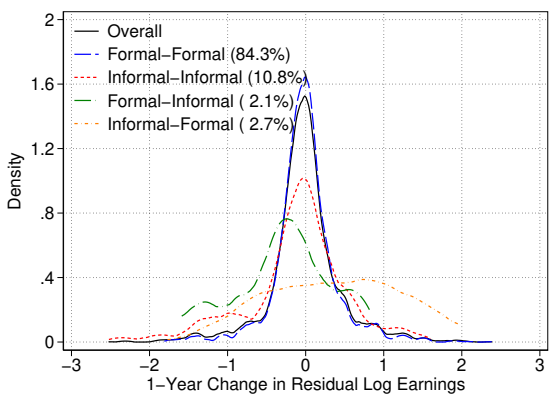

(B) MEN, <HS, AGE 35-44

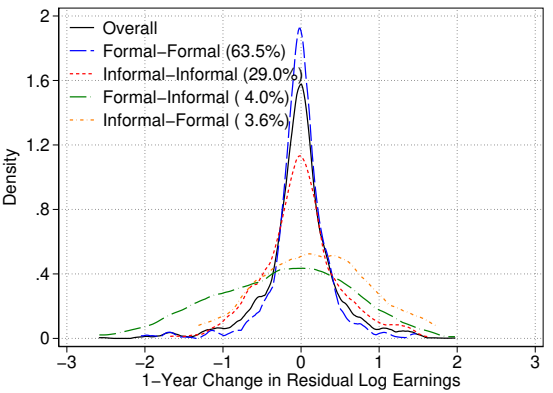

(E) MEN, $\geq$ HS, AGE 35-44

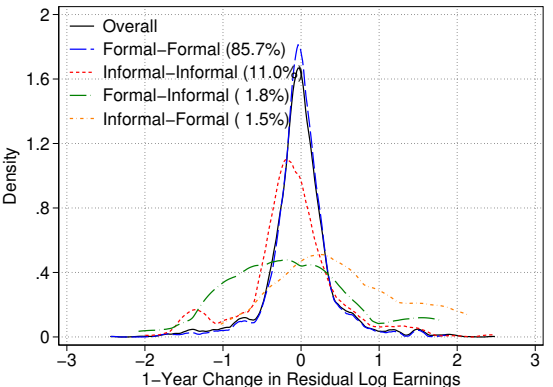

(H) WOMEN, < HS, AGE 35-44

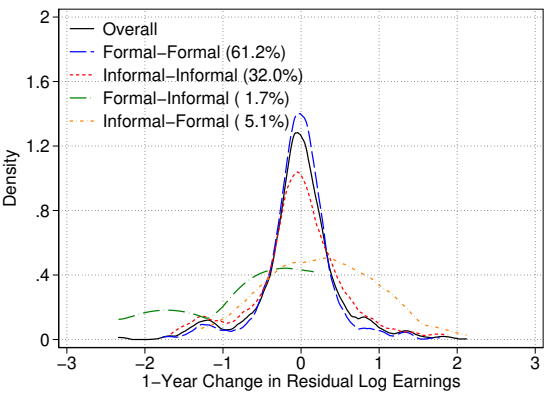

(K) WOMEN, $\geq$ HS, AGE 35-44

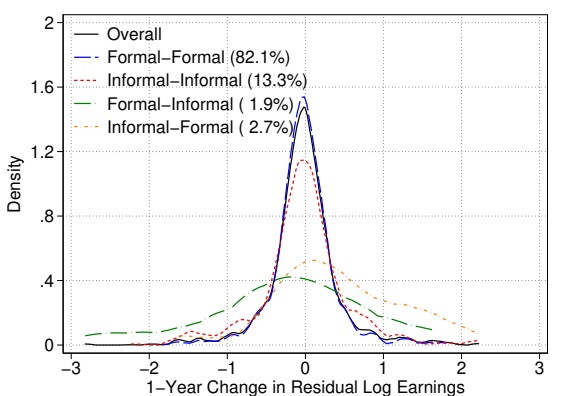

(C) MEN, <HS, AGE 45-55

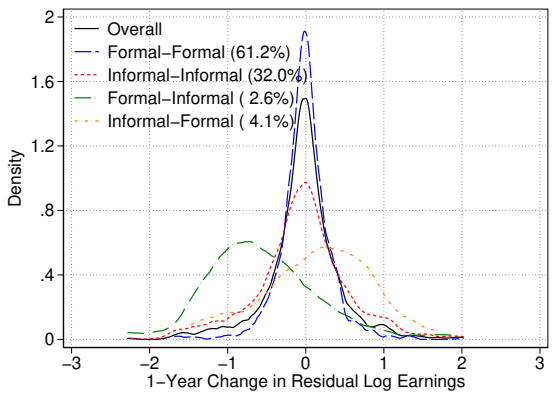

(F) MEN, $\geq$ HS, AGE 45-55

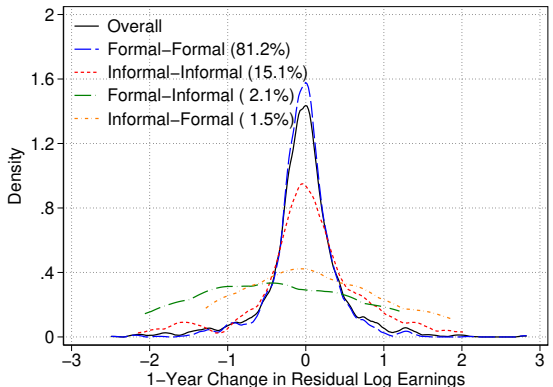

(I) WOMEN, <HS, AGE 45-55

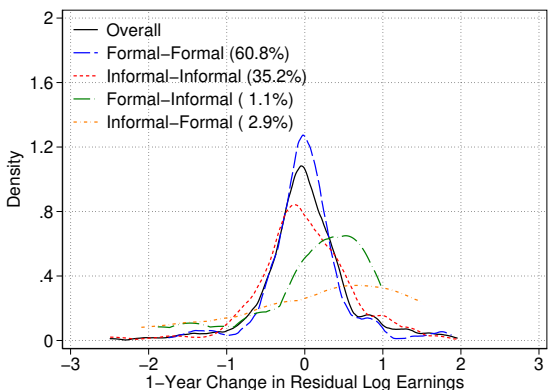

(L) WOMEN, $\geq$ HS, AGE 45-55

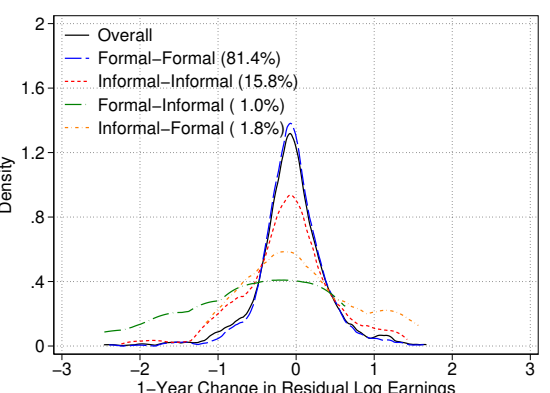

Note: Workers aged 25-55. Kernel densities of one-year change in residual log earnings by worker group. Residuals are calculated controlling for age and survey wave fixed effects, separately by gender and year. Different lines denote different combinations of a worker's current sector of employment and that in the next survey wave (e.g., "Formal-Informal" denotes current employment in the formal sector and employment in the informal sector in the next survey wave). Source: PME, 2014-2015. 


\section{A.4 The Role of Multiple Job Holdings}

One may wonder whether the decrease in the informal employment share in Brazil is driven by changes in the prevalence of workers concurrently holding multiple jobs with a mix between formal and informal employment. To investigate this, Table A4 summarizes the share of workers who hold multiple jobs in a month, broken down by whether the main job is in the formal sector (Panel A) or informal sector (Panel B). Holding multiple job is not particularly common in Brazil, with roughly 2 percent of employed workers holding multiple jobs. The fraction is modestly lower among informal sector workers. Among formal sector workers with a second job, roughly half of them contribute to social security in their second job (a proxy for the formality status of the second job). Moreover, the (un)importance of holding multiple jobs has remained roughly stable over time. Hence, the main margin of formalization is the extensive margin-workers switching entirely into the formal sector-as opposed to a declining prevalence of workers holding multiple jobs in both the informal and formal sector.

Table A4. Evolution of Multiple-Job-Holding Rates

\begin{tabular}{|c|c|c|c|c|c|c|c|c|}
\hline & \multicolumn{4}{|c|}{ Panel A. Formal sector } & \multicolumn{4}{|c|}{ Panel B. Informal sector } \\
\hline & $2002-04$ & $2005-08$ & 2009-11 & $2012-15$ & $2002-04$ & $2005-08$ & 2009-11 & 2012-15 \\
\hline Share with secondary job (\%) & 2.8 & 2.9 & 2.7 & 2.3 & 2.1 & 2.3 & 2.1 & 2.2 \\
\hline Average weekly hours in main job & 42.8 & 42.5 & 42.3 & 42.0 & 41.8 & 41.6 & 41.0 & 40.3 \\
\hline Average weekly hours in secondary jobs & 17.5 & 17.2 & 15.0 & 16.7 & 22.2 & 21.8 & 20.2 & 21.6 \\
\hline Share with SS contributions in secondary job & 51.2 & 52.2 & 54.4 & 59.1 & 25.0 & 23.5 & 25.7 & 30.9 \\
\hline
\end{tabular}




\section{A.5 The Limited Role of Demographics in Explaining the Decline of the Variance of Resid- ual Log Earnings Changes}

We here present a between- versus within-group decomposition similar to that in equation (4) of Section 4.1.4 of the main text. Specifically, we decompose the overall variance of earnings changes for workers undergoing formal-formal and informal-informal sector transitions into between and within components by worker subgroups. Specifically, we focus on worker subgroups by four education groups. We restrict attention to the formal-formal and informal-informal worker groups because they constitute the great majority of Brazilian employment. Motivated by the fact that the within-education group component accounts for the great majority of changes in the volatility of earnings among formal-formal and informal-informal workers, we further consider a shift-share analysis of the within-education group component in the same spirit as above. We focus on educational composition because Brazil experienced a rapid increase in educational attainment over this period. ${ }^{29}$

Figure A28 plots the results of these exercises. As noted above, the great majority of the decline in the volatility of earnings among formal-formal and informal-informal workers is accounted for by the within component. The great majority of the fall in the within component is, in turn, driven by changes within education groups in the variance of earnings, as opposed to changes in the educational composition of the workforce combined with differences across education groups in their volatility of earnings. The reason is that although Brazil has seen rapid changes in educational composition over this period, the differences across education groups in the within-education group volatility of earnings are not that large. While the findings of this type of accounting exercise in the absence of an equilibrium model should be cautiously interpreted, at face value, they do suggest a limited role for rising educational attainment in driving the fall in earnings volatility among formal-formal and informal-informal workers.

\footnotetext{
${ }^{29}$ In unreported results, we find that compositional shifts in other demographic dimensions such as age and gender account for even less of the overall change over this period.
} 


\section{Figure A28. The Role of Changes in Educational Attainment}

(A) BETWEEN VS WITHIN, FORMAL-FormAL

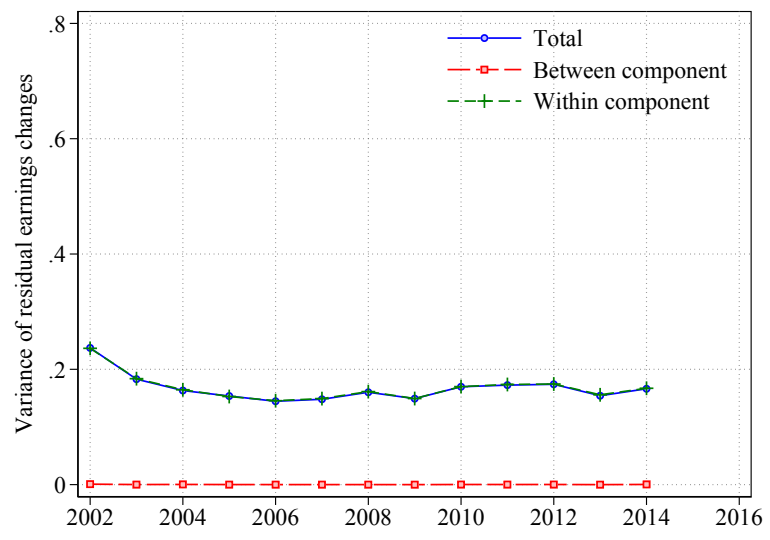

(C) BETWEEN VS WITHIN, INFORMAL-INFORMAL

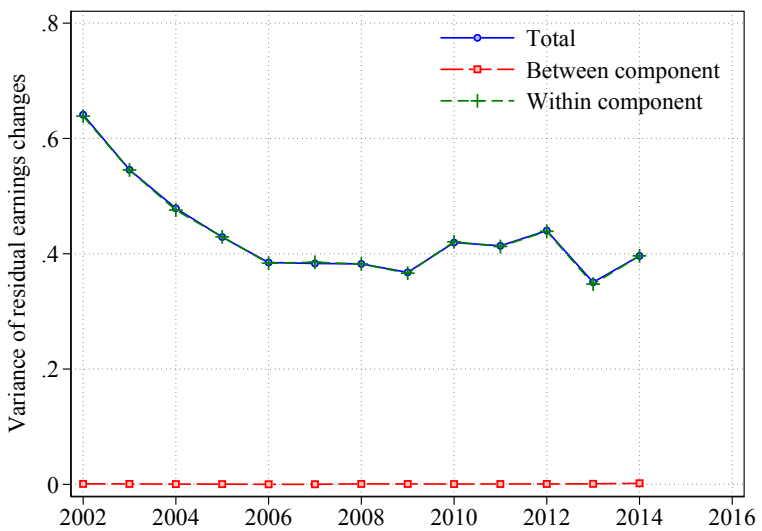

(B) WiTHIN COMPONENT, FORMAL-FORMAL

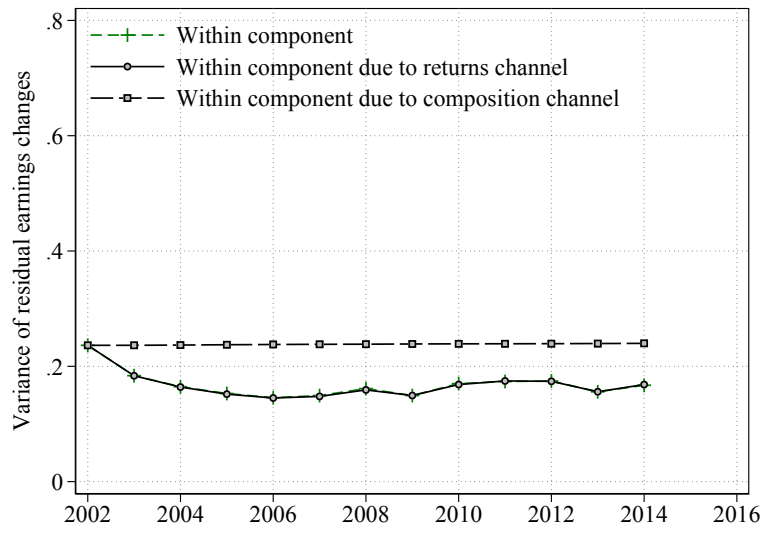

(D) WITHIN COMPONENT, INFORMAL-INFORMAL

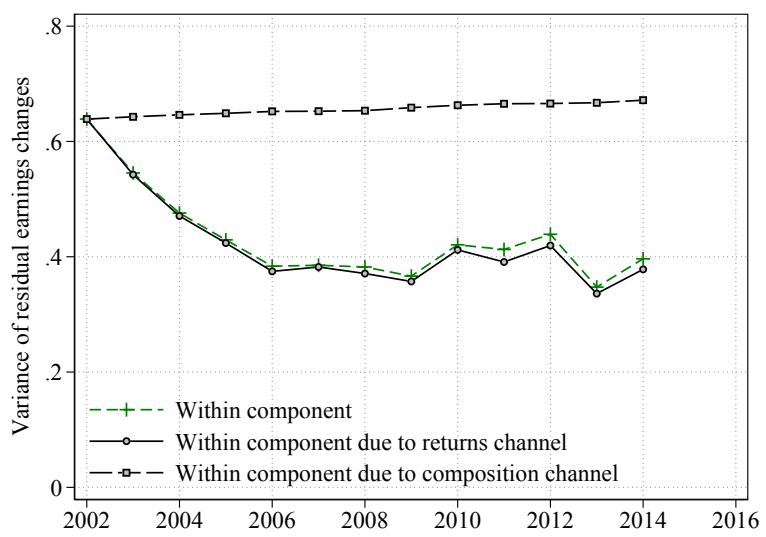

Note: Workers aged 25-55. Panels A and C show a between/within decomposition of the variance of earnings changes within the formalformal (Panel A) and informal-informal (Panel C) worker groups based on (4) across four education groups. Panels B and D show shift-share analyses of the within-education group component of (4) across four education groups within the formal-formal (Panel B) and informalinformal (Panel D) worker groups. Returns channel means holding the education composition fixed at its initial level and letting the withingroup variances evolve as in the data. Composition channel means holding the within-group variances fixed at their initial level and letting the education composition evolve as in the data. Source: PME, 2002-2015. 